NBER WORKING PAPER SERIES

\title{
RETURN TO VENTURE CAPITAL IN THE AGGREGATE
}

\author{
Shumiao Ouyang \\ Jiaheng $\mathrm{Yu}$ \\ Ravi Jagannathan \\ Working Paper 27690 \\ http://www.nber.org/papers/w27690 \\ NATIONAL BUREAU OF ECONOMIC RESEARCH \\ 1050 Massachusetts Avenue \\ Cambridge, MA 02138 \\ August 2020, Revised October 2021
}

We thank Marco Sammon, Morten Sorensen, and participants at the 2020 AFA Meeting for their valuable comments. We thank an anonymous referee for valuable comments and for pointing out an omission in the attributions in the earlier version of the paper that appeared under the title "Life cycle cash flows of ventures". We thank Honghao Wang and Tiange Ye for excellent research assistance. Shumiao Ouyang thanks the Julis-Rabinowitz Center for Public Policy \& Finance (JRCPPF) for funding. All errors are our own. Please send correspondence to Ravi Jagannathan, rjaganna@kellogg.northwestern.edu. The views expressed herein are those of the authors and do not necessarily reflect the views of the National Bureau of Economic Research.

At least one co-author has disclosed additional relationships of potential relevance for this research. Further information is available online at http://www.nber.org/papers/w27690.ack

NBER working papers are circulated for discussion and comment purposes. They have not been peer-reviewed or been subject to the review by the NBER Board of Directors that accompanies official NBER publications.

(C) 2020 by Shumiao Ouyang, Jiaheng Yu, and Ravi Jagannathan. All rights reserved. Short sections of text, not to exceed two paragraphs, may be quoted without explicit permission provided that full credit, including ( $)$ notice, is given to the source. 
Return to Venture Capital in the Aggregate

Shumiao Ouyang, Jiaheng Yu, and Ravi Jagannathan

NBER Working Paper No. 27690

August 2020, Revised October 2021

JEL No. G0,G00,G1,G10,G12,G19

\section{ABSTRACT}

We examine the performance of the Aggregate Portfolio of All Equity Investments (APAEI) in 17,242 ventures with first funding round between 1980 and 2006 by following them till 2018, or their exits if earlier. The Gornall and Strebulaev (2020) upward bias in later-stage pre-moneyvaluations, while affecting all funding-round-to-exit returns, does not affect APAEI's performance. APAEI had an internal rate of return of $22 \%$, and a superior Generalized Public Market Equivalent of 1.44. When the best $5 \%$ of the ventures are dropped from the APAEI portfolio, the risk adjusted return becomes negative. The APAEI portfolio return declines after 1999.

Shumiao Ouyang

Princeton University

Department of Economics

Bendheim Center for Finance

Princeton, NJ 08450

United States

souyang@princeton.edu
Ravi Jagannathan

Kellogg Graduate School of Management

Northwestern University

2211 Campus Drive

Evanston, IL 60208

and NBER, ISB, SAIF-SJTU

rjaganna@kellogg.northwestern.edu

Jiaheng Yu

MIT Sloan School of Management

Cambridge, MA 02139

yujh@mit.edu 


\section{Introduction}

Venture capital (VC) is an important asset class, ${ }^{1}$ with a large literature examining the risks and rewards to VC investments. Measuring the risk adjusted return to ventureinvestments poses several challenges. First, venture investments are highly illiquid. Investors in a venture have to wait for a long period of time in order to realize their returns. Ventures take on average six years from the first funding round to exit, and more than $10 \%$ of successful ventures have taken longer than 10 years to exit. Second, ventures are not subject to mandatory disclosure requirements for their funding rounds and non-IPO exits and therefore there are severe missing data issues. While the money raised information is available for almost all the funding rounds of a venture, data on pre and post money valuations are more likely to be available if the venture has successfully exited through an IPO. Further, ventures tend to raise money when they are doing well and their valuations are observed only during those times. Several methods have been proposed in the literature for addressing these issues.

Recently Gornall and Strebulaev (2020) identified another issue. By going through the legal filings of ventures that are unicorns, ${ }^{2}$ they found that shares ${ }^{3}$ issued in later-stage funding rounds are entitled to protections such as IPO issue price guarantees, vetoes over down-IPOs and seniority to other investor. However, reported pre-money valuations ignored the fact that shares issued in earlier funding rounds lacked these protections, and treated all shares the same. In their sample they found that this resulted in the pre-money valuation being overstated by $48 \%$ on average. ${ }^{4}$ We address this issue in this paper.

We show that this would bias not only the the measured funding round to exit returns for later stage funding rounds, but for all other funding rounds as well. However, this would not bias the measured realized return to all equity investors in a venture's various funding rounds taken together as single group, since that would require valuation information for the first funding round and exit - but not valuation information for other funding rounds along with the amount raised information for the various funding rounds. We therefore pool all the cash flows - amounts raised and exit values - of all the ventures together and measure the return to all the equity investors in ventures, i.e., all founders, venture capitalists, and other equity investors taken together as a single group. We refer to it as the return to the

\footnotetext{
${ }^{1}$ According to Whyte (2017), $88 \%$ of institutional investors have some exposure to venture capital and private equity, with nearly a third having an allocation greater than $10 \%$.

${ }^{2}$ Unicorns are ventures with a valuation of more than a billion dollars.

${ }^{3}$ Venture companies typically issue preferred shares to raise money in a funding round. The preferred shares would automatically convert to common shares upon certain pre-specified events taking place, like exit through an IPO with an issue price above a floor.

${ }^{4}$ Phalippou and Gottschalg (2009) find that private equity fund performance reported in previous research is overstated due to inflated accounting valuation of ongoing investments and a bias towards better performing funds in the data.
} 
Aggregate Portfolio of All Equity Investments (APAEI).

It is well recognized that funding-round-level valuation data is sparse in the widely used VC databases in the literature. ${ }^{5}$ However, some funding-round variables are better recorded than others. In our sample, although the post-money valuation data is missing for $76.3 \%$ of the rounds, amount raised data is missing for only $4.2 \%$ of the rounds. Recorded data on first round post-money valuations and exit values are representative $-25.5 \%$ of the first rounds have post-money valuation data, accounting for about $29 \%$ of the total amount raised in the first rounds; exit values are available for all IPO exits with only a few exceptions and more than half of the exits through Mergers and Acquisitions (MA). We impute for the missing first round post-money valuations, and as we show later, our findings are not very sensitive to errors in the imputed values. Our approach is less subject to selection bias which arises from the fact that ventures performing better are more likely to raise new money and report their valuations. ${ }^{6}$ Since our venture return measure only requires the post-money valuation data of the first round, it is not subject to selection bias in the later rounds. Since we measure the return to all equity investors in the various funding rounds taken as a group, our approach also avoids the need for analyzing the allocations of cash flow rights in each funding round between founders and outside investors delineated by the complex VC contracts. ${ }^{7}$

We consider two methods to address the missing data in these cash flows: imputation that uses a variation of the statistical model in Hall and Woodward (2010); and a variation of the resampling method in Korteweg and Nagel (2016) and Korteweg and Sorensen (2010), which we call resampling for convenience. In our analysis, the subsample of ventures to resample from consists of $17 \%$ of the universe of ventures $(2,954 / 17,242)$. This is not much different from Korteweg and Nagel (2016), where the number of funding rounds with round-to-round returns data - the subsample to resample from, is about $11 \%$ of all funding rounds. The statistical model we use for imputation builds on Hall and Woodward (2010) by incorporating more covariates to balance in-sample and out-of-sample goodness of fit measures. We find that while the imputation method is comparable to the resampling method, it has the advantage of not oversampling time periods that had many more ventures exiting through IPOs as during the dot-com bubble period. Further, the imputation method helps us to make use of the information in observed covariates to fill missing data. Hence, we use imputation following Hall and Woodward (2010) as the preferred method. We report the

\footnotetext{
${ }^{5}$ See, for example, Kaplan, Strömberg, and Sensoy (2002).

${ }^{6}$ Cochrane (2005) addresses this using a selection function for venture valuation disclosure, under the assumption that the probability of obtaining new financing smoothly increases with the value of the venture. Korteweg and Sorensen (2010) build a dynamic selection model.

${ }^{7}$ Ewens, Gorbenko, and Korteweg (2018) find that the way the interest is split between founders and VCs are usually complex, heterogeneous, and generally not observable.
} 
results for the resampling method as well, and our conclusions do not rely on the choice of a particular method.

Our primary risk adjusted return measure is the ratio of discounted venture cash inflows to cash outflows, i.e., the Public Market Equivalent (PME) proposed by Kaplan and Schoar (2005). We also examine its generalized version (GPME) proposed by Korteweg and Nagel (2016). In addition, we also examine the internal rate of return (IRR), a measure of return without any risk adjustment.

Since cash flows are random and occur infrequently at random unknown times in the future with possibly time varying exposure to systematic risks, when evaluating the returns, we cannot directly apply the linear beta version of the standard capital asset pricing model (CAPM) or their multifactor analogues for risk adjustments. To overcome this issue, we use the PME method, which as Sorensen and Jagannathan (2015) point out, is equivalent to discounting cash flows using the stochastic discount factor (SDF) corresponding to the dynamic Rubinstein CAPM for a particular choice of the wealth portfolio of the evaluator, and the GPME method to compute risk-adjusted returns. The PME method matches the $\mathrm{VC}$ investments at each time period to an investment in the publicly traded market index proxy portfolio, and use the realized market return to risk adjust the VC investment return. The GPME method nests PME, and ensures the modeled SDF can accurately reflect risk-free rates and returns on the market index portfolio.

The cash flows include initial inflows (measured by first-round post-money valuation), amount raised in subsequent rounds, and exit values. For exits in the form of an IPO or merger/acquisition (MA), exit values are valuations of equity revealed by these event. For exits through bankruptcies, we assume the exit values are zero, which is conservative. Our data ends in 2018, and we limit attention to ventures that had their first funding rounds before 2006, which allows for a minimum life cycle length of 12 years. We assume that ventures that remain private during the entire sample have died and have zero exit values.

We apply the GPME/PME methods to examine the aggregate risk-adjusted return to venture capital investments in the collection of US-based ventures in the SDC VentureXpert database. The GPME and PME performance measures, as well as most other venture return measures, requires data on the venture's exit events (whether through an IPO or an acquisition or through bankruptcy) and the corresponding exit values. In order to improve the data coverage on the exit events, we cross-checked the exit events of ventures using multiple data sources like PitchBook, Bloomberg, NASDAQ, Crunchbase and other Internet sources. We find that a large number of ventures with no recorded exit events in VentureXpert experienced bankruptcies or were acquired according to the other data sources.

We find that the portfolio of all the ventures in our sample had a Public Market Equivalent 
(PME) of 1.42. The internal rate of return (IRR) of the portfolio was $22 \%$. In comparison, the IRR of the venture-mimicking portfolio of public market industry portfolios was only $7 \%$. We construct this venture-mimicking public market portfolio by investing each venture's amount raised into its corresponding industry's portfolio (taking returns from Fama-French 10 industry portfolios). We liquidate the industry portfolio when the venture exits through IPO, MA and bankruptcy, or, the earlier of 12 years after the last observed round and December 31, 2018 if no exit is observed. The venture-mimicking portfolio, however, does not correct for the higher leverage embedded in the corresponding venture companies. To extrapolate from the venture-mimicking portfolio to the venture portfolio we need to adjust for the higher embedded leverage induced risk in individual ventures relative to their industry portfolios.

In addition to measuring the return to all equity investors in all the ventures in our sample taken as a single group, we also examine the following. We form a portfolio of ventures that had their first funding round in a given calendar quarter between 1992Q1 and 2006Q4, and construct the quarterly time series of the PMEs and GPMEs. ${ }^{8}$ In order to examine the impact of the dot-com bubble period, ${ }^{9}$ we also form portfolios that exclude ventures that had any funding rounds or exits in 1999 and 2000 - during which period the Nasdaq composite index rose sharply relative to the S\&P500 index before crashing.

We find that the risk-adjusted performance as measured by the PME and GPME and the performance without risk adjustment as measured by IRR comes down after 1999, which is consistent with Harris, Jenkinson, and Kaplan (2014) who observed that venture returns have come down after 2000. While the GPME and PME of the ventures come down, they are above 1.0 for all but one of the 24 quarters (2001Q1-2006Q4) with an average PME value of 1.40 and an IRR of $16 \%$, which is much higher than the IRR of $6 \%$ on the venturemimicking portfolio of public market industry portfolios during the same period. Our finding of a structural break in the time series of GPMEs even after removing ventures with funding rounds or exits within the dot-com bubble period suggests that the decline in the return on venture investments is unlikely to be entirely due the high equity valuations during the dot-com bubble period. The break we find is in the first or second quarter of 1999, 1 year before the peak of the dot-com bubble and 2 years following the passage of the National Securities Markets Improvement Act (NSMIA), which went into effect on January of 1997. Ewens and Farre-Mensa (2019) find that NSMIA increased the supply of capital to ventures,

\footnotetext{
${ }^{8}$ Prior to 1992, post money valuation data for the first round was missing for most ventures. Further, the amount raised was small. For those reasons we examine the time series properties of quarterly PMEs and GPMEs for ventures that had their first funding round in 1992Q1 or later.

${ }^{9}$ Ventures exited during the bubble period would have high valuation and higher return; ventures who raised money during the bubble would have high valuation and lower return.
} 
and that may have played a role in venture returns coming down after 1999Q1.

Some limitations of our venture return measure should be mentioned. One obvious limitation is that it cannot measure the return to any specific group of investors. Although silent on the allocation of risk and return across investors in various funding rounds, the measure still offers a useful metric for assessing the risk adjusted return on venture investments in the aggregate. To the extent we do not take into account employee stocks and stock option grants, our measure of the return to investors and founders may have an upward bias. Our measure may still have remaining selection bias, as the imputation model and the resampling approach extrapolate from the ventures disclosing valuation data, which tend to be better ventures. Further, we assume that all convertible preferred shares used in the funding rounds automatically convert upon exit when calculating the exit value of equity holders. While this is generally true, there may be exceptions, and to that extent our measure has a downward bias. We also assume that ventures that remain private during the entire sample have died and have zero exit values, and that bankrupt ventures have zero exit values, potentially understating the return to ventures.

\section{Related Literature}

Several methods have been proposed in the literature for computing the risk adjusted present value of cash flows from ventures and venture capital and private equity funds. Driessen, Lin, and Phalippou (2011) propose a modified internal rate of return method. Gupta, Stern, and Nieuwerburgh (2019) propose a "strip-by-strip" method for risk adjustment. Ang, Chen, Goetzmann, and Phalippou (2018) develop a Bayesian Markov Chain Monte Carlo method for private equity (PE) returns using cash flows accruing to limited partners and factor returns from public capital markets. Kaplan and Schoar (2005) and Korteweg and Nagel (2016) develop methods for risk-adjusting venture capital cash flows and returns based on the stochastic discount factor framework, which we make use of in this article for reasons mentioned earlier.

Cochrane (2005) and Korteweg and Sorensen (2010) address the selection bias and information incompleteness in venture's disclosure. Gornall and Strebulaev (2020) find that post money valuations in later funding rounds of ventures have a potentially large upward bias. We address this bias by measuring the return to equity investors in all funding rounds taken as a group that does not make use of post money valuation information except for the first funding round.

Phalippou and Gottschalg (2009) examine return to investing in PE funds by selecting funds that are at least ten years old and no sign of activities to ensure that the funds have been liquidated to avoid using potentially inflated self reported net asset values. By limiting 
our analysis to ventures that had their first round of funding in 2006 and following them through till 2018 we provide a more complete picture of the return to investors in venture companies.

Ljungqvist and Richardson (2003) find a return premium to investing in private equity (PE) relative to the public equity market, which potentially compensates for the illiquidity of PE investments. Harris, Jenkinson, and Kaplan (2015) find that the performance of VC funds varies over time, and VC funds that started when the venture sector received high capital inflows had lower performance. Harris, Jenkinson, and Kaplan (2014) show that VC funds outperformed public equities in the 1990s, but under-performed in the 2000s. Nanda and Rhodes-Kropf (2013) find that VC-backed startups receiving initial investment in hot markets are more likely to go bankrupt. Our findings using venture company cash flows complement the above studies that use return to VC fund limited partners. Focusing on the venture companies directly also steers clear of VC fund fees and factors that affect VC fund returns. $^{10}$

We find a significant risk-adjusted return premium to investing in venture companies, which comes down after 1999, generally consistent with these findings in the literature. However, while the return to all equity investors in venture companies come down after 1999, they continue to outperform their public market equivalent.

The rest of the paper is organized as follows. Section 2 explains the valuation methodology. Section 3 explains the data we use. Section 4 describes our empirical results. Section 5 concludes.

\section{Methodology}

\subsection{Public Market Equivalent Measure of Venture Performance}

We use the Public Market Equivalent (PME) measure of (Kaplan and Schoar, 2005) and its generalization, Generalized Public Market Equivalent (GPME) measure of Korteweg and Nagel (2016) for evaluating the return to investing in ventures. The PME and GPME are based on the present value of cash flows that the venture company receives from all the equity investors taken together as a group in the various funding rounds, and the cash flows equity investors receive upon exit. They differ in the way they compute the present values of future cash flows. Both are measures of the return to a hypothetical investor who participates in all the funding rounds of a venture and provides all the financing cash flows.

$\mathrm{VC}$ databases record the amount raised by a venture in $\mathrm{VC}$ funding rounds - we treat

\footnotetext{
${ }^{10}$ Fees and pre-fee performance may be related, with more skilled VCs charging higher fees
} 
those as cash outflows from the outside equity investors. Before VC investments, the founders of the venture have already invested various resources, including effort and financial resources. We treat the pre-money valuation of the venture in the first $\mathrm{VC}$ funding round as cash outflow from founders - that is, the value of founders' total investment.

The cash flow inflow received by equity holders upon the venture's exit is measured by its equity value. If a venture exits through an Merger or Acquisition (MA), then the equity value at exit is computed using the fraction of equity transacted and the transaction value. If the venture exits through an IPO, then the equity value at exit is the pre-IPO equity value. If the venture goes bankrupt, we regard the exit equity value as zero.

To calculate the present value of the cash flows, we need to appropriately adjust for the risk. The PME method computes the realized present value at time 0 of a cash flow, $C_{t}$, that occurs at a random time $t$ in the future as $M_{t} C_{t}$, where the $M_{t}$ equals the inverse of the time $t$ value of a dollar invested at time 0 in the market portfolio of all stocks, i.e., $\frac{1}{\left(1+R_{m 1}\right)_{\ldots}\left(1+R_{m t}\right)}$, where $R_{m s}$ is the publicly traded equity market portfolio's rate of return during time period $s$. The realized present value $M_{t} C_{t}$ is the amount one would have had to invest in the market portfolio at time 0 to get $C_{t}$ at time $t$. We use the return on the CRSP value weighted stock index portfolio as the proxy for the market portfolio of all stocks, retrieved from Ken French's data library (Fama and French, 1993).

More generally, as Hansen and Richard (1987) show, the present value at time 0 of a random cash flow, $C_{t}$, that occurs at a random time $t$ in the future can be written as $\mathbf{E}\left(M_{t} C_{t}\right)$, where $M_{t}$ is the stochastic discount factor (SDF) and $\mathbf{E}($.$) is the expectation operator.$ Each asset pricing model - can be the standard Capital Asset Pricing Model (CAPM), or the multifactor asset pricing model, or other models like the Black-Scholes option pricing model - takes a particular stand on what the valid SDF is. The PME method's choice of $\frac{1}{\left(1+R_{m 1}\right) \ldots\left(1+R_{m t}\right)}$ as the SDF is supported by the dynamic capital asset pricing model of Rubinstein (1976). In the case of the GPME, the stochastic discount factor (SDF) is specified as: 11

$$
M_{t}=\exp \left(a t-b r_{m, t}\right)
$$

where $t$ is the time of a funding round or exit since the first round - that is, the first round of the venture takes place at time $t=0$. $a$ and $b$ parameters that are positive constants, and $r_{m, t}$ is the log cumulative return on the publicly traded equity market portfolio since the first round. ${ }^{12}$ We use the parameter values, $\mathrm{a}=0.033$, and $\mathrm{b}=1.444$, which are the

\footnotetext{
${ }^{11}$ This comes from Equation (1) in Korteweg and Nagel (2016).

${ }^{12}$ To simplify the calculation, we treat the cash flows after 15 years from the first round as occurring in the 15th year. Few ventures still receive funding or successfully exit after 15 years from the first round.
} 
values estimated by Korteweg and Nagel (2016) using round to round returns on ventures. ${ }^{13}$ The SDF of the GPME nests the SDF of the PME as the special case where $a=0$ and $b=1$ in the expression for the SDF given in equation(1).

The realized GPME performance measures equal the discounted cash inflow divided by the sum of discounted cash outflows, using the corresponding SDFs, i.e.,

$$
\text { Realized Venture GPME }=\frac{P V_{\text {in }}}{P V_{\text {out }}}=\frac{M_{T} \times c_{T}}{\sum_{t=0}^{T-1} M_{t} \times C_{t}}
$$

where $c_{T}$ is outflow from the venture paid out to investors upon exit. $C_{0}$ is first-round postmoney valuation, which is the sum of the first-round pre-money valuation and first-round amount raised, and $C_{1}, \ldots C_{T-1}$ are the cash contributions by equity holders in subsequent funding rounds. We use capital letters to denote money invested in the venture, i.e., outflows from investors, and lower case letters to denote money paid out to investors, i.e., inflows to investors. Equation (2) defines the realized PME when we set the $a=0$ and $b=1$ in the equation. A venture with a realized GPME/PME greater than 1 is viewed to have outperformed the public benchmark.

\subsection{Venture GPME/PME and the Gornall and Strebulaev (2020) Bias}

While the bias in the valuation data documented in Gornall and Strebulaev (2020) materially affects all the measured round-to-exit returns, it does not affect the venture PME measure. To see why, consider the hypothetical venture given in Table 1 . The venture raises one round per year and exits through an IPO at the end of the 4th year. The market return is $10 \%$ every year. With the amount raised and post-money valuation data in each round, we can calculate the venture PME. We also calculate ownership given up, and the round-to-round return and round-to-exit return.

$$
\begin{aligned}
& \text { Ownership Given Up by Founder }=\frac{\text { Amount Raised }}{\text { Post-Money Valuation }} \\
& \text { Round-to-Round Return for Round } t \text { Investor }=\frac{\text { Pre-Money Valuation }}{t+1} \frac{\text { Post-Money Valuation }}{t}-1 \\
& \text { Round-to-Exit Return for Round } t \text { Investor }=\frac{\text { Exit Value to Equity Holders in Round } t}{\text { Post-Money Valuation }_{t}}
\end{aligned}
$$

Panel A reports the return measures calculated based on correct data. Panel B in contrast reports the return measures when the post-money valuation of round 4 is biased upwards to reflect the fact that the observed value of existing common shares in late rounds is biased upward as documented by Gornall and Strebulaev (2020). We see that this bias in round 4

\footnotetext{
${ }^{13}$ See Table 6 of Korteweg and Nagel (2016). We also re-estimated the SDF parameters based on roundto-round returns using our sample of data. The re-estimated parameters are close to these values.
} 
would bias the round-to-round returns from both round 3 and round 4, and round-to-exit returns for all rounds. But it does not affect the calculated PME of the venture, and it follows that the venture's GPME will also not be affected since the two differ only in their SDFs.

\section{[Insert Table 1 near here]}

\subsection{Portfolio GPMEs}

Our primary interest is in examining how the Aggregate Portfolio of All Equity Investments (APAEI) performed. Therefore, analogous to the GPME of a single venture, we define the GPME of a portfolio of ventures as the present value of all the aggregate cash outflows (money raised by the ventures in the portfolio) divided by the realized present value of all the aggregate cash inflows (exit values paid to investors from ventures in the portfolio). Notice that the aggregate venture capital portfolio will have cash outflows to ventures and cash inflows to investors in a systematic stochastic manner over time, unlike an individual venture that pays investors off only upon its exit. Let $P V_{i n}^{i}$ denotes the present value of cash inflows to investors from venture $i$, discounted to its first round. And let $P V_{\text {out }}^{i}$ denotes the present value of cash outflows from investors to venture $i$, discounted to its first round. Equation (2) describes how the present values are calculated for an individual venture.

The realized GPME (and PME) of the portfolio of ventures is given by:

$$
\text { Realized Value of Portfolio GPME/PME }=\frac{1 / N\left(\sum_{i=1}^{N} P V_{i n}^{i}\right)}{1 / N\left(\sum_{i=1}^{N} P V_{o u t}^{i}\right)}
$$

When the numerator and the denominator in the above expression converge in probability to their population analogues by the law of large numbers, the ratio of the two will converge to the ratio of their respective population analogues given below, by applying Slutzky's theorem:

$$
\lim _{N \rightarrow \infty} \text { Realized Value of Portfolio GPME/PME }=\frac{\mathbf{E}\left(P V_{\text {in }}^{i}\right)}{\mathbf{E}\left(P V_{\text {out }}^{i}\right)}
$$

where $\mathbf{E}($.$) denotes the expectation operator. Note that when the right side of Equation (4)$ is greater than 1, the NPV of the investments in the aggregate venture portfolio is positive.

The time series length of the sample, 1980 to 2018 may not be sufficiently large to appeal to the law of large numbers, especially since ventures take several years to exit from the start of their first funding date. Therefore, in addition to computing the realized GPME of the aggregate portfolio of all the ventures in our sample, we also compute the realized 
GPME of the portfolio all ventures that had their first funding round in a given calendar quarter and examine the time series properties of the quarterly realized GPMEs to assess their variability, and the likelihood of the realized GPME taking a value that is less than 1.0. Similarly we also consider portfolios of ventures that had their first funding round in a given calendar year, compute their GPMEs and examine their time series properties.

\section{Data}

\subsection{Data Description}

Our sample comes from the universe of ventures in VentureXpert, which is the standard database for many venture capital studies. We augment VentureXpert with data on funding rounds and exit events from multiple sources. Our data ends in 2018, and we limit attention to ventures that had their first funding rounds before $12 / 31 / 2006$. This allows us to observe every venture for at least 12 years since the first round.

We first collect data on venture funding rounds from VentureXpert that includes the time, amount raised, and post money valuation of each funding round. Then, we collect data on the exit events of these ventures. Based on information in VentureXpert, we classify a venture's exit event as IPO, MA, or bankruptcy. Ventures whose VentureXpert status is "Went Public" are classified as exiting through an IPO. Those whose VentureXpert status is "LBO", "Merger", "Acquisition" or "Pending Acquisition" are classified as exiting through an MA. Those whose VentureXpert status is "Defunct", "Bankruptcy - Chapter 7" or "Bankruptcy - Chapter 11" are classified as exiting through a bankruptcy. Finally, we classify the final outcome of a venture having none of these exit events as remaining private. For the ventures that exited through an IPO or MA, we further collect the data on their exits from SDC Merger and Acquisition and SDC Global New Issues databases.

Some of the ventures in VentureXpert either have no recorded exit events or have recorded exit events but not the associated exit values. We therefore cross-checked the outcomes and exit events of a large subset of VentureXpert ventures with other data sources, in order to enhance the data coverage on venture exits. There are 17,242 VentureXpert ventures in our final sample of analysis. Given the cross-check involves significant amount of manual labor, we cross-checked a subset consisting of 10,175 ventures. Since that the bankruptcies recorded by VentureXpert appear to be quite accurate, and that our main focus is on the return of ventures in 1992Q1 and 2006Q4, we cross-checked 10,175 ventures that received the first funding round between 1992 and 2006, and was not bankrupt according to VentureXpert, with PitchBook, Bloomberg, NASDAQ, Crunchbase and other internet sources. 
For the remaining ventures, including those that received the first funding round between 1980 and 1991, data on outcomes and exit events come solely from the SDC databases SDC VentureXpert, SDC Merger and Acquisition and SDC Global New Issues databases. As shown in Table 2, of the 2,090 ventures with no recorded exit events in VentureXpert, 628 exited through bankruptcy, 14 through IPO, and 460 through MA according to other sources. ${ }^{14}$ Only 988 have no recorded exit events after checking with other data sources.

\section{[Insert Table 2 near here]}

After identifying the exit events of the ventures, we combine data from various sources to get the exit values of the ventures. As shown in Table 3, data from the other sources improved the coverage of exit values. Our sample for analysis includes 17,242 US-based ventures in SDC VentureXpert database that had the first rounding round in 1980-2006. Among 6,407 ventures that went to MAs, 5,779 MAs are recorded by the SDC data, where the SDC data provide pre-MA valuations for 2,809 ventures, and the other data provide pre-MA valuations for 401 ventures; and 628 MAs are solely recorded in other data sources, where 145 MAs have pre-MA valuations available. There are 150 ventures whose pre-MA valuations recorded in the SDC databases conflict with those in other data sources ${ }^{15}$. For these cases, we adopted the data that appear more reliable. The table also reports how the other data sources help provide better coverage on venture IPOs and bankruptcies.

\section{[Insert Table 3 near here]}

For IPOs, we are particularly mindful of the data quality of the pre-IPO valuations. We note that there are cases where SDC data can be incorrect. For example, the pre-IPO market value of Targanta Therapeutics Corp is reported as 0.3 million dollars, however from the prospectus we know that the pre-IPO market value is about 152 million dollars. ${ }^{16}$

To ensure the data is correct, we calculate three measures of the pre-IPO market value and cross-validate them. The first measure is the product of pre-IPO shares outstanding and the IPO offering price. The second measure is the difference between post-IPO market value and the IPO proceeds. The third measure is the pre-IPO market value as reported in SDC database. If large discrepancy is observed across these three measures, we manually check the prospectus and use the prospectus value. Overall, we find the first measure to be most reliable. In calculating these three measures, we closely examine other detailed data issues.

\footnotetext{
${ }^{14}$ For the 14 exits through IPOs, we list the ventures' names, IPO exchanges, IPO dates and CRSP PERMCO in Table IA.1 in the internet appendix.

${ }^{15}$ We regard the exit values in SDC as conflicting with other sources if they differ by more than $5 \%$

${ }^{16}$ According to the prospectus, there were 15.2 million pre-IPO shares and its offering price was $\$ 10$ per share.
} 
First, shares outstanding data in SDC might be missing for some NASDAQ IPOs, for which we use the shares outstanding on the first trading day in CRSP for calculation. ${ }^{17}$ Second, in some foreign IPOs the offering prices are in foreign currencies instead of US dollars, for which we either avoid using offering price, or use the ratio of proceeds and offering shares to back out the price in dollars.

Utilizing other data sources to cross-check and supplement the standard SDC data gives us a more comprehensive and accurate coverage of the ventures' exit events. This strengthens our measure of venture investment returns, which heavily relies on the valuations of ventures at exit events.

Two remaining data issues remain. The first issue is that post money valuations of the funding rounds are usually unavailable. Figure 1 shows the extent of this missing data issue for each year of the funding rounds. Post money valuation is available for less than $5 \%$ of the funding rounds that happened before 1990. From 1990 to 2000, we see an increase in the availability of post money valuations, but then a rapid decline after 2000. Over all, post-money valuation is missing for $76.3 \%$ of the rounds and the availability of data varies significantly over time. Rather, amount raised data is generally available for more than $90 \%$ of the rounds every year and such availability appears steady over time.

\section{[Insert Figure 1 near here]}

Table 4 reports the extent of the missing data issue by the stage of financing rounds. We see that the extent of the missing data issue does not vary much with the financing stage. In terms of financing stage, a venture can either have only one round or multiple rounds. If a venture has multiple rounds, a funding round can be classified as its first round, a interim round or its last round. We see from the table that amount raised is available for $93.5 \%$ - $96.8 \%$ of the first rounds, interim rounds and last rounds, and for $86.8 \%$ of the rounds for ventures with only one round. Post-money valuation is available for $21.1 \%-25.5 \%$ of the first rounds, interim rounds, and last rounds, and for $16.6 \%$ of the rounds of ventures with only one round. We also calculated the round-to-next-event return according to the literature. Due to severe missing data issue for post-money valuations, round-to-next-event return used in literature is available for only around $15 \%$ of the rounds. In calculating the venture GPMEs/PMEs, we impute the missing observations in first-round post-money

valuations. And as we mentioned earlier, the venture GPMEs/PMEs are not sensitive to errors in imputed first round post money valuations.

\section{[Insert Table 4 near here]}

\footnotetext{
${ }^{17}$ To the extent that employees who received compensation in shares later exited in the IPO, there will be a bias upward.
} 
Our valuation approach utilizes the fact that amount raised data is available for most ventures. As we had mentioned earlier, our aggregate portfolio GPME performance measure needs as input the first round post money valuation and amount raised, i.e., cash outflows from investors, and the exit values, i.e., cash inflows to investor. Table 5 shows that overall $21.7 \%$ of ventures have data on the amounts of all the cash outflows of our interest, and the fraction is higher for ventures that exited through IPO and MA (36.6\% and 25.8\% respectively). $86.9 \%$ of ventures have all amounts raised information and $22.9 \%$ of ventures have first round post money valuation information. We observe the exit values (inflows to investors) for $97.8 \%$ of IPOs and $50.5 \%$ of MAs, and the associated ventures account for $29.6 \%$ of all ventures in our sample. We assume that bankrupt ventures and ventures with no observed exit until 2018 (the end of our sample period), have exit value of 0 . Under such assumptions, we have as input for venture PMEs the cash flows over the life cycle for $17.1 \%$ of all ventures.

\section{[Insert Table 5 near here]}

The second data issue is right-censoring. For ventures, time to exit can be very long. For example, Table 6 summarizes the number of rounds, time to exit, amount raised and exit value for ventures with different exit types, ${ }^{18}$ and it shows that it takes a venture on average 5-7 years before exit happens through IPO, MA, or bankruptcy. This poses a challenge in terms of data requirement, since our objective is to evaluate the return of ventures over their entire lifecylce, i.e., from the first funding round till exit. There will be ventures whose exit events will happen long after our data ends. To deal with this issue, while our data ends in 2018, we limit attention to ventures that had their first funding rounds before 2006, allowing for observation of a minimum life cycle length of 12 years. As of 2018, there are 5,031 firms ( $29.2 \%$ of the sample) that remain private, of which 291 ventures $(5.8 \%)$ have had some financing activities (i.e., funding rounds) from 2013-2018, while the remaining 4,740 (94.2\%) have had no financing activity. The former, observed active ventures, account for only $5.6 \%$ of the amount raised by ventures in total. They play a less important role in affecting the average return of ventures. The latter, observed inactive ventures, as we will show next, are unlikely to have successful exits, so assuming their exit values are zero is reasonable.

\section{[Insert Table 6 near here]}

\footnotetext{
${ }^{18}$ In our data, $11.1 \%$ of ventures went to IPO, after on average receiving 4.1 rounds, raising 46.8 million dollars, and exiting with a value of 296.3 million dollars. $37.2 \%$ of ventures went to MA, after on average receiving 3.9 rounds, raising 32.9 million dollars, and exiting with a value of 108.6 million dollars. $22.6 \%$ of ventures went to bankruptcy, after on average receiving 2.9 rounds, raising 17.4 million dollars.
} 
To show that ventures that remain private as of 2018, with no financing activity within the past 5 years, are unlikely to have successful exits, we use a bootstrap approach. Specifically, we focus on ventures that remain private as of 2006 and had no financing activity during the following 5 years, i.e., from 2001-2006, a total of 3,448 ventures. We trace their final outcomes as of 2018, and see how many of them ever had successful exits. Panel A of Table 7 reports the summary statistics for these ventures. We see that only $0.7 \%$ of them went to IPO, $12.3 \%$ of them went to MA - the likelihood of successful exit is much lower than the average venture in the full sample. These ventures with successful exits in total raised 12 billion dollars, and were valued in total 64.2 billion dollars in successful exits. Compared to the full sample, they account for only $2.7 \%(12 / 452.8)$ of the total amount raised, and $5.1 \%(64.2 / 1248.8)$ of the total venture value in successful exits. There are 5,097 remaining ventures that remain private as of 2006 but had financing activities from 2001-2006. Panel $\mathrm{B}$ of the table reports the summary statistics for them as well.

\section{[Insert Table 7 near here]}

The status of a venture at any point in time can be the following: remain private but active within the past 5 years, remain private but inactive within the past 5 years, exit through an IPO, exit through an MA, and went bankrupted. Table 8 shows the fraction of ventures in each of these statuses by years elapsed from the first funding round. By including ventures that started the first round before 2006, the table illustrates the benefit of observing ventures for more than 12 years. We see that after around 12 years from the first round, the fraction of ventures that exit through IPO, MA or bankruptcy remain close to the same. In other words, not many more exit events will be observed even if we extend the sample further after 2018. In a similar spirit, Table 9 reports the cash inflows and cash outflows of all the ventures taken together, by years from the first round. We see that the $86.7 \%$ of the exit values realized and $98.2 \%$ of cash outflows (amount raised from outside investors and founders) happen before 12 years from the first round.

\section{[Insert Table 8 near here]}

\section{[Insert Table 9 near here]}

Figure 2 below shows a diagram of the number of venture companies in the sample and how they progressed over time to various destinations. We also present the PME/GPME/IRR for ventures in each destination.

\section{[Insert Figure 2 near here]}




\subsection{Methodology for Addressing Missing Data Issue}

We explored two methods to address the missing data in venture cash flows: imputation method that uses a variation of the statistical model used in Hall and Woodward (2010), and the resampling method motivated by Korteweg and Nagel (2016) and Korteweg and Sorensen (2010).

The imputation model relies on observed characteristics of a venture to predict its firstround post money valuation, amount raised in a funding round and the exit value, and the fitted values from the model are the imputed values, if any of these data are missing. For the amount raised data, we impute the missing values using linear regression models. For each round separately, we first estimate the relationship between the amount raised and the number of investors who participated, the amount raised in the previous round, as well as industry fixed effects, funding stage fixed effects and time fixed effects. There are few funding rounds after the ninth round and they are all in late stages, so we treat them all together as a group. For them, instead of relating the amount raised in a round to the previous round's, we relate it to the ninth round's. The estimation model is as below.

$$
\log \text { AmountRaised }_{i, r}=\alpha+\beta \log \text { AmountRaised }_{i, r-1}+\gamma Z_{i, r}+\epsilon_{i, r}
$$

where AmountRaised ${ }_{i, r}$ is the amount raised by venture $i$ in round $r . Z_{i, r}$ include the mentioned fixed effects.

To fill the missing data in first-round post-money valuation, we impute first-round ownership given up first. Ownership given up in a funding round is the ratio of amount raised over post-money valuation. As it is bounded from 0 to 1, ownership given up is easier to model and impute than post money valuation. Specifically, we estimate a logit model relating the ownership given up in each round to a rich set of variables. The logit model is as below.

$$
\begin{aligned}
\log \frac{\text { OwnershipGivenU } p_{i, r}}{1-\text { OwnershipGivenU } p_{i, r}} & =\alpha+\beta_{1} \log \text { AmountRaised }_{i, r}+\beta_{2}\left(\log \text { AmountRaised }_{i, r}^{2}+\right. \\
& \beta_{3} \log \text { CumulativeAmountRaised }_{i, r}+\gamma Z_{i, r}+\epsilon_{i, r}
\end{aligned}
$$

where the right hand side variables are, for venture $i$ in round $r$, the $\log$ amount raised in the round and its square, log cumulative amount raised starting from the first round, and controlling for fixed effects on industry, funding stage, the number of rounds that have occurred, time and the number of investors. As a robustness check, we estimate the model only for first funding round; and use the estimated parameter values to impute the post money valuation for the first round. This does not affect our findings materially. In Table IA.3, IA.4 and Figure IA.3 in the Internet Appendix, we present the estimated GPME/PME 
of ventures when the first round ownership given up is imputed using only data on the first rounds.

For the pre-IPO valuations and pre-MA valuations, the imputation uses the following linear regression model.

$$
\begin{aligned}
\text { Valuation }_{i} & =\alpha+\beta_{1} \overline{\text { Valuation }}_{i}+\beta_{2} \text { lastPMVtoExit }_{i}+\beta_{3} \overline{\text { Valuation }}_{i} \times \text { lastPMVtoExit }_{i} \\
& +\beta_{4} \log \text { FinalAmountRaised }_{i}+\beta_{5} \text { FinalRoundtoExit }_{i} \\
& +\beta_{6} \text { NASDAQReturn }_{i}+\gamma Z_{i} \epsilon_{i}
\end{aligned}
$$

where Valuation $_{i}$ is either pre-IPO valuation or pre-MA valuation of venture $i . \overline{\text { Valuation }}_{i}$ is the extrapolated valuation for venture $i$, which equals the last available post-money valuation multiplied by the cumulative NASDAQ stock return from the last post-money valuation date to the venture's exit. lastPMVtoExit $t_{i}$ is the number of years from the last post-money valuation date to the venture's exit. FinalAmountRaised is $_{i}$ the amount raised by venture $i$ in its last funding round. FinalRoundtoExit ${ }_{i}$ is the number of years from venture $i$ 's last funding round to the its exit. NASDAQReturn $n_{i}$ is the cumulative NASDAQ stock return from venture $i$ 's last funding round to its exit. $Z_{i}$ include fixed effects for industry, funding stage, and number of rounds received.

\section{[Insert Table 10 near here]}

\section{[Insert Table 11 near here]}

\section{[Insert Table 12 near here]}

\section{[Insert Table 13 near here]}

Table 10, 11, 12, 13 report the estimation results of these imputation models, for the amount raised, ownership given up in the first round, pre-IPO valuation, and exit values in MA respectively. Hall and Woodward (2010) provide an imputation model for the first round ownership given up. Our imputation model for first round ownership given up improves over Hall and Woodward (2010) by increasing the number of covariates and avoid overfitting by balancing the in-sample and out-of-sample goodness of fit measures. Their model controls for amount raised and cumulative increase in the Wilshire index over the past two years in the first round. Instead of controlling for the increase in Wilshire index, we control for the increase in Nasdaq index. Also, our model is estimated using ownership given up in

\footnotetext{
${ }^{18}$ The Hall and Woodward (2010) model imputes the venture share of ownership in each funding round, and effectively imputes the first round ownership given up by venture founders. See Table A2 in their paper.
} 
all funding rounds with round fixed effects, and additionally controls for the square of log amount raised, log cumulative amount raised, and fixed effects on round number, industry, funding stage, calendar year and the number of investors. Using data from all funding rounds enlarges the sample for training the imputation model, and the additional covariates appear to be significantly related to ownership given up. For example, the square of log amount raised is negatively related with ownership given up.

For assessing the goodness of fit of the imputation models, we rely on the out-of-sample $R^{2}$, in addition to the standard in-sample $R^{2}$. We use the ten-fold cross-validation method to calculate the out-of-sample $R^{2}$. First, we randomly partition the sample that enters the regression model, into ten equal-sized sub-samples. Second, we iterate over each one of the ten subsamples, while in each iteration, we calculate the fitted values for one subsample based on the model estimated by the rest nine subsamples, and record the pseudo- $R^{2}$, that is, the square of the correlation coefficient of the fitted and actual values of the dependent variable. After ten iterations, we collect ten pseudo- $R^{2}$ 's for the subsamples. Finally, we repeat the random sample partition ten times, while each time perform the same procedure and collect the pseudo- $R^{2}$ 's, and we report the average of all the pseudo- $R^{2}$ 's after ten sample partitions as the out-of-sample $R^{2}$. The in-sample adjusted $R^{2}$ and out-of-sample $R^{2}$ of our model in predicting ownership given up in all the funding rounds are 0.488 and 0.486 (See Table 11).

The out-of-sample $R^{2}$ of the Hall and Woodward (2010) model in our data in predicting first round ownership given up is 0.116 . We calculate this out-of-sample $R^{2}$ by estimating their model on the first rounds, constructing the fitted values for first round ownership given up, and calculate the pseudo- $R^{2}$ 's. In comparison, the out-of-sample $R^{2}$ of our model in predicting first round ownership given up is 0.244 . We calculate this out-of-sample $R^{2}$ by estimating our model in Equation (6) on all the rounds, constructing the fitted values for the first round ownership given up, and calculate the pseudo- $R^{2}$ 's only for the first rounds.

The second approach to address the missing data is a reweighting method which is an analogue of the resampling method in Korteweg and Nagel (2016) and Korteweg and Sorensen (2010). The first-round post-money valuation data, amount raised data, and exit value data, are more likely to be missing for unsuccessful ventures. For example, in the sample with all these data (2,954 ventures), 23.3\% of the ventures exited through IPO, 29.6\% exited through MA, $27.8 \%$ exited through bankruptcy, and $19.4 \%$ remain private as of 2018 . But in the full sample (17,242 ventures), $11.1 \%$ of ventures exited through IPO, $37.2 \%$ through MA, $22.6 \%$ through bankruptcy, and $29.2 \%$ remain private as of 2018 . We correct for this selection bias by reweighting ventures that have all of these data, to match the distribution across 
exit types of the full sample that includes ventures with missing data. ${ }^{19}$ For example, for each venture that went to IPO and has first-round post-money valuation data, amount raised data, and exit value data, we weight its cash flows and present values by 0.48 (11.1\%/23.3\%). The reweighting procedure assumes that the missing data of each exit type come from the same distribution as the observed data, as in the resampling approach in KN and KS. Table 14 indicates that the covariates in the imputation model do play an important role, as the imputation models produce values that are on average less than the corresponding observed values. For example, 2,945 ventures have first round valuation, amount raised and exit values data all available (see Panel A of the table), and 17,242 ventures are in the full sample where first round valuation imputed, amount raised imputed, exit values are imputed (see Panel D of the table). From 2,945 to 17,242, the number of ventures increases by $485 \%$. However, the aggregate first round valuation, aggregate amount raised, and aggregate exit valuation increase only by $292 \%, 316 \%$, and $244 \%$, respectively. Although imputation models produce values that are on average lower than the observed ones, the GPME/PME of the reweighted subsample and the imputed full sample are not necessarily dissimilar. GPME/PME depends on both cash outflows and inflows, and the times of their occurrences. It is possible that the effects of differences in these determinants of GPME/PME cancel out.

\section{[Insert Table 14 near here]}

\section{Empirical Results}

After filling the missing data, we compute the return of investing in the portfolio of the universe of ventures, based on different methods of filling in the missing data and different sample period. We study several return measures - GPME in Equation (1) and its variants where the SDF features no discounting $\left(M_{t}=1\right)^{20}$, discounting using the PME's parameters $(a=0, b=1)$, and discounting using risk free rate $\left(M_{t}=e^{-r_{f} t}\right)$. We also provide IRR as a return measure. When calculating GPME and PME, we discount cash outflows and inflows of individual ventures to their first funding round, and calculate the ratio of aggregate discounted inflows to aggregate discounted outflows. When calculating the IRR, all the cash flows to the portfolio of ventures are ranked by calendar time, and the IRR sets the discounted value of these cash flows to zero. We consider three samples: the full sample including ventures receiving first funding round before 2006, the pre-2006 sample derived from the full sample but assuming our observation of these ventures stop in 2006, and the

\footnotetext{
${ }^{19}$ The reweighting method is equivalent to resampling ventures infinite times with replacement.

${ }^{20}$ This is the same return measure used in Cole, Melecky, Mölders, and Reed (2020).
} 
no-bubble sample derived by excluding ventures with any financing activities or or exits in 1999 and 2000 from the full sample ${ }^{21}$. We use the pre-2006 sample to reveal the effect of the right-censoring data issue. The boom of ventures that initiated around 2000 leads to disproportionately more young actively financed ventures that remain private as of 2006 . It is not appropriate to assume these actively financed 5,097 ventures that remain private as of 2006 have zero exit values, since Panel B of Table 7 indicates that $6.8 \%$ and $52.6 \%$ of them eventually went to IPO and MA. So the pre-2006 sample excludes from the full sample these 5,097 ventures. We use the no-bubble sample to avoid the effect of dot com bubble on the return to investing in ventures.

Table 15 provides a comparison of the returns by the different samples and methods. We see that the GPME of all the aggregate all-ventures portfolio are greater than 1, i.e., in the aggregate investing in the ventures outperformed the market. The IRR of investing in ventures is about $22 \%-30 \%$, also large. For comparison, the IRR of the venture-mimicking portfolio of public market industry portfolios was $7 \% .^{22}$ Specifically, we construct the venture-mimicking portfolio of public market industry portfolios by investing each venture's amount raised into its corresponding industry's portfolio (taking returns from Fama-French 10 industry portfolios). We liquidate the industry portfolio when the venture exits through IPO,MA and bankruptcy, or, the earlier of (a) 12 years after the last observed round and (b) December 31, 2018, if no exit is observed. We take all the cash flows associated with the mimicking public market portfolio, and find the IRR that sets the present value of the net cash inflows to 0 to be $7 \%$.

The imputation method and the reweighting method to fill missing data result in comparable PME and GPME in the full sample, which are around 1.42-1.47. Our preferred return measure is the GPME. While in all the three samples, the imputation method produces very consistent GPMEs ranging between 1.41-1.48, the reweighting method produces a GPME of 1.47 in the full sample, 1.61 in the pre-2006 sample and 1.19 in the no-bubble sample. The inconsistency of GPMEs produced by reweighting method across the samples led us choose imputation method as the preferred data filling method. Besides, the reweighting method uses data of only $17 \%$ of the universe of ventures $(2,954 / 17,242)$, while the imputation method leverages the information in the observed data of all the ventures to a larger extent by using covariates to address differences across time periods.

\section{[Insert Table 15 near here]}

\footnotetext{
${ }^{21}$ We define the bubble period as from 1999 to 2000, when Nasdaq return significantly deviates from SP500 (See Figure IA.1).

${ }^{22}$ Note that the venture-mimicking portfolio will have a lower systematic risk than underlying ventures. The underlying ventures have higher embedded leverage than the industry average. To that extent the venture-mimicking portfolio will have a lower return.
} 
A closer analysis suggests that the reweighting method leads to oversampling of cash flows in specific time periods. Figure 3 plots the number of ventures and the total of amount raised by ventures by the time of the ventures' first rounds. It shows that in the reweighted sample, total amount raised by ventures initiated during the dot com bubble is significantly larger than the original sample, and total amount raised by ventures initiated after 2003 is significantly less than the original sample. This is be due to the fact that large fraction of ventures receiving financing during the dot-com bubble eventually exited through MA with observed valuations, and such ventures are weighted more than other exit types. ${ }^{23}$

\section{[Insert Figure 3 near here]}

\subsection{Cash Flows over Venture's Life Cycle}

To examine the cash flows over the life cycle of the ventures, we construct the cumulative discounted cash flows of each individual venture following its first round, and then aggregate across all the ventures. Figure 4 plots the aggregate cumulative cash inflows (i.e., exit values realized), cash outflows (i.e., amount raised from all equity investors including the founders in various rounds) and net cash inflows (i.e., exit values realized minus amount raised from all equity investors) against the time from the first funding round. There are two observations. First, the cash outflows from investors (hence inflows to the venture) is on average larger during the initial funding stages. Around $80 \%$ of the total funding occurs within five years from the first round. Second, in the aggregate, investors have to wait five years from the first funding round for the discounted cash flows from the ventures to become positive (see Panel $\mathrm{C}$ of the figure). That is, our hypothetical investor who participates in all funding rounds of all ventures had to wait five years in the aggregate on average for breaking even relative to the alternative of investing in the corresponding public market alternative, i.e., the PME to become positive in the aggregate.

\section{[Insert Figure 4 near here]}

\subsection{Time Series Properties of Returns}

Based on the GPME measure, we examine how the return to investing in ventures changes over time depending on the ventures' vintage, i.e., the first year in which the first funding round happened. In particular, for each year from 1980 to 2006, we study the GPME to a

\footnotetext{
${ }^{23} 23.3 \%$ ventures went to IPO in the subsample with all cash flows data $(2,954$ ventures $)$, but $11.1 \%$ of ventures went to IPO in the full sample (17,242 ventures), so the weight on ventures went to IPO is 0.48 $(11.1 \% / 23.3 \%)$. Similarly, the weight on ventures went to MA is $1.26(37.2 \% / 29.6 \%)$.
} 
hypothetical investor who invests in the portfolio of ventures that received the first funding round in that year. The GPME is calculated as the ratio of discounted cash inflows to discounted cash outflows to the portfolio of ventures. Table 16 reports the historical time series of GPME, its variants, and IRR, by the year of the first round. We see quite large variations in the GPME over time, ranging from 0.34 to 2.89. The median and average of the GPMEs are 1.48 and 1.39. We regard data for the ventures with first round happening after 1991 as more reliable, and from 1991 to 2006, venture GPME ranges from 1.00 to 2.89. The time period when GPME is high is from 1991 to 1998. After 1998, venture GPME declines. We show that the PME and GPME calculations are not sensitive even if the first round ownership given up raised is off by as much as 18\%, a one standard deviation change in the first round ownership given up. It is however sensitive to errors in observed exit values. We show what the effect will be on the PME/GPME if the exit values that we impute are off by $25 \%$ in our sensitivity analysis. Table IA.5 and IA.6 in the Internet Appendix tabulate the results of these sensitivity tests. An across the board $25 \%$ reduction in imputed exit values will reduce the PME and GPME to about 1.1 (1.07 for PME, and 1.08 for GPME) and the IRR to about $11 \%$ - still significant premium over the public market equivalent. We also provide the bootstrapped confidence intervals of the PME/GPME in Table IA.7 in the Internet Appendix. The lower boundaries of the 95\% confidence intervals of PME and GPME are also mostly greater than 1 after 1991, suggesting that ventures have significant premium over the public market equivalent.

\section{[Insert Table 16 near here]}

Ang, Chen, Goetzmann, and Phalippou (2018) (ACGP) use Bayesian Markov Chain Monte Carlo (MCMC) to estimate a time series of PE returns using cash flows accruing to limited partners, and by decomposing returns into a component due to exposure to traded factors and a time-varying PE premium not spanned by traded factors. They provide a historical time series of returns to investment in private equity funds from 1994 to 2008. The average of fund PMEs comparing private equity returns to equivalent-timed investments in the S\&P 500 index, is 1.67. Apart from being different measures of profitability, there are other differences between our venture GPME and their private equity return. On the one hand, our GPME does not deduct the PE fees, hence should imply a higher return. On the other hand, PEs may invest in better venture companies, hence realizing a higher return. Despite the differences, similar to the pattern in our time series of GPMEs, the private equity return in ACGP is high during 1994-1998, and declines after 1998.

Having more granular observations of the return to investing in ventures allows us to better study its time series property. Hence we also compute the return to investing in 
ventures that had their first funding round in the same calendar quarter. Figure 5 offers a graphical illustration of the time series. In particular, for each quarter from 1992Q1 to 2006Q4, we plot the GPME to a hypothetical investor who invests in the portfolio of ventures that received the first funding round in that quarter. A direct observation of the figure reveals that venture GPME is generally greater than 1 over time. The venture GPME, as well as the venture PME, are less than 1 only in 4 quarters during the period 1992Q1 to 2006 Q4. But there is a structural break in the time series - venture GPME declines substantially after around 1999. To not let the dot-com bubble period confound this finding, we plot the GPME based on sample that excludes ventures with any financing activities or or exits between 1999 and 2001. Still present is the structural break, venture GPME is much lower after 2001 than before 1999. The same structural break is also shown in the times series of IRR.

\section{[Insert Figure 5 near here]}

The quarterly time series of GPMEs also allows us to construct a statistical test of whether expected GPME is greater than 1 that takes into account the serial correlation in venture returns. We first approximate the time series of GPMEs by an ARMA(p,q) process, where the exact ARMA model is derived based on BIC model selection criterion. While the quarterly time series of GPMEs can be extended to the 1980s, we would have to fill in a lot of data for the earlier GPMEs, ${ }^{24}$ so they are less reliable and we don't use them for the model selection and the later analysis. We limit our attention to the quarterly time series from 1992Q1 to 2006Q4. Table 17 reports the best ARMA models that fit the time series of venture GPME and PME in 1992Q1-2006Q4, 1992Q1-1999Q1, and 1999Q2-2006Q4, respectively. $\mathrm{AR}(2)$ is the best ARMA model for both GPME and PME in both 1992Q12006Q4 and 1999Q2-2006Q4. AR(1) is the best ARMA model for both GPME and PME in 1992Q1-1999Q1. Then we construct a t-test of the mean of the time series against 1, based on the standard errors of the implied by the best ARMA model. The tests show that GPME and PME are significantly greater than 1, regardless of the time periods. We also provide t-test based on Newey-West standard errors, and the results are similar. ${ }^{25}$

\section{[Insert Table 17 near here]}

To not let the dot-com bubble to confound the GPMEs, Table 18 reports the best ARMA models for the no-bubble sample, derived by excluding ventures that ever had financing

\footnotetext{
${ }^{24}$ As Table 16 shows, before 1991 less than $4.4 \%$ of the ventures have first round valuation data.

${ }^{25}$ The expected value of GPME and PME will not in general be the same as ratio of the expected values of the numerator and the denominator expressions in GPME and PME. This should not be a major concern since the GPME was less than 1 only during 4 of the 60 quarters during 1992/Q1 - 2006/Q4.
} 
activities or exit events during 1999-2000 from the full sample. ${ }^{26}$ The best ARMA model for PME and GPME is AR(1) during 1992Q1-1999Q1, and is AR(2) during 2001Q1-2006Q4. The t-tests still show that GPME and PME are significantly greater than 1 .

\section{[Insert Table 18 near here]}

\subsection{The Structural Break}

Figure IA.2 in the Internet Appendix presents the histogram of the realized NPVs of ventures that had their first round in each calendar quarter. We find that when cash flows are discounted using the PME specification, the realized NPV is positive in 55 of the 60 quarters in our sample (1992Q1-2006Q4). When cash flows are discounted using the GPME specification, the realized NPV is positive in 56 of the 60 quarters. During the 1980-1989 period, the PME and GPME were negative for 7 of the 10 years. The PME and GPME calculations for that time period are however not reliable since the data on post money valuation for the first round of funding was available for less than $5 \%$ of the ventures.

To confirm the observation from Figure 5 that there is a structural break in the time series of GPME, and to identify when the break happens, we apply a Supremum Wald test (Quandt, 1960; Andrews, 1993). The test assumes the GPME fluctuates around a constant, and looks for a structural break in the constant parameter of the model, at an unknown break time. Table 19 shows the test result, indicating that there is a structural break in the time series of GPME at 1999Q1, and after the break GPME significantly declines. Results are similar for the time series of PME and IRR. Test for IRR suggests a structural break at 1999Q2. The test is informal, as it assumes uncorrelated residuals in the GPME time series while the fitness of $\operatorname{AR}(1)$ and $\operatorname{AR}(2)$ process suggests strong autocorrelation. Hence, the interpretation of the test result requires some cautiousness. The purpose of the test is diagnostic, aiming to identify the structural break date that is coherent with the direct observation. In the same table, we provide some additional tests that allow for heteroskedastic and serially correlated residuals that confirm the presence of a structural break in 1999Q1. That is, we report regression results from $\mathrm{GPME}_{t}=a+a_{1} \mathcal{I}_{t \geq 1999 Q 1}+\epsilon_{t}$, with t-statistics of $a_{1}$ using White standard errors and Newey-West standard errors. The t-statistics suggest $a_{1}$ is significantly negative.

\section{[Insert Table 19 near here]}

\footnotetext{
${ }^{26}$ Figure IA.1 gives the time series plot of the S\&P500 and Nasdaq composite indices, normalized to 100 at the beginning of our sample period. As can be seen from the figure, the normalized Nasdaq index was above the normalized S\&P500 index during the period 1999Q1-2000Q4, providing some justification for 1999-2000 being the dot-com years. See Phillips, Shi, and Yu (2015) for testing multiple bubbles.
} 
What might have caused the structural break? There are two confounding events. First is the Dot Com bubble. Figure 1 Panel A gives the time series plot of the amount raised and the value of exits in the various calendar quarters. As can be seen, both the amount raised and value realized through exits sharply rise during early 1990s reaching a peak in 1999 and crashing in 2001. Once can argue that ventures that exited during this period realized high returns and investors paid too much to ventures that raised money during this period leading to poor returns on those investments.

Second, the NSMIA Act liberalizing investment was passed in 1996. Ewens and FarreMensa (2019) argue that NSMIA increased the supply of capital to the ventures. The increase in capital supply may in part explain the decline in the return to investing in ventures.

Two distinct provisions of NSMIA have helped increase the supply of private capital, including venture capital. First, NSMIA exempts qualified private security issuers from having to comply with the blue sky laws of each state. Traditionally, a venture seeking external financing needed to comply with the laws governing the issuance of securities in each state where its securities were sold, commonly known as blue sky laws. Compliance with blue sky laws required significant time and efforts. NSMIA exempts private issuers from compliance with blue sky laws in each and every state, as long as all investors are "accredited investors", hence facilitated venture's security issuance. Second, NSMIA makes it possible for $\mathrm{VC}$ and $\mathrm{PE}$ funds to raise capital from a large number of investors but without registering under the Investment Company Act (ICA) of 1940, enabling VC and PE funds to raise fund at lower cost. ${ }^{27}$

It is difficult to disentangle the two effects since they may be influencing each other. We attenuated the effect of the Dotcom bubble period (1999-2000 when the Nasdaq index was higher than the S\&P500 index when the latter was normalized to match the Nasdaq index value of 771 in January 1994) by excluding ventures that had any funding rounds or exits during these two years. The Andrews (1993) structural break test when applied to the PME times series with this exclusion restriction still identifies 1999Q1 as the structural break quarter. This suggests that the structural break may not be solely due to investor exuberance during the Dotcom bubble period.

${ }^{27}$ The ICA required VC and PE funds to register with the SEC and imposed extensive regulations on registered entities, including investment and leverage restrictions, restrictions on related party transactions, and ongoing reporting requirements. NSMIA to a large extent allows exemptions of these regulatory requirements, for certain classes of investors. 


\subsection{Cross Section of Venture Returns}

While the aggregate venture portfolio earned an attractive return, a few ventures in the portfolio contributed to most of the returns.

Figure 6 gives the empirical frequency diagram of the PMEs and GPMEs of individual ventures. As the figure shows, $70 \%$ of the ventures had a PME of less than 1.0, and $61 \%$ of the ventures had a PME of less than 0.5. Similarly, $69 \%$ of the ventures had a GPME of less than 1.0, and $61 \%$ of the ventures had a GPME of less than 0.5 .

\section{[Insert Figure 6 near here]}

If we omit the most profitable $5 \%$ of the ventures (ventures with highest $5 \% \mathrm{PME}$ ) from the aggregate venture portfolio, the PME and GPME become less than 1.0, that is, the performance is worse than corresponding investments in the U.S. stock index portfolio.

\section{Summary and Conclusion}

We show that the potentially large bias in the pre-money valuations of latter financing rounds of venture companies documented in Gornall and Strebulaev (2020) (GS bias) will affect the funding round to exit return for all funding rounds, not just the latter rounds. We address this issue by measuring the return to equity investors in all the funding rounds of a venture taken together as a group, which is not affected by the GS bias, and requires only the amounts raised information along with the post money information for the first funding round and exit value information.

Our sample consists of VC funded ventures in VentureXpert during 1980-2018. We examine ventures that had their first funding round in December 2006 or earlier, and follow them till 2018, i.e., for a minimum of 12 years following their first funding round. Our return measure relies mainly on the well-populated amount raised data, which allows us to study a significantly enlarged set of ventures and rounds - we use in our analysis almost $95 \%$ of the ventures in the sample.

Most of the ventures, 71\%, exited by December 2018. The other ventures remained private as of 2018, and we assumed that they had zero exit values. While the amount raised information is available for $87 \%$ of all ventures (and $96 \%$ of all the rounds), first round valuation information is available for $23 \%$ of the ventures and exit values are available for $98 \%$ of ventures that exited through IPOs and $51 \%$ of ventures that exited through Mergers or Acquisitions.

We address the missing data issue using a variation of the imputation method in Hall and Woodward (2010) and the resampled subsample method in Korteweg and Nagel (2016) 
and Korteweg and Sorensen (2010). Both methods give similar results. We measure the return to equity investors in all the 17,242 venture companies in our sample taken together as a group in several ways: the Kaplan and Schoar (2005) Public Market Equivalent (PME), the Korteweg and Nagel (2016) Generalized PME, and the Internal Rate of Return (IRR). We find that equity investors as group earned a substantial premium over the public market equivalent - with a PME of 1.42 and a GPME of 1.44. The IRR is $22 \%$ which is much higher than the IRR of $7 \%$ on the venture-mimicking portfolio that invested the amounts raised in the Fama-French industry portfolios till the venture companies' exit. The higher IRR is compensation for the higher risks due to the higher leverage of venture companies relative to publicly traded firms in their industry as well as compensation for illiquidity.

We show that our findings are not sensitive to errors associated with first round post money valuation estimates that are as large as $18 \%$ in absolute value - that is, one standard deviation of first round post money valuation. However, our return measures are sensitive to errors in imputed exit values. An across the board $25 \%$ reduction in imputed exit values will reduce the PME and GPME to about 1.1 (1.07 for PME, and 1.08 for GPME) and the IRR to about $11 \%$ - still significant premium over the public market equivalent.

Ventures take a long time to exit, and in the aggregate, investors have to wait five years from the first funding round for the discounted cash flows from the ventures to become positive. We construct the time series of the return to investing in ventures formed at different times taking into account the long waiting time to exit, and find that the return to investing in ventures outperforms the public benchmark. This result is robust to valuation methods, data filling methods, and not confounded by the dot-com bubble.

There is a structural break in 1991Q1 in the return to investing in ventures, and venture returns come down after the break but still earn a premium over their public market equivalent investments. The structural break is unlikely to be entirely due to the higher valuations during the Dot-Com bubble, and is likely to be in part due to the increased supply of capital to ventures after the passage of the National Securities Markets Improvement Act (NSMIA). 


\section{References}

Andrews, D. W. K., 1993. Tests for Parameter Instability and Structural Change With Unknown Change Point. Econometrica 61, 821.

Ang, A., Chen, B., Goetzmann, W. N., Phalippou, L., 2018. Estimating Private Equity Returns from Limited Partner Cash Flows. The Journal of Finance 73, 1751-1783.

Cochrane, J. H., 2005. The Risk and Return of Venture Capital. Journal of Financial Economics $75,3-52$.

Cole, S. A., Melecky, M., Mölders, F., Reed, T., 2020. Long-run returns to impact investing in emerging markets and developing economies. NBER Working Paper .

Driessen, J., Lin, T.-C., Phalippou, L., 2011. A New Method to Estimate Risk and Return of Non-Traded Assets from Cash Flows: The Case of Private Equity Funds. SSRN Electronic Journal .

Ewens, M., Farre-Mensa, J., 2019. The Deregulation of the Private Equity Markets and the Decline in IPOs. Working Paper 26317, National Bureau of Economic Research.

Ewens, M., Gorbenko, A. S., Korteweg, A., 2018. Venture Capital Contracts p. 59.

Fama, E. F., French, K. R., 1993. Common risk factors in the returns on stocks and bonds. Journal of Financial Economics 33, 3-56.

Gornall, W., Strebulaev, I. A., 2020. Squaring Venture Capital Valuations with Reality. Journal of Financial Economics 135, 120-143.

Gupta, A., Stern, N., Nieuwerburgh, S. V., 2019. Valuing Private Equity Investments Strip by Strip p. 71, 1 .

Hall, R. E., Woodward, S. E., 2010. The Burden of the Nondiversifiable Risk of Entrepreneurship. American Economic Review 100, 1163-1194.

Hansen, L. P., Richard, S. F., 1987. The role of conditioning information in deducing testable restrictions implied by dynamic asset pricing models. Econometrica: Journal of the Econometric Society pp. 587-613.

Harris, R. S., Jenkinson, T., Kaplan, S. N., 2014. Private Equity Performance: What Do We Know? The Journal of Finance 69, 1851-1882. 
Harris, R. S., Jenkinson, T., Kaplan, S. N., 2015. How Do Private Equity Investments Perform Compared to Public Equity? SSRN Electronic Journal .

Kaplan, S. N., Schoar, A., 2005. Private Equity Performance: Returns, Persistence, and Capital Flows. The Journal of Finance 60, 1791-1823.

Kaplan, S. N., Strömberg, P., Sensoy, B. A., 2002. How Well Do Venture Capital Databases Reflect Actual Investments? SSRN Scholarly Paper ID 939073, Social Science Research Network, Rochester, NY.

Korteweg, A., Nagel, S., 2016. Risk-Adjusting the Returns to Venture Capital. The Journal of Finance 71, 1437-1470.

Korteweg, A., Sorensen, M., 2010. Risk and Return Characteristics of Venture CapitalBacked Entrepreneurial Companies. The Review of Financial Studies 23, 3738-3772.

Ljungqvist, A., Richardson, M., 2003. The Cash Flow, Return and Risk Characteristics of Private Equity. Working Paper 9454, National Bureau of Economic Research.

Nanda, R., Rhodes-Kropf, M., 2013. Investment Cycles and Startup Innovation. Journal of Financial Economics 110, 403-418.

Phalippou, L., Gottschalg, O., 2009. The performance of private equity funds. The Review of Financial Studies 22, 1747-1776.

Phillips, P. C., Shi, S., Yu, J., 2015. Testing for multiple bubbles: Historical episodes of exuberance and collapse in the s\&p 500. International economic review 56, 1043-1078.

Quandt, R. E., 1960. Tests of the Hypothesis That a Linear Regression System Obeys Two Separate Regimes. Journal of the American Statistical Association 55, 324-330.

Rubinstein, M., 1976. The valuation of uncertain income streams and the pricing of options. The Bell Journal of Economics pp. 407-425.

Sorensen, M., Jagannathan, R., 2015. The Public Market Equivalent and Private Equity Performance. Financial Analysts Journal 71, 43-50.

Whyte, A., 2017. Survey: Endowments and foundations unfazed by private equity valuations. Institutional Investor . 
Fig. 1: Amount Raised, First-Round Valuation and Exit Values Over Time

(a) Amount raised and exit values

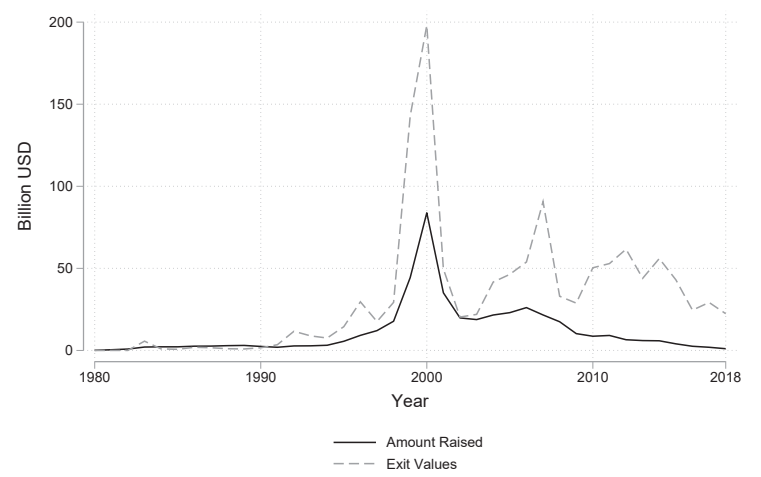

(c) Fraction of first rounds with non-missing first round valuation

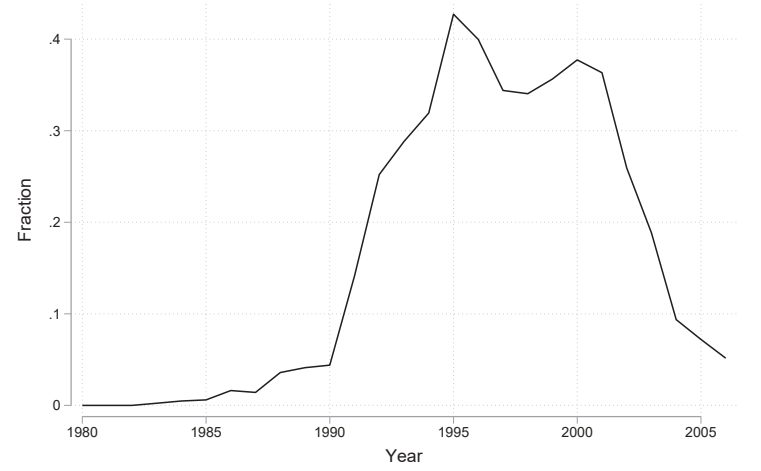

(b) Fraction of rounds with nonmissing data

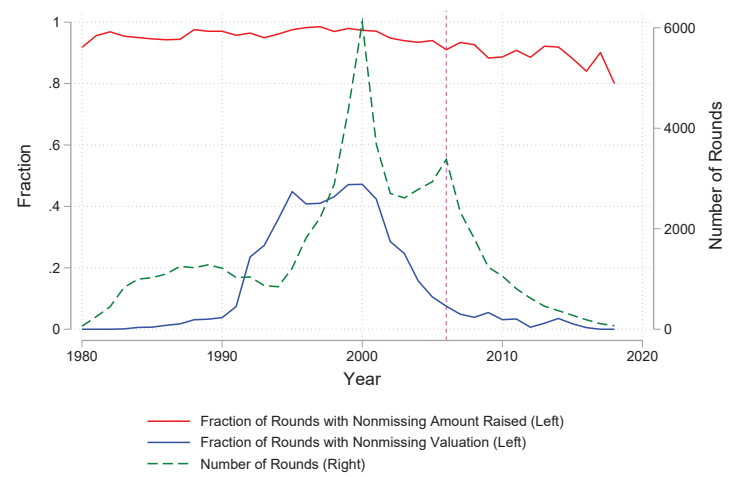

(d) Amount raised in first round as a fraction of lifetime amount raised

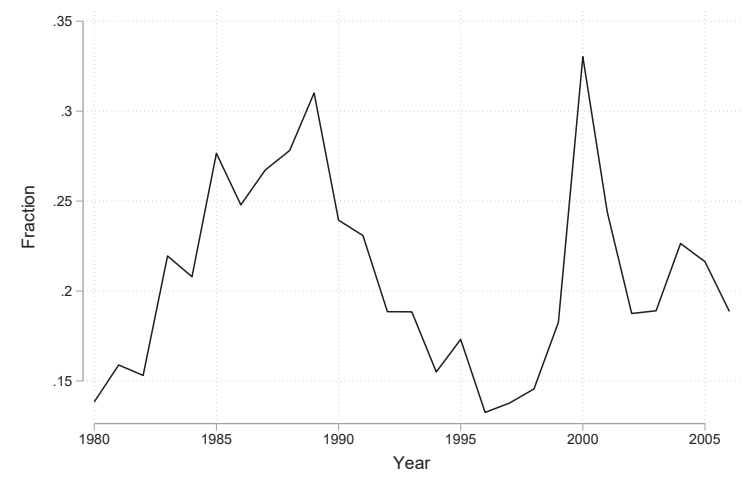

Notes: In Panel (a), we plot the total amount raised and exit values of ventures in each calendar year. Panel (b) plots the number of funding rounds received by the ventures in each year, as well as the fraction of the funding rounds in each year that have non-missing amount raised data and non-missing post-money valuation data. Panel (c) plots the fraction of first rounds with non missing first round valuation. Panel (d) plots the amount raised in first round as a fraction of life time amount raised. The sample includes 17,242 US-based ventures in SDC VentureXpert database that had the first funding round in 1980-2006, and we trace their funding rounds in 1980-2018. 
Fig. 2: Diagram of the amount raised, exit value, and return to investing in ventures

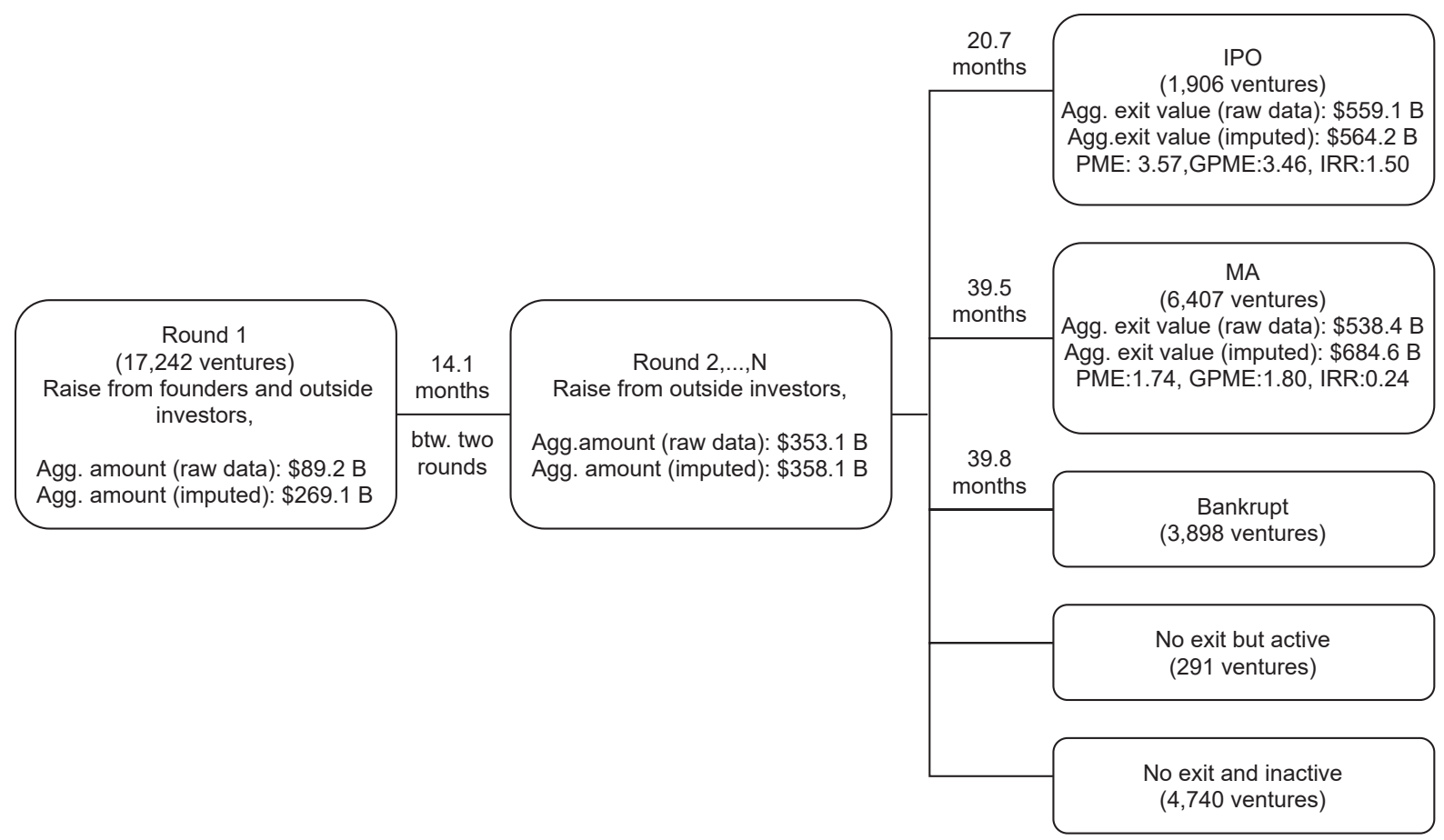

Notes: In round 1, 17,242 ventures raise $\$ 89.2$ billion from founders and outside investors in the aggregate, based on the raw data; while based on the imputed data, that is, after filling in the missing observations of first round post money valuations, the ventures raise $\$ 269.1$ billion. In the subsequent rounds, the ventures raise $\$ 353.1$ billion in the aggregate based on the raw data and $\$ 358.1$ billion based on the imputed data. The average time between two rounds is 14.1 months. After the last round, ventures spend 20.7 months on average before IPO, with an aggregate exit value of $\$ 559.1$ billion based on raw data, and $\$ 564.2$ billion based on the imputed data. After the last round, ventures spend 30.5 months on average before MA, with an aggregate exit value of $\$ 538.4$ billion based on raw data, and $\$ 684.6$ billion based on the imputed data. We also provide the PME, GPME and IRR for ventures that went to IPO and MA, respectively. 
Fig. 3: Imputation and Reweighting Method to Fill Missing Data: Number of Ventures and Amount Raised over Time in Filled Data

(a) Number of Ventures

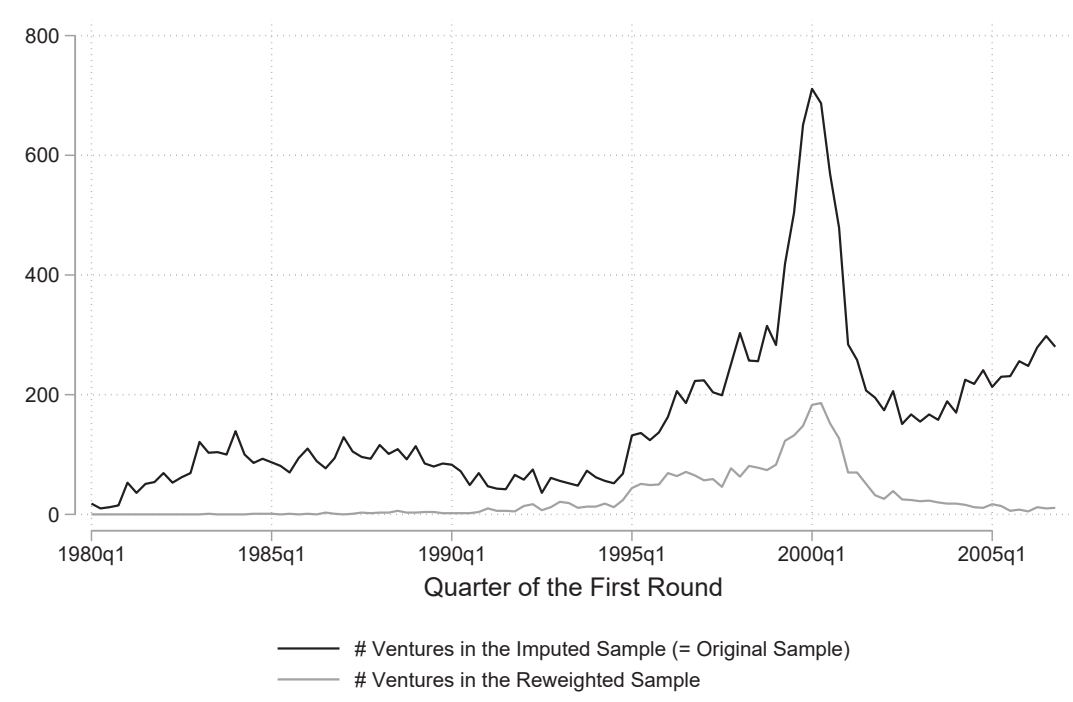

(b) Amount Raised

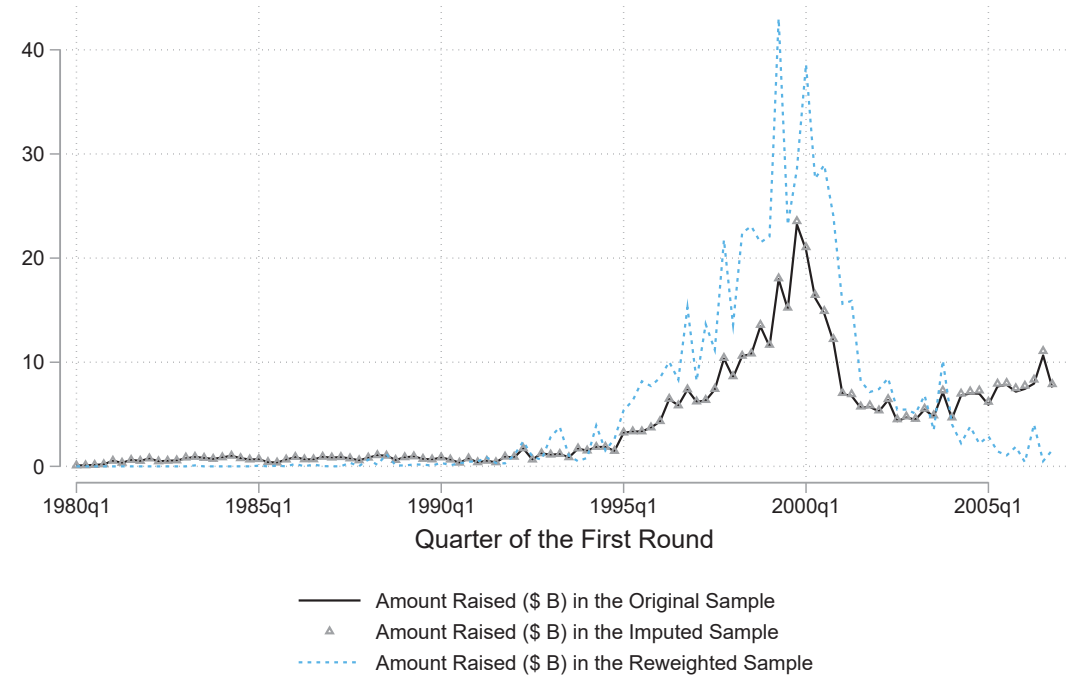

Notes: Panel A of the figure plots the number of ventures in the imputed sample, and the reweighted sample by the quarter of the first funding round. We start from the sample that includes 17,242 US-based ventures in the SDC VentureXpert database that had the first funding round in 1980-2006, and we trace their funding rounds in 1980-2018. This is called the "original sample" in this plot, consists of 17,242 ventures in total. From there, the imputed sample is derived by imputing missing data in first-round post-money valuation, amount raised, and exit value (17,242 ventures in total). The reweighted sample includes ventures with first-round post-money valuation, amount raised, and exit value all available (2,954 ventures in total). Panel B plots the amount raised of ventures in the original sample, the imputed sample (that is the original sample with some data imputed), and the weighted amount raised in the reweighted sample. When plotting the amount raised for the reweighted sample, each venture's amount raised in the reweighted sample is additionally multiplied by $5.84(17,242 / 2,954)$ in order to provide a fair comparison with the original sample and the imputed sample (with 17,242 ventures). 


\section{Fig. 4: Cumulative Cash Flows by Quarters from the First Round}

(a) No Discounting

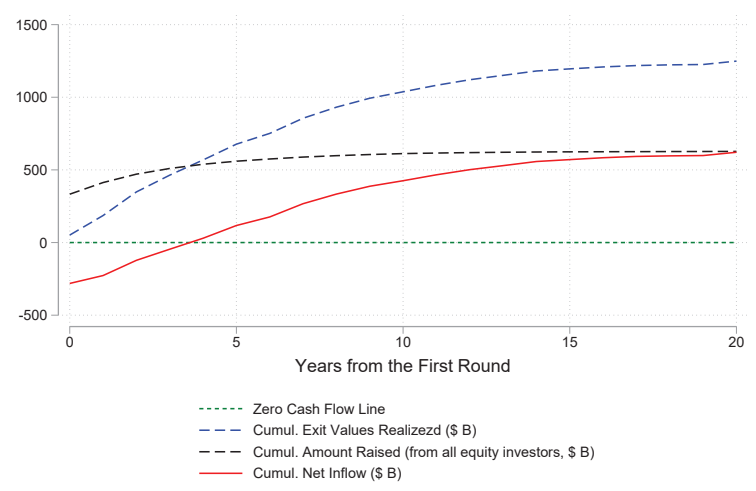

(c) Discounting using PME SDF Specification

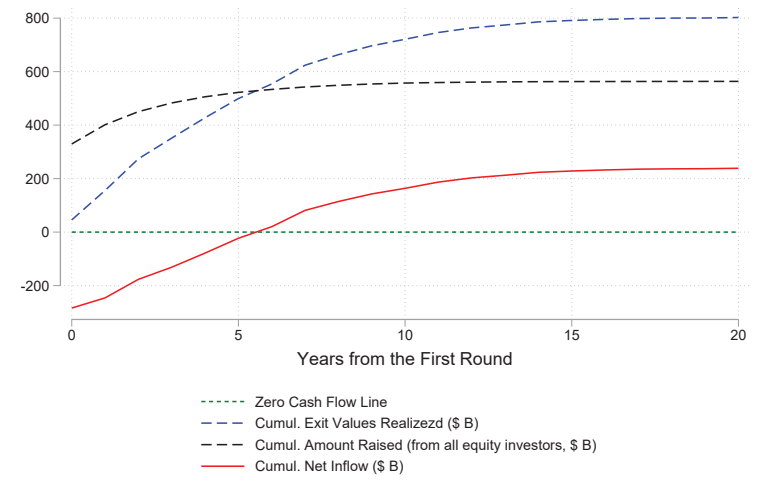

(b) Risk Free Rate Discounting

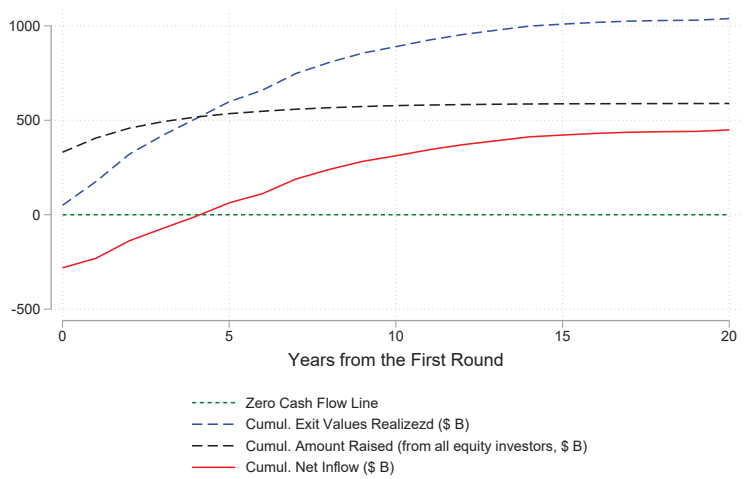

(d) Discounting using GPME SDF Specification

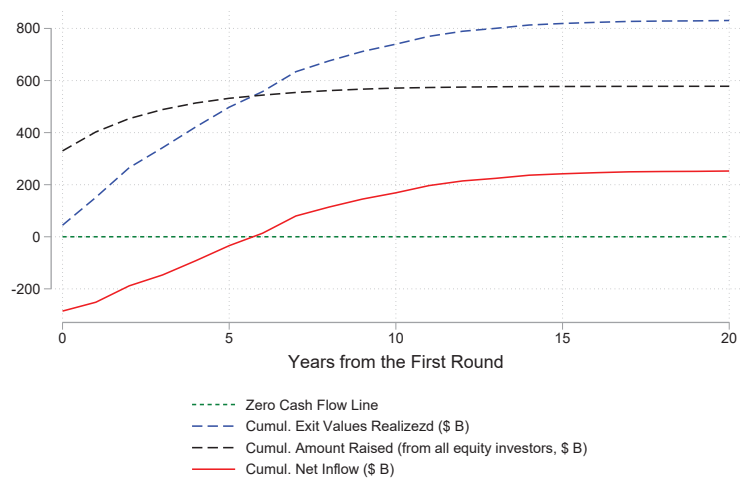

Notes: Over the life cycle of the venture, the figure plots the aggregate cumulative exit values realized, aggregate cumulative amount raised (from all equity investors) and aggregate cumulative net cash flow for investors investing in the portfolio of 17,242 US-based ventures in SDC VentureXpert database who had the first funding round in 1980-2006, and we trace their funding rounds in 1980-2018. Cumulative net cash flow is defined as cumulative amount raised minus cumulative exit values realized. Amount raised and exit values are not discounted in Panel (a), discounted with risk free rate in Panel (b), discounted with SDF specification in PME $(a=0, b=1)$ in Panel (c), discounted with SDF specification in GPME $(a=0.033, b=1.444)$ to the venture's first funding round's date. 
Fig. 5: Return to Investing in Ventures by Time of the First Round

(a) PME

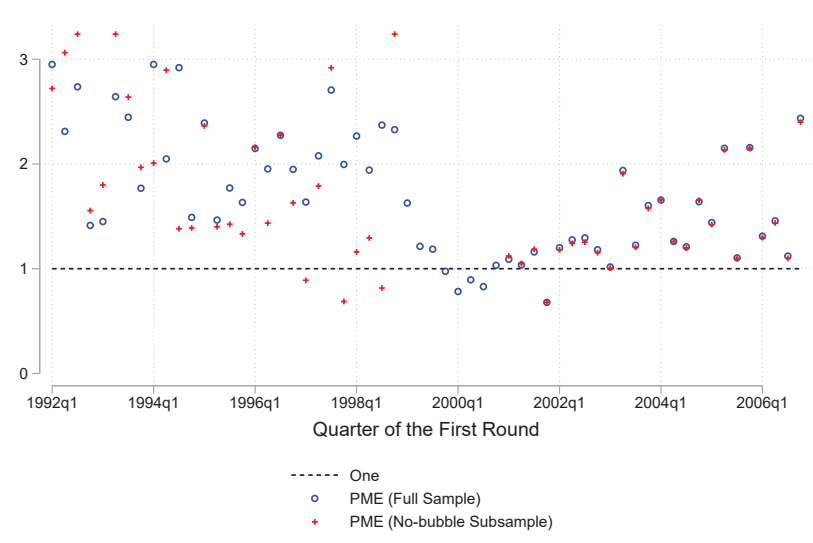

(b) GPME

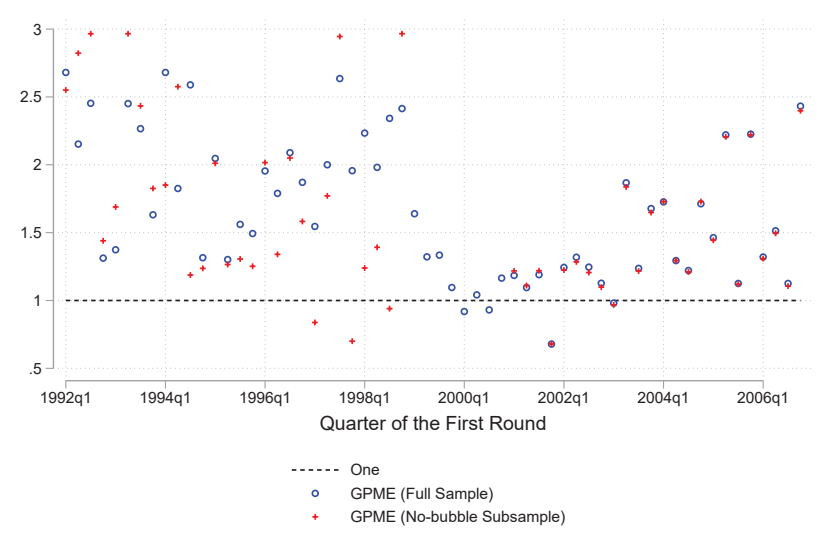

(c) IRR

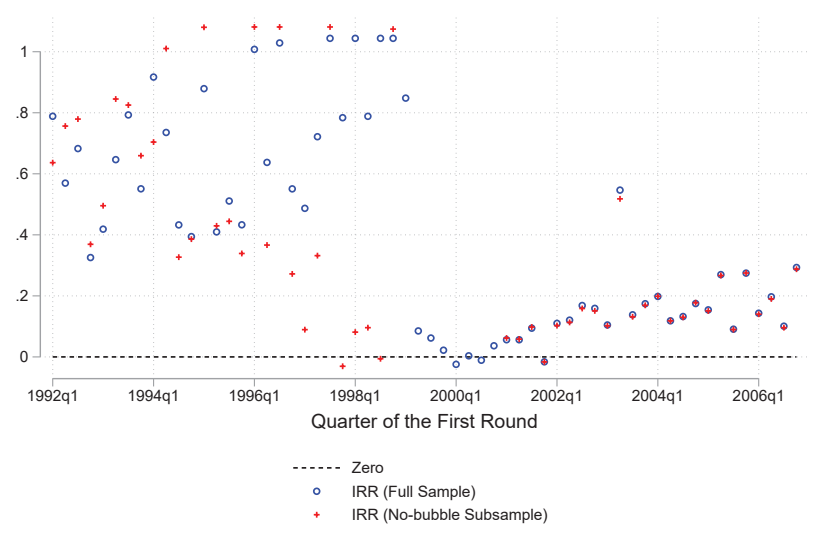

Notes: The figure plots the PME, GPME and IRR of the portfolio of ventures that received the first funding round in each quarter. The sample includes 13,516 US-based ventures in SDC VentureXpert database that had the first funding round in 1992-2006, and we trace their funding rounds in 1992-2018. The no-bubble subsample excludes ventures that ever had financing activities or exit events in 1999 and 2000. 
Fig. 6: Histogram of Individual Venture's PME/GPME

(a) PME Discounting

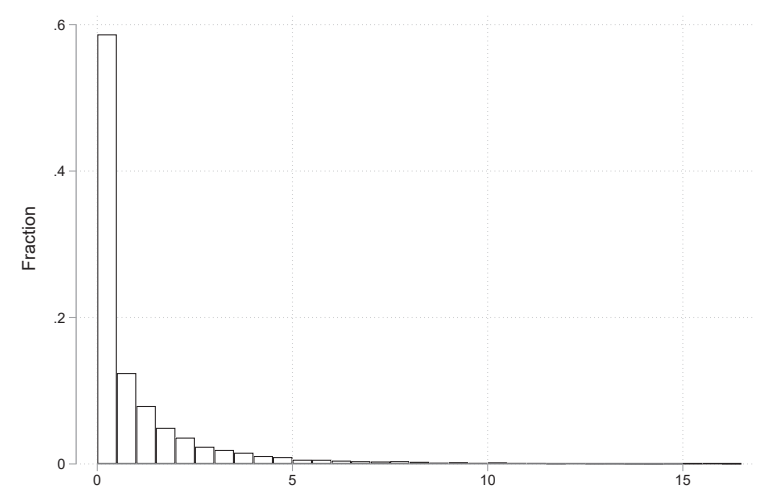

(b) GPME Discounting

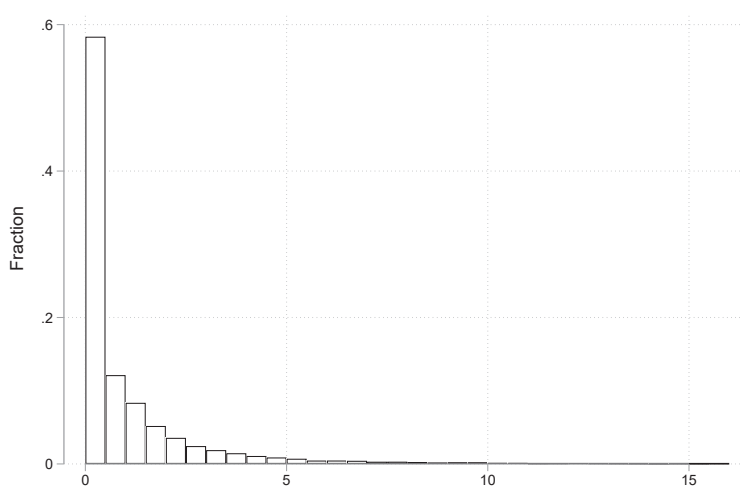

Notes: The figure plots the histogram of the PME/GPME of the individual ventures. The sample includes 17,242 US-based ventures in SDC VentureXpert database that had the first funding round in 1980-2006, and we trace their funding rounds in 1980-2018. The cash flows are discounted with SDF specification in PME $(a=0, b=1)$ in Panel $(a)$, and discounted with SDF specification in GPME $(a=0.033, b=1.444)$ in Panel $(b)$, to the venture's first funding round's date. 
Table 1: Effect of error in post money valuation data in a later funding round on round-toexit returns: An example

Panel A. Correct Valuation

\begin{tabular}{lrrrrr}
\hline Year & 0 & 1 & 2 & 3 & 4 \\
\hline Stage & Round 1 & Round 2 & Round 3 & Round 4 & IPO \\
Amount Raised (\$ M) & 5.14 & $\mathbf{9 . 3 7}$ & $\mathbf{1 4 . 4 3}$ & $\mathbf{1 6 . 7 6}$ & n.a. \\
Post-Money Valuation (\$ M) & $\mathbf{1 4 . 6 3}$ & 37.66 & 70.59 & 86.07 & $\mathbf{3 6 8 . 3 4}$ \\
Market Return from Last Round & n.a. & $16.8 \%$ & $14.1 \%$ & $15.6 \%$ & $19.6 \%$ \\
\hline Gross Market Return from Year 0 & n.a. & $116.8 \%$ & $133.3 \%$ & $154.1 \%$ & $184.3 \%$ \\
Present Value of Cash Flows & -14.63 & -8.02 & -10.82 & -10.88 & 199.91 \\
Pre-Money Valuation & 9.49 & 28.29 & 56.16 & 69.31 & n.a. \\
Ownership Given Up & $35.1 \%$ & $24.9 \%$ & $20.4 \%$ & $19.5 \%$ & n.a. \\
Round-to-Round Return & $93.3 \%$ & $49.1 \%$ & $-1.8 \%$ & $328.0 \%$ & n.a. \\
Round-to-Exit Return & $111.3 \%$ & $526.5 \%$ & $320.2 \%$ & $328.0 \%$ & n.a. \\
PME & 4.51 & & & & \\
NPV (PME Approach) & 155.55 & & & & \\
\hline
\end{tabular}

Panel B. Observed Valuation

\begin{tabular}{lrrrrr}
\hline Year & 0 & 1 & 2 & 3 & 4 \\
\hline Stage & Round 1 & Round 2 & Round 3 & Round 4 & IPO \\
Amount Raised (\$ M) & 5.14 & $\mathbf{9 . 3 7}$ & $\mathbf{1 4 . 4 3}$ & $\mathbf{1 6 . 7 6}$ & n.a. \\
Post-Money Valuation (\$ M) & $\mathbf{1 4 . 6 3}$ & 37.66 & 70.59 & 127.38 & $\mathbf{3 6 8 . 3 4}$ \\
Market Return from Last Round & n.a. & $16.8 \%$ & $14.1 \%$ & $15.6 \%$ & $19.6 \%$ \\
\hline Gross Market Return from Year 0 & n.a. & $116.8 \%$ & $133.3 \%$ & $154.1 \%$ & $184.3 \%$ \\
Present Value of Cash Flows & -14.63 & -8.02 & -10.82 & -10.88 & 199.91 \\
Pre-Money Valuation & 9.49 & 28.29 & 56.16 & 110.62 & n.a. \\
Ownership Given Up & $35.1 \%$ & $24.9 \%$ & $20.4 \%$ & $13.2 \%$ & n.a. \\
Round-to-Round Return & $93.3 \%$ & $49.1 \%$ & $56.7 \%$ & $189.2 \%$ & n.a. \\
Round-to-Exit Return & $1206.3 \%$ & $575.7 \%$ & $353.1 \%$ & $189.2 \%$ & n.a. \\
PME & 4.51 & & & & \\
NPV (PME Approach) & 155.55 & & & & \\
\hline
\end{tabular}

Notes: The table shows the life cycle of a hypothetical venture with complete information on funding rounds and the exit. The venture raises one round per year and exits through an IPO at the end of the 4th year. The amount raised and exit value of this venture reflects that of the average venture in our sample. The market return is 10\% every year. Panel A records the correct amount raised and valuation data, and the corresponding return measures calculated based on the data. In Panel B, the post-money valuation of round 4 is biased upwards due to measurement error - to reflect the fact that observed value of existing common shares in late rounds is biased upwards as documented by Gornall and Strebulaev (2020). Numbers colored in red show that this bias leads to biases in the return measures. 
Table 2: Outcomes of Ventures that Remain Private Based on Other Data Sources

\begin{tabular}{crrrrrl}
\hline \hline SDC Outcome $\backslash$ Outcomes in Other Data & Remain Private & BR & IPO & MA & Total & Other Data \\
\hline & 62 & 463 & 8 & 395 & 928 & PitchBook \\
Remain Private & 202 & 97 & 0 & 37 & 336 & Bloomberg \\
& 0 & 0 & 4 & 0 & 4 & Nasdaq \\
& 31 & 16 & 1 & 6 & 54 & Crunchbase \\
& 693 & 52 & 1 & 22 & 768 & Others \\
\hline Total & 988 & 628 & 14 & 460 & 2090 & \\
\hline \hline
\end{tabular}

Notes: We collect information on ventures' outcomes from the universe of SDC VentureXpert, SDC Merger \& Acquisition, and SDC Global New Issues data from 1980 until the end of 2018. Based on the SDC data, we classify a venture whose current situation is active or if we do not observe its exit event as "Remain Private". For 10,175 US-based ventures that had the first funding round in 1992-2006 and was not bankrupt according to VentureXpert data, we cross-checked their outcomes with various other data sources including PitchBook, Bloomberg, Nasdaq, Crunchbase and other Internet sources. Among the cross-checked ventures, for 2,090 ventures that remain private, the table tabulates their outcomes based on the other data sources. 
Table 3: Data Source of Venture Outcomes and Exit Values

\begin{tabular}{|c|c|c|c|c|}
\hline \multicolumn{5}{|l|}{ A. Source of the Venture Outcomes } \\
\hline \# of Ventures \Outcome & IPO & MA & $\mathrm{BR}$ & Remain Private \\
\hline Outcome recorded in SDC & 1,592 & 5,779 & 3,353 & 4,545 \\
\hline Outcome solely from other sources & 314 & 628 & 545 & 486 \\
\hline Total & 1,906 & 6,407 & 3,898 & 5,031 \\
\hline \multicolumn{5}{|l|}{ B. Exit Values for Outcomes Recorded in SDC } \\
\hline \# of Ventures \Outcome & IPO & MA & & \\
\hline Exit values non-missing & 1,438 & 2,809 & & \\
\hline Exit values complemented by other sources & 124 & 401 & & \\
\hline Total & 1,592 & 5,779 & & \\
\hline \multicolumn{5}{|c|}{ C. Exit Values for Outcomes Solely from Other Sources } \\
\hline \# of Ventures \Outcome & IPO & MA & & \\
\hline Exit values non-missing & 303 & 145 & & \\
\hline Total & 314 & 628 & & \\
\hline \multicolumn{5}{|l|}{ D. Miscellaneous } \\
\hline \# of Ventures \Outcome & $\mathrm{IPO}$ & MA & & \\
\hline Total \# of ventures with exit values & 1,865 & 3,355 & & \\
\hline SDC exit values conflicted with other sources & 75 & 150 & & \\
\hline
\end{tabular}

Notes: We collect information on ventures' outcomes from the universe of SDC VentureXpert, SDC Merger \& Acquisition, and SDC Global New Issues data from 1980 until the end of 2018. Based on SDC data, ventures are observed to exit through IPO, MA, bankruptcy (i.e. "BR"), or have no observed exit (i.e. "Remain Private"). For 10,175 US-based ventures that had the first funding round in 1992-2006 and was not bankrupt according to VentureXpert data, we cross-checked their outcomes with various other data sources including PitchBook, Bloomberg, Nasdaq, Crunchbase and other Internet sources, and we supplement the SDC data with data from these other sources. Our sample for analysis includes 17,242 US-based ventures in SDC VentureXpert database that had the first funding round in 1980-2006. Panel A of this table reports a breakdown of the data sources that identify the outcomes for ventures in our sample for analysis. Panel B shows a breakdown of the data sources that provide the exit values for ventures in our sample for analysis. A "conflict" in exit values refers to the case where the exit values in SDC databases and in other data source differ by more than $5 \%$. 
Table 4: Fraction of Rounds with Available Data for Venture Valuations

\begin{tabular}{|c|c|c|c|c|c|c|}
\hline \multirow[b]{2}{*}{ Sample } & \multirow{2}{*}{ Variable } & \multirow{2}{*}{ All } & \multicolumn{4}{|c|}{ Round Type } \\
\hline & & & First & Interim & Last & The Only \\
\hline Full Sample & \# Rounds & 54,525 & 12,260 & 30,005 & 12,260 & 4,982 \\
\hline \multirow{2}{*}{ With Amount Raised } & \# Rounds & 52,262 & 11,760 & 29,042 & 11,460 & 4,324 \\
\hline & $\%$ Rounds & $95.8 \%$ & $95.9 \%$ & $96.8 \%$ & $93.5 \%$ & $86.8 \%$ \\
\hline \multirow{2}{*}{ With Post-money Valuation } & \# Rounds & 12,913 & 3,123 & 7,201 & 2,589 & 827 \\
\hline & $\%$ Rounds & $23.7 \%$ & $25.5 \%$ & $24.0 \%$ & $21.1 \%$ & $16.6 \%$ \\
\hline \multirow{2}{*}{ With Round-to-Next-Event Return } & \# Rounds & 8,393 & 1,971 & 4,297 & 2,125 & 687 \\
\hline & $\%$ Rounds & $15.4 \%$ & $16.1 \%$ & $14.3 \%$ & $17.3 \%$ & $13.8 \%$ \\
\hline
\end{tabular}

Notes: The table reports the fraction of rounds in different stages with available data for the purpose of valuing the venture. The data availability of a funding round may depend on whether it is the first round, a interim round or the last round of a venture (if the venture has multiple round), as well as if it is the only round of a venture. The sample includes 17,242 US-based ventures in SDC VentureXpert database that had the first funding round in 1980-2006, and we trace their funding rounds in 1980-2018.

Table 5: Fraction of Ventures with Data for Venture GPME Calculation by Exit Type

\begin{tabular}{llrrrrrr}
\hline & & All & IPO & MA & Bankrupt & $\begin{array}{c}\text { Private } \\
\text { (Active) }\end{array}$ & $\begin{array}{c}\text { Private } \\
\text { (Inactive) }\end{array}$ \\
& & & & & & & \\
Full Sample & \# Ventures & 17,242 & 1,906 & 6,407 & 3,898 & 291 & 4,740 \\
\hline \multirow{2}{*}{ With All Cash Outflows } & \# Ventures & 3,740 & 697 & 1,650 & 821 & 26 & 546 \\
& \% Ventures & $21.7 \%$ & $36.6 \%$ & $25.8 \%$ & $21.1 \%$ & $8.9 \%$ & $11.5 \%$ \\
\hline \multirow{2}{*}{ With Exit Values } & \# Ventures & 5,100 & 1,864 & 3,236 & - & - & - \\
& \% Ventures & $29.6 \%$ & $97.8 \%$ & $50.5 \%$ & - & - & - \\
\multirow{2}{*}{ With All Cash Flows } & \# Ventures & 2,954 & 688 & 873 & 821 & 26 & 546 \\
& \% Ventures & $17.1 \%$ & $36.1 \%$ & $13.6 \%$ & $21.1 \%$ & $8.9 \%$ & $11.5 \%$ \\
\hline
\end{tabular}

Notes: The table reports the fraction of ventures with the data necessary for the calculation of venture GPME by exit type. "Private (Active)" ventures refer to those with no observed exit events as of 2018 and had financing activities in the past 5 years, that is, from 2013 to 2018. "Private (Inactive)" ventures refer to those with no observed exit events as of 2018 and had no financing activities in the past 5 years, that is, from 2013 to 2018. A venture "with all cash outflows" data refers to that it has data on first round post-money valuation and amount raised in all funding rounds. A venture "with all cash flows" data refers to that it has data on first round post-money valuation, amount raised in all funding rounds and exit values. The sample includes 17,242 US-based ventures in SDC VentureXpert database that had the first funding round in 1980-2006, and we trace their funding rounds in 1980-2018. We assume ventures that are bankrupt and that remain private as of 2018 have an exit value of 0 . 
Table 6: Summary Statistics by Exit Type

\begin{tabular}{|c|c|c|c|c|c|c|}
\hline \multirow{2}{*}{ Variable } & \multirow[b]{2}{*}{ Statistics } & \multicolumn{5}{|c|}{ Exit Type } \\
\hline & & IPO & MA & Bankrupt & Private (Active) & Private (Inactive) \\
\hline \multicolumn{7}{|l|}{ Panel A. } \\
\hline \# Ventures & Sum & 1,906 & 6,407 & 3,898 & 291 & 4,740 \\
\hline$\%$ Ventures & Sum & $11.1 \%$ & $37.2 \%$ & $22.6 \%$ & $1.7 \%$ & $27.5 \%$ \\
\hline \multirow{3}{*}{ \# Rounds } & Median & 4.0 & 3.0 & 2.0 & 8.0 & 2.0 \\
\hline & Mean & 4.1 & 3.9 & 2.9 & 8.1 & 2.7 \\
\hline & S.D. & 2.8 & 2.7 & 2.3 & 3.7 & 2.4 \\
\hline \multirow{3}{*}{$\begin{array}{l}\text { First Round } \\
\text { to Exit (Year) }\end{array}$} & Median & 4.0 & 5.8 & 5.1 & - & - \\
\hline & Mean & 5.0 & 6.6 & 6.2 & - & - \\
\hline & S.D. & 3.8 & 4.3 & 4.3 & - & - \\
\hline \multicolumn{7}{|l|}{ Panel B. } \\
\hline Total Amount & Sum & $89,266.6$ & $210,723.3$ & $67,662.7$ & $25,392.0$ & $59,711.4$ \\
\hline \multirow[t]{3}{*}{ Raised (\$ M) } & Median & 24.9 & 20.0 & 6.0 & 61.1 & 4.5 \\
\hline & Mean & 46.8 & 32.9 & 17.4 & 87.3 & 12.6 \\
\hline & S.D. & 62.8 & 41.2 & 33.8 & 114.2 & 23.9 \\
\hline \multirow{4}{*}{ Exit Valuation $(\$ M)$} & Sum & $564,226.7$ & $684,569.9$ & - & - & - \\
\hline & Median & 139.8 & 40.0 & - & - & - \\
\hline & Mean & 296.3 & 108.6 & - & - & - \\
\hline & S.D. & 744.0 & 440.3 & - & - & - \\
\hline \multicolumn{7}{|l|}{ Panel C. } \\
\hline \multirow{3}{*}{$\begin{array}{l}\text { First Round } \\
\quad \text { to Exit (Month) }\end{array}$} & Median & 48.5 & 70.6 & 61.8 & - & - \\
\hline & Mean & 60.7 & 80.8 & 75.6 & - & - \\
\hline & S.D. & 46.2 & 52.3 & 52.8 & - & - \\
\hline \multirow{3}{*}{$\begin{array}{l}\text { Last Round } \\
\text { to Exit (Month) }\end{array}$} & Median & 11.8 & 25.9 & 24.3 & - & - \\
\hline & Mean & 20.7 & 39.5 & 39.8 & - & - \\
\hline & S.D. & 27.5 & 40.5 & 41.1 & - & - \\
\hline \multirow{3}{*}{$\begin{array}{l}\text { Between Rounds } \\
\quad \text { (Month) }\end{array}$} & Median & 10.1 & 10.9 & 9.1 & 13.9 & 10.2 \\
\hline & Mean & 12.8 & 14.0 & 12.0 & 21.9 & 14.9 \\
\hline & S.D. & 13.3 & 13.8 & 12.0 & 29.4 & 18.6 \\
\hline
\end{tabular}

Notes: The table reports the summary statistics of the key variables by venture's exit type. "Private (Active)" ventures refer to those with no observed exit events as of 2018 and had financing activities in the past 5 years, that is, from 2013 to 2018. "Private (Inactive)" ventures refer to those with no observed exit events as of 2018 and had no financing activities in the past 5 years, that is, from 2013 to 2018. The sample includes 17,242 US-based ventures in SDC VentureXpert database that had the first funding round in 1980-2006, and we trace their funding rounds in 1980-2018. We assume ventures that are bankrupt and that remain private as of 2018 have an exit value of 0. 
Table 7: Summary Statistics for Ventures that Remain Private as of 2006

Panel A. Ventures with No Activity Since 2001

\begin{tabular}{|c|c|c|c|c|c|c|}
\hline Variable & Statistics & IPO & MA & $\begin{array}{r}\text { Ex } \\
\text { Bankrupt }\end{array}$ & $\begin{array}{l}\text { it Type } \\
\text { Private (Active) }\end{array}$ & Private (Inactive) \\
\hline \# Ventures & Sum & 24 & 430 & 13 & 17 & 3,004 \\
\hline$\%$ Ventures & Sum & $0.7 \%$ & $12.3 \%$ & $0.4 \%$ & $0.5 \%$ & $86.1 \%$ \\
\hline \multirow{3}{*}{ \# Rounds } & Median & 3.0 & 2.0 & 1.0 & 4.0 & 2.0 \\
\hline & Mean & 3.4 & 2.8 & 2.8 & 5.1 & 2.6 \\
\hline & S.D. & 2.1 & 2.0 & 3.1 & 3.2 & 2.3 \\
\hline \multirow{3}{*}{$\begin{array}{l}\text { First Round } \\
\text { to Exit (Year) }\end{array}$} & Median & 14.6 & 12.7 & 9.9 & - & - \\
\hline & Mean & 16.1 & 13.3 & 12.8 & - & - \\
\hline & S.D. & 7.2 & 4.8 & 6.6 & - & \\
\hline \multirow{4}{*}{$\begin{array}{l}\text { Total Amount } \\
\quad \text { Raised }(\$ \mathrm{M})\end{array}$} & Sum & 852.9 & $11,125.6$ & 268.0 & 807.4 & $28,976.0$ \\
\hline & Median & 15.2 & 13.1 & 10.0 & 26.0 & 3.9 \\
\hline & Mean & 35.5 & 25.9 & 20.6 & 47.5 & 9.6 \\
\hline & S.D. & 58.8 & 39.0 & 20.7 & 50.1 & 16.9 \\
\hline \multirow{4}{*}{ Exit Value $(\$ M)$} & Sum & $9,560.1$ & $54,676.0$ & 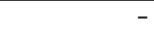 & - & \\
\hline & Median & 192.7 & 44.6 & - & - & \\
\hline & Mean & 415.7 & 127.4 & - & - & \\
\hline & S.D. & 464.4 & 417.9 & - & - & \\
\hline Amout Raised/ & Median & 0.17 & 0.24 & 0.13 & 0.10 & 0.25 \\
\hline \multirow[t]{2}{*}{ Total Amout Raised } & Mean & 0.30 & 0.35 & 0.35 & 0.20 & 0.39 \\
\hline & S.D. & 0.30 & 0.32 & 0.39 & 0.23 & 0.36 \\
\hline Exit Value/ & Median & 6.02 & 2.90 & - & - & \\
\hline \multirow{2}{*}{ Total Amount Raised } & Mean & 60.06 & 16.82 & - & - & - \\
\hline & S.D. & 140.44 & 97.44 & - & - & - \\
\hline
\end{tabular}

Panel B. Ventures with Some Activity Since 2001

\begin{tabular}{|c|c|c|c|c|c|c|}
\hline Variable & Statistics & IPO & MA & $\begin{array}{r}\text { Exi } \\
\text { Bankrupt I }\end{array}$ & $\begin{array}{l}\text { it Type } \\
\text { Private (Active) }\end{array}$ & Private (Inactive) \\
\hline \# Ventures & Sum & 345 & 2,683 & 59 & 274 & 1,736 \\
\hline$\%$ Ventures & Sum & $6.8 \%$ & $52.6 \%$ & $1.2 \%$ & $5.4 \%$ & $34.1 \%$ \\
\hline \multirow{3}{*}{ \# Rounds } & Median & 6.0 & 4.0 & 4.0 & 8.0 & 2.0 \\
\hline & Mean & 6.6 & 4.8 & 4.1 & 8.3 & 2.9 \\
\hline & S.D. & 3.5 & 3.0 & 2.5 & 3.7 & 2.7 \\
\hline \multirow{3}{*}{$\begin{array}{l}\text { First Round } \\
\text { to Exit (Year) }\end{array}$} & Median & 8.6 & 7.9 & 5.0 & - & \\
\hline & Mean & 9.0 & 8.3 & 5.3 & - & \\
\hline & S.D. & 3.6 & 3.9 & 2.4 & - & \\
\hline \multirow{4}{*}{$\begin{array}{l}\text { Total Amount } \\
\text { Raised }(\$ \mathrm{M})\end{array}$} & Sum & $37,416.91$ & $09,585.1$ & $2,508.9$ & $24,584.6$ & $30,735.4$ \\
\hline & Median & 83.6 & 27.0 & 22.6 & 62.9 & 5.6 \\
\hline & Mean & 108.5 & 40.8 & 42.5 & 89.7 & 17.7 \\
\hline & S.D. & 94.0 & 48.6 & 54.1 & 116.6 & 32.0 \\
\hline \multirow{4}{*}{ Exit Value $(\$ M)$} & Sum & $164,093.33$ & $08,421.7$ & & - & \\
\hline & Median & 255.8 & 47.4 & - & - & \\
\hline & Mean & 477.0 & 117.4 & - & - & \\
\hline & S.D. & 898.6 & 386.2 & - & - & \\
\hline Amout Raised/ & Median & 0.10 & 0.14 & 0.16 & 0.08 & 0.21 \\
\hline \multirow[t]{2}{*}{ Total Amout Raised } & Mean & 0.15 & 0.21 & 0.24 & 0.12 & 0.34 \\
\hline & S.D. & 0.17 & 0.21 & 0.25 & 0.14 & 0.34 \\
\hline Exit Value/ & Median & 2.41 & 1.54 & 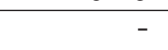 & - & - \\
\hline \multirow{2}{*}{ Total Amount Raised } & Mean & 6.37 & 3.96 & - & - & \\
\hline & S.D & 27.84 & 27.21 & - & - & _ \\
\hline
\end{tabular}

Notes: The table reports the summary statistics of the key variables by venture's exit type, for ventures that remain private as of 2006. Among these ventures, Panel A reports summary statistics for those that are inactive as of 2006, that is, those that have had no financing activities in the past 5 years, from 2001 to 2006. Panel B reports summary statistics for those that are active as of 2006, that is, those that have had financing activities in the past 5 years, from 2001 to 2006. We trace the outcomes and the exits of all the ventures until the end of 2018, based on which we produce the summary statistics. In both panels, the columns labeled by "Private (Active)" and "Private (Inactive)", refer to ventures that remain private as of 2018 and had financing activities in the past 5 years, from 2013 to 2018, and ventures that remain private and had no financing activities in the past 5 years, respectively. We assume ventures that are bankrupt and that remain private as of 2018 have an exit value of 0 . 
Table 8: Composition of Ventures by Years from the First Round

\begin{tabular}{rrrrrr}
\hline \multicolumn{1}{c}{$\begin{array}{c}\text { Years from } \\
\text { the First Round }\end{array}$} & \% Private (Active) & \% Private (Inactive) & \% IPO & \% MA & \% Bankrupt \\
\hline 1 & $97.9 \%$ & $0.0 \%$ & $0.9 \%$ & $1.0 \%$ & $0.2 \%$ \\
2 & $92.6 \%$ & $0.0 \%$ & $2.3 \%$ & $4.3 \%$ & $0.9 \%$ \\
3 & $86.5 \%$ & $0.0 \%$ & $3.9 \%$ & $7.8 \%$ & $1.8 \%$ \\
4 & $80.2 \%$ & $0.0 \%$ & $5.5 \%$ & $11.7 \%$ & $2.5 \%$ \\
5 & $54.7 \%$ & $12.6 \%$ & $6.8 \%$ & $15.7 \%$ & $10.3 \%$ \\
6 & $44.9 \%$ & $15.0 \%$ & $7.7 \%$ & $19.4 \%$ & $13.1 \%$ \\
7 & $35.1 \%$ & $18.0 \%$ & $8.4 \%$ & $22.6 \%$ & $15.9 \%$ \\
8 & $27.4 \%$ & $20.4 \%$ & $9.1 \%$ & $25.4 \%$ & $17.8 \%$ \\
9 & $21.3 \%$ & $22.1 \%$ & $9.5 \%$ & $27.8 \%$ & $19.2 \%$ \\
10 & $16.4 \%$ & $23.6 \%$ & $9.9 \%$ & $29.8 \%$ & $20.4 \%$ \\
11 & $12.9 \%$ & $24.5 \%$ & $10.2 \%$ & $31.3 \%$ & $21.0 \%$ \\
12 & $9.9 \%$ & $25.3 \%$ & $10.4 \%$ & $32.8 \%$ & $21.5 \%$ \\
13 & $7.6 \%$ & $25.9 \%$ & $10.6 \%$ & $34.0 \%$ & $21.8 \%$ \\
14 & $5.9 \%$ & $26.5 \%$ & $10.8 \%$ & $34.8 \%$ & $22.1 \%$ \\
15 & $4.4 \%$ & $27.0 \%$ & $10.8 \%$ & $35.4 \%$ & $22.3 \%$ \\
16 & $3.4 \%$ & $27.5 \%$ & $10.9 \%$ & $35.9 \%$ & $22.4 \%$ \\
17 & $2.5 \%$ & $27.9 \%$ & $11.0 \%$ & $36.3 \%$ & $22.4 \%$ \\
18 & $1.8 \%$ & $28.2 \%$ & $11.0 \%$ & $36.6 \%$ & $22.5 \%$ \\
19 & $1.3 \%$ & $28.5 \%$ & $11.0 \%$ & $36.7 \%$ & $22.5 \%$ \\
20 & $1.0 \%$ & $28.6 \%$ & $11.0 \%$ & $36.9 \%$ & $22.5 \%$ \\
\hline
\end{tabular}

Notes: The table reports the fraction of ventures in each status by years from the first round. For example, \%IPO refers to the percent of ventures that have gone to IPO as of a specific number of years after the first round. \%Private (Active) refers to percent of ventures that remain private as of a specific number of years after the first round, but remain active, that is, have had financing activities in the past 5 years. The sample includes 17,242 US-based ventures in SDC VentureXpert database that had the first funding round in 1980-2006, and we trace their funding rounds in 1980-2018. 
Table 9: Aggregate Cash Flows by Years from the First Round

\begin{tabular}{rrrrrr}
\hline $\begin{array}{l}\text { Year from } \\
\text { the First Round }\end{array}$ & $\begin{array}{c}\text { Cumul. } \\
\text { Inflows }(\$ \mathrm{~B})\end{array}$ & $\begin{array}{r}\text { \% Cumul. } \\
\text { Inflows }\end{array}$ & $\begin{array}{c}\text { Cumul. } \\
\text { Outflows }(\$ \mathrm{~B})\end{array}$ & $\begin{array}{r}\text { \% Cumul. } \\
\text { Outflows }\end{array}$ & $\begin{array}{c}\text { Cumul. } \\
\text { Net Inflows }(\$ \mathrm{~B})\end{array}$ \\
\hline 1 & 51.5 & $4.1 \%$ & 332.8 & $53.0 \%$ & -281.3 \\
2 & 185.8 & $14.9 \%$ & 412.9 & $65.8 \%$ & -227.1 \\
3 & 348.5 & $27.9 \%$ & 470.8 & $75.1 \%$ & -122.3 \\
4 & 464.0 & $37.2 \%$ & 509.8 & $81.3 \%$ & -45.9 \\
5 & 568.5 & $45.5 \%$ & 538.9 & $85.9 \%$ & 29.6 \\
6 & 677.3 & $54.2 \%$ & 559.9 & $89.3 \%$ & 117.3 \\
7 & 751.3 & $60.2 \%$ & 575.1 & $91.7 \%$ & 176.2 \\
8 & 855.6 & $68.5 \%$ & 588.3 & $93.8 \%$ & 267.3 \\
9 & 931.7 & $74.6 \%$ & 598.0 & $95.3 \%$ & 333.7 \\
10 & 993.3 & $79.5 \%$ & 605.9 & $96.6 \%$ & 387.4 \\
11 & $1,037.6$ & $83.1 \%$ & 612.1 & $97.6 \%$ & 425.4 \\
12 & $1,082.3$ & $86.7 \%$ & 615.9 & $98.2 \%$ & 466.3 \\
13 & $1,120.6$ & $89.7 \%$ & 618.9 & $98.7 \%$ & 501.7 \\
14 & $1,150.9$ & $92.2 \%$ & 621.4 & $99.1 \%$ & 529.4 \\
15 & $1,180.9$ & $94.6 \%$ & 623.1 & $99.3 \%$ & 557.8 \\
16 & $1,195.4$ & $95.7 \%$ & 624.4 & $99.5 \%$ & 571.0 \\
17 & $1,208.7$ & $96.8 \%$ & 625.0 & $99.6 \%$ & 583.7 \\
18 & $1,218.3$ & $97.6 \%$ & 625.6 & $99.7 \%$ & 592.7 \\
19 & $1,223.1$ & $97.9 \%$ & 626.4 & $99.9 \%$ & 596.6 \\
20 & $1,225.5$ & $98.1 \%$ & 626.7 & $99.9 \%$ & 598.8 \\
\hline
\end{tabular}

Notes: The table reports the cumulative cash inflows and outflows (not discounted) of the universe of ventures by years from the first round. The sample includes 17,242 US-based ventures in SDC VentureXpert database that had the first funding round in 1980-2006, and we trace their funding rounds in 1980-2018. 
Table 10: Performance of the Imputation Model for Amount Raised

\begin{tabular}{|c|c|c|c|c|c|c|c|c|c|c|}
\hline & (1) & (2) & $(3)$ & (4) & (5) & (6) & (7) & (8) & (9) & (10) \\
\hline VARIABLES & \multicolumn{10}{|c|}{ Log Amount } \\
\hline ROUND & 1 & 2 & 3 & 4 & 5 & 6 & 7 & 8 & 9 & $>9$ \\
\hline Log Amount $_{t-1}$ & & $\begin{array}{c}0.305^{* * *} \\
(0.008)\end{array}$ & $\begin{array}{c}0.336^{* * *} \\
(0.009)\end{array}$ & $\begin{array}{c}0.297^{* * *} \\
(0.011)\end{array}$ & $\begin{array}{c}0.291^{* * *} \\
(0.013)\end{array}$ & $\begin{array}{c}0.258^{* * *} \\
(0.016)\end{array}$ & $\begin{array}{c}0.282^{* * *} \\
(0.019)\end{array}$ & $\begin{array}{c}0.292^{* * *} \\
(0.024)\end{array}$ & $\begin{array}{c}0.272^{* * *} \\
(0.028)\end{array}$ & $\begin{array}{c}0.274^{* * *} \\
(0.023)\end{array}$ \\
\hline Constant & $\begin{array}{c}16.656^{* * *} \\
(0.691)\end{array}$ & $\begin{array}{c}16.151^{* * * *} \\
(0.883)\end{array}$ & $\begin{array}{c}12.179^{* * *} \\
(0.787)\end{array}$ & $\begin{array}{c}14.147^{* * *} \\
(0.779)\end{array}$ & $\begin{array}{c}12.273^{* * *} \\
(0.795)\end{array}$ & $\begin{array}{c}14.717^{* * *} \\
(0.718)\end{array}$ & $\begin{array}{c}13.099 * * * \\
(0.691)\end{array}$ & $\begin{array}{c}13.419 \text { *** } \\
(0.922)\end{array}$ & $\begin{array}{c}13.299^{* * *} \\
(0.905)\end{array}$ & $\begin{array}{c}13.548^{* * *} \\
(0.622)\end{array}$ \\
\hline Observations & 16,084 & 11,803 & 8,716 & 6,366 & 4,450 & 3,041 & 2,041 & 1,391 & 924 & 1,770 \\
\hline Adjusted $R^{2}$ & 0.328 & 0.507 & 0.547 & 0.533 & 0.508 & 0.466 & 0.508 & 0.486 & 0.490 & 0.495 \\
\hline Industry FE & Yes & Yes & Yes & Yes & Yes & Yes & Yes & Yes & Yes & Yes \\
\hline Stage FE & Yes & Yes & Yes & Yes & Yes & Yes & Yes & Yes & Yes & Yes \\
\hline Year FE & Yes & Yes & Yes & Yes & Yes & Yes & Yes & Yes & Yes & Yes \\
\hline \# Investors FE & Yes & Yes & Yes & Yes & Yes & Yes & Yes & Yes & Yes & Yes \\
\hline Psuedo- $R^{2}$ Mean & 0.318 & 0.481 & 0.502 & 0.505 & 0.494 & 0.485 & 0.481 & 0.478 & 0.450 & 0.466 \\
\hline Psuedo- $R^{2} \mathrm{Sd}$ & 0.009 & 0.008 & 0.009 & 0.011 & 0.011 & 0.015 & 0.016 & 0.017 & 0.020 & 0.025 \\
\hline Repeats of CV & 10 & 10 & 10 & 10 & 10 & 10 & 10 & 10 & 10 & 10 \\
\hline
\end{tabular}

Standard errors in parentheses

${ }^{*} p<0.1,{ }^{* *} p<0.05,{ }^{* * *} p<0.01$

Notes: The table reports the regression results when estimating the imputation models for the amount raised in each venture funding round. The sample includes all US-based ventures in SDC VentureXpert database that had the first funding round in 1980-2006, and we trace their funding rounds in 1980-2018. 
Table 11: Performance of the Imputation Model for Ownership Given Up

\begin{tabular}{|c|c|c|c|c|}
\hline & (1) & $(2)$ & $(3)$ & (4) \\
\hline VARIABLES & \multicolumn{4}{|c|}{ Logit Ownership Given Up } \\
\hline Log Amount & $\begin{array}{c}0.429^{* * *} \\
(0.007)\end{array}$ & $\begin{array}{c}0.431^{* * *} \\
(0.008)\end{array}$ & $\begin{array}{c}2.349^{* * *} \\
(0.097)\end{array}$ & $\begin{array}{c}2.438^{* * *} \\
(0.089)\end{array}$ \\
\hline Log Amount Squared & & & $\begin{array}{c}-0.063^{* * *} \\
(0.003)\end{array}$ & $\begin{array}{c}-0.049^{* * *} \\
(0.003)\end{array}$ \\
\hline Log Cumulative Amount & & & & $\begin{array}{c}-0.713^{* * *} \\
(0.015)\end{array}$ \\
\hline Recent Nasdaq Return & $\begin{array}{c}-0.264^{* * *} \\
(0.014)\end{array}$ & $\begin{array}{c}-0.129^{* * *} \\
(0.033)\end{array}$ & $\begin{array}{c}-0.117^{* * *} \\
(0.033)\end{array}$ & $\begin{array}{c}-0.119^{* * *} \\
(0.030)\end{array}$ \\
\hline Constant & $\begin{array}{c}-6.956^{* * *} \\
(0.103)\end{array}$ & $\begin{array}{c}-7.262^{* * *} \\
(0.444)\end{array}$ & $\begin{array}{c}-21.453^{* * *} \\
(0.837)\end{array}$ & $\begin{array}{c}-15.255^{* * *} \\
(0.784)\end{array}$ \\
\hline Observations & 13,710 & 13,710 & 13,710 & 13,710 \\
\hline Adjusted $R^{2}$ & 0.317 & 0.383 & 0.400 & 0.488 \\
\hline Round Number FE & Yes & Yes & Yes & Yes \\
\hline Industry FE & No & Yes & Yes & Yes \\
\hline Stage FE & No & Yes & Yes & Yes \\
\hline Year FE & No & Yes & Yes & Yes \\
\hline \# Investors FE & No & Yes & Yes & Yes \\
\hline Psuedo- $R^{2}$ Mean & 0.316 & 0.380 & 0.398 & 0.486 \\
\hline Psuedo- $R^{2} \mathrm{Sd}$ & 0.026 & 0.026 & 0.028 & 0.030 \\
\hline Repeats of CV & 10 & 10 & 10 & 10 \\
\hline
\end{tabular}

Standard errors in parentheses

${ }^{*} p<0.1,{ }^{* *} p<0.05,{ }^{* * *} p<0.01$

Notes: The table reports the regression results when estimating the imputation models for the ownership given up by the venture founders. The sample includes all the US-based ventures in the SDC VentureXpert database and had the first funding round in 1980-2006, and we trace their funding rounds in 1980-2018. Column (4) is the specification adopted for the imputation. 
Table 12: Performance of the Imputation Model for Pre-IPO Valuation

\begin{tabular}{|c|c|c|c|c|c|c|c|c|}
\hline & (1) & $(2)$ & (3) & (4) & $(5)$ & (6) & (7) & $(8)$ \\
\hline VARIABLES & \multicolumn{8}{|c|}{ Log Pre-IPO Valuation } \\
\hline Extrapolated Valuation & & $\begin{array}{c}0.509^{* * *} \\
(0.024)\end{array}$ & $\begin{array}{c}0.579^{* * *} \\
(0.028)\end{array}$ & $\begin{array}{c}0.529^{* * *} \\
(0.032)\end{array}$ & $\begin{array}{c}0.504^{* * *} \\
(0.032)\end{array}$ & $\begin{array}{c}0.424^{* * *} \\
(0.066)\end{array}$ & $\begin{array}{c}0.487^{* * *} \\
(0.046)\end{array}$ & $\begin{array}{c}0.574^{* * *} \\
(0.069)\end{array}$ \\
\hline Years between Valuation and Exi & & & $\begin{array}{c}0.557^{* * *} \\
(0.118)\end{array}$ & $\begin{array}{c}0.548^{* * *} \\
(0.119)\end{array}$ & $\begin{array}{c}0.539 * * * \\
(0.119)\end{array}$ & $\begin{array}{l}0.534^{* *} \\
(0.227)\end{array}$ & $\begin{array}{c}0.546^{* * *} \\
(0.181)\end{array}$ & $\begin{array}{c}0.622^{* *} \\
(0.243)\end{array}$ \\
\hline $\begin{array}{c}\text { Extrapolated Valuation } \times \text { Years } \\
\text { between Valuation and Exit }\end{array}$ & & & $\begin{array}{c}-0.029^{* * *} \\
(0.007)\end{array}$ & $\begin{array}{c}-0.028^{* * *} \\
(0.007)\end{array}$ & $\begin{array}{c}-0.027^{* * * *} \\
(0.006)\end{array}$ & $\begin{array}{c}-0.026^{* *} \\
(0.012)\end{array}$ & $\begin{array}{l}-0.030^{* * * *} \\
(0.010)\end{array}$ & $\begin{array}{c}-0.032^{* *} \\
(0.013)\end{array}$ \\
\hline Log(Final Round Amount) & & & & $\begin{array}{c}0.052^{* * *} \\
(0.017)\end{array}$ & $\begin{array}{c}0.056^{* * *} \\
(0.017)\end{array}$ & $\begin{array}{c}0.087^{* * *} \\
(0.032)\end{array}$ & $\begin{array}{c}0.095^{* * *} \\
(0.026)\end{array}$ & $\begin{array}{l}-0.026 \\
(0.036)\end{array}$ \\
\hline \# Years (Final Round to Exit) & & & & $\begin{array}{c}-0.036^{* *} \\
(0.018)\end{array}$ & $\begin{array}{c}-0.077^{* * *} \\
(0.020)\end{array}$ & $\begin{array}{c}{ }^{*}-0.120^{* * * *} \\
(0.039)\end{array}$ & $\begin{array}{c}-0.079 * * \\
(0.035)\end{array}$ & $\begin{array}{l}-0.021 \\
(0.042)\end{array}$ \\
\hline $\begin{array}{l}\text { NASDAQ Return } \\
\text { (Final Round to Exit) }\end{array}$ & & & & & $\begin{array}{c}0.204^{* * *} \\
(0.048)\end{array}$ & $\begin{array}{c}0.307^{* * *} \\
(0.095)\end{array}$ & $\begin{array}{c}0.413^{* * *} \\
(0.080)\end{array}$ & $\begin{array}{l}-0.033 \\
(0.086)\end{array}$ \\
\hline Constant & $\begin{array}{c}19.658^{* * *} \\
(0.738)\end{array}$ & $\begin{array}{c}10.150^{* * * *} \\
(0.797)\end{array}$ & $\begin{array}{c}8.805^{* * *} \\
(0.834)\end{array}$ & $\begin{array}{c}9.054^{* * * *} \\
(0.836)\end{array}$ & $\begin{array}{c}9.454^{* * *} \\
(0.837)\end{array}$ & $\begin{array}{c}9.586^{* * *} \\
(1.324)\end{array}$ & $\begin{array}{c}10.255^{* * *} \\
(1.613)\end{array}$ & $\begin{array}{c}10.770^{* * *} \\
(1.767)\end{array}$ \\
\hline Observations & 1,880 & 1,833 & 1,833 & 1,833 & 1,833 & 555 & 873 & 405 \\
\hline Adjusted $R^{2}$ & 0.361 & 0.480 & 0.488 & 0.505 & 0.510 & 0.440 & 0.545 & 0.508 \\
\hline Industry FE & Yes & Yes & Yes & Yes & Yes & No & No & No \\
\hline Stage FE & Yes & Yes & Yes & Yes & Yes & Yes & Yes & Yes \\
\hline Round Number FE & Yes & Yes & Yes & Yes & Yes & Yes & Yes & Yes \\
\hline Year FE & Yes & Yes & Yes & Yes & Yes & Yes & Yes & Yes \\
\hline Psuedo- $R^{2}$ Mean & 0.229 & 0.399 & 0.415 & 0.450 & 0.450 & 0.356 & 0.345 & 0.362 \\
\hline Psuedo- $R^{2} \mathrm{Sd}$ & 0.026 & 0.035 & 0.034 & 0.034 & 0.034 & 0.035 & 0.034 & 0.038 \\
\hline Repeats of CV & 10 & 10 & 10 & 10 & 10 & 10 & 10 & 10 \\
\hline Industry & All & All & All & All & All & Health & IT & Others \\
\hline
\end{tabular}

Standard errors in parentheses

${ }^{*} p<0.1,{ }^{* *} p<0.05,{ }^{* * *} p<0.01$

Notes: The table reports the regression results when estimating the imputation models for the pre-IPO valuations of ventures. The sample includes all US-based ventures in SDC VentureXpert database that had the first funding round in 1980-2006, and we trace their funding rounds in 1980-2018. Column (5) is the specification adopted for the imputation. 
Table 13: Performance of the Imputation Model for Exit Values in Mergers and Acquisitions

$\begin{array}{lllllll}(1) & (2) & (3) & (4) & (5) & (6)\end{array}$

VARIABLES

Log Mergers and Acquisitions Valuation

Extrapolated Valuation

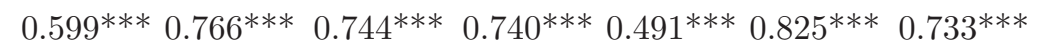

Years between Valuation and Exit

$\begin{array}{lllllll}(0.028) & (0.039) & (0.043) & (0.044) & (0.104) & (0.057) & (0.096)\end{array}$

$\begin{array}{llllll}0.690^{* * *} & 0.785^{* * *} & 0.789^{* * *} & 0.258 & 0.937^{* * *} & 0.990^{* * *}\end{array}$

Extrapolated Valuation $\times$ Years

$\begin{array}{llllll}(0.112) & (0.112) & (0.113) & (0.228) & (0.160) & (0.243)\end{array}$

between Valuation and Exit

Log(Final Round Amount)

$-0.038^{* * *}-0.039^{* * *}-0.039^{* * *}-0.011-0.049 * * *-0.048^{* * *}$

$\begin{array}{llllll}(0.006) & (0.006) & (0.006) & (0.013) & (0.009) & (0.013)\end{array}$

$0.108^{* * *} \quad 0.110^{* * *} 0.203^{* * *} 0.088^{* * *} \quad 0.085^{*}$

\# Years (Final Round to Exit)

$\begin{array}{lllll}(0.021) & (0.021) & (0.049) & (0.029) & (0.044)\end{array}$

\# Years (Final Round to Exit)

$-0.109^{* * *}-0.114^{* * *}-0.115^{* *}-0.097^{* * *}-0.115^{* * *}$

NASDAQ Return

$\begin{array}{lllll}(0.017) & (0.018) & (0.046) & (0.024) & (0.034)\end{array}$

(Final Round to Exit)

$\begin{array}{llll}0.037 & 0.073 & 0.086 & -0.082\end{array}$

Constant

$$
\begin{array}{ccccccccc}
18.078^{* * *} & 7.580^{* * *} & 4.546^{* * *} & 3.144^{* * *} & 3.186^{* * *} & 7.911^{* * *} & 3.111^{* *} & 1.652 \\
(0.874) & (0.955) & (1.072) & (1.068) & (1.069) & (2.357) & (1.554) & (2.099)
\end{array}
$$

Observations

$3,523 \quad 3,438$

3,438

3,438

3,438

$\begin{array}{lll}629 & 1,974 & 835\end{array}$

Adjusted $R^{2}$

$0.045 \quad 0.157$

0.166

0.194

$0.194 \quad 0.193$

$0.214 \quad 0.169$

Industry FE

Yes Yes

Yes

Yes

Yes

No

No No

Stage FE

Round Number FE

Yes Yes Yes

Yes

Yes

Yes

Yes

Yes

Year FE

CV Psuedo-R2 Mean

CV Psuedo-R2 Sd

Yes Yes Yes

Yes

Yes

Yes

Yes

Yes

Yes Yes

Yes

Yes

Yes

Yes

Yes

Yes

$0.006 \quad 0.091$

0.100

0.133

0.133

0.087

0.108

0.101

$0.004 \quad 0.014$

0.014

0.017

0.017

0.016

$0.014 \quad 0.015$

Repeats of 10-fold CV

$10 \quad 10$

All

All

10

10

10

10

Standard errors in parentheses

All Health IT Others

${ }^{*} p<0.1,{ }^{* *} p<0.05,{ }^{* * *} p<0.01$

Notes: The table reports the regression results when estimating the imputation models for exit values for MA exits. The sample includes all US-based ventures in SDC VentureXpert database that had the first funding round in 1980-2006, and we trace their funding rounds in 1980-2018. Column (5) is the specification adopted for the imputation. 
Table 14: Imputed Values

\begin{tabular}{|c|c|c|c|c|c|c|}
\hline \multirow{2}{*}{ Variable } & \multirow[b]{2}{*}{ Total } & \multicolumn{5}{|c|}{ Exit Type } \\
\hline & & IPO & MA & Bankrupt & Private (Active) & Private (Inactive) \\
\hline \multicolumn{7}{|c|}{ Panel A. (first round valuation, amount raised and exit values available ) } \\
\hline \# Ventures & 2,945 & 688 & 871 & 820 & 26 & 540 \\
\hline Agg. First Round Valuation & 68.6 & 19.8 & 21.1 & 17.2 & 0.3 & 10.3 \\
\hline Agg. Amount Raised (\$ B) & 108.9 & 34.1 & 39.1 & 20.9 & 4.1 & 10.8 \\
\hline Agg. Exit Valuation $(\$ B)$ & 363.4 & 231.5 & 131.9 & - & - & - \\
\hline \multicolumn{7}{|c|}{ Panel B. (first round valuation imputed, amount raised available, exit values available) } \\
\hline \# Ventures & 12,201 & 1,671 & 2,827 & 3,564 & 179 & 3,960 \\
\hline Agg. First Round Valuation & 198.0 & 35.6 & 57.8 & 46.5 & 1.7 & 56.4 \\
\hline Agg. Amount Raised (\$ B) & 310.1 & 74.8 & 107.2 & 62.3 & 15.0 & 50.7 \\
\hline Agg. Exit Valuation (\$ B) & 897.2 & 467.7 & 429.5 & - & - & - \\
\hline \multicolumn{7}{|c|}{ Panel C. (first round valuation imputed, amount raised available, exit values imputed) } \\
\hline \# Ventures & 14,984 & 1,704 & 5,577 & 3,564 & 179 & 3,960 \\
\hline Agg. First Round Valuation & 243.0 & 36.2 & 102.2 & 46.5 & 1.7 & 56.4 \\
\hline Agg. Amount Raised (\$ B) & 385.4 & 75.5 & 181.9 & 62.3 & 15.0 & 50.7 \\
\hline Agg. Exit Valuation $(\$ B)$ & 1027.7 & 472.1 & 555.6 & - & - & - \\
\hline \multicolumn{7}{|c|}{ Panel D. (first round valuation imputed, amount raised imputed, exit values imputed) } \\
\hline \# Ventures & 17,242 & 1,906 & 6,407 & 3,898 & 291 & 4,740 \\
\hline Agg. First Round Valuation & 269.2 & 39.6 & 113.7 & 49.4 & 3.1 & 63.4 \\
\hline Agg. Amount Raised (\$ B) & 452.8 & 89.3 & 210.7 & 67.7 & 25.4 & 59.7 \\
\hline Agg. Exit Valuation $(\$ B)$ & 1248.8 & 564.2 & 684.6 & - & - & - \\
\hline
\end{tabular}

Notes: The table reports the summary statistics of the key variables by venture's exit type. "Private (Active)" ventures refer to those with no observed exit events as of 2018 and had financing activities in the past 5 years, that is, from 2013 to 2018. "Private (Inactive)" ventures refer to those with no observed exit events as of 2018 and had no financing activities in the past 5 years, that is, from 2013 to 2018. Panel A is for the subsample of ventures that have data on first round valuation, amount raised in all rounds, and exit values. Panel $\mathrm{B}$ is for the subsample of ventures that have data on amount raised in all rounds, and exit values, while first round valuations use imputed data. Panel $\mathrm{C}$ is for the subsample of ventures that have data on amount raised in all rounds, while first round valuations and exit values use imputed data. Panel $\mathrm{D}$ is for all ventures in our sample for analysis - that is, 17,242 US-based ventures in SDC VentureXpert database that had the first funding round in 1980-2006, and we trace their funding rounds in 1980-2018. 
Table 15: Aggregate Portfolio of Ventures: Full Sample and Sub-Sample Results

\begin{tabular}{|c|c|c|c|c|c|c|c|}
\hline \multirow[t]{2}{*}{ Sample } & \multicolumn{5}{|c|}{$\mathrm{PME}_{\text {nodisc }} \mathrm{PME}$ GPME PME $\mathrm{PM}_{r f} \mathrm{IRR}$ \#Ventures } & \multirow{2}{*}{\multicolumn{2}{|c|}{$\begin{array}{c}\text { Amount } \quad \text { Exit } \\
\text { Raised }(\$ B) \text { Value }(\$ B)\end{array}$}} \\
\hline & & & & & & & \\
\hline Full Sample (Imputation) & 1.99 & 1.42 & 1.44 & 1.760 .22 & 17,242 & 452.8 & 1248.8 \\
\hline Full Sample (Reweighted) & 1.86 & 1.46 & 1.47 & 1.700 .30 & & 595.2 & 1610.2 \\
\hline No-bubble Sample (Imputation) & 2.05 & 1.42 & 1.41 & 1.820 .19 & 10,542 & 210.2 & 603.2 \\
\hline No-bubble Sample (Reweighted) & 1.72 & 1.20 & 1.19 & 1.520 .15 & 1,066 & 261.4 & 678.6 \\
\hline Pre-2006 Sample (Imputation) & 2.05 & 1.51 & 1.48 & 1.820 .35 & 11,552 & 225.2 & 710.2 \\
\hline Pre-2006 Sample (Reweighted) & 2.07 & 1.63 & 1.61 & 1.880 .45 & 2,307 & 311.0 & 1038.3 \\
\hline
\end{tabular}

Notes: The table provides a comparison of the returns by the different samples, missing data-filling methods and return measures. The full sample includes 17,242 US-based ventures in SDC VentureXpert database that had the first funding round in 1980-2006, and we trace their funding rounds in 1980-2018. The no-bubble sample is derived by excluding ventures with any financing activities or or exits in 1999 and 2000 from the full sample. For the two samples, we assume the ventures that remain private as of 2018 have an exit value of 0 . The pre-2006 sample is derived from the full sample but assuming our observation of these ventures stop in 2006/12, and excludes from the full sample 5,097 ventures that remain private as of 2006 but had financing activities since 2001. In this sample, we assume the ventures that remain private as of 2006 but had no financing activities since 2001 have an exit value of 0 . "Imputation" and "reweighted" refer to two ways of filling in the missing data (see text for the details). For example, for the full sample, we reweight 2,954 ventures that have all the required data for the venture GPME calculation. $\mathrm{PME}_{\text {nodisc }}$ is the venture PME without discounting the cash flows (i.e., $M_{t}=1$ ). PME uses in the SDF specification the PME's parameters (i.e., $a=0, b=1$ ). GPME uses the GPME's parameters (i.e., $a=0.033, b=1.444$ ). $\mathrm{PME}_{r f}$ uses the risk free rate to discount the cash flows (i.e., $M_{t}=e^{-r_{f} t}$ ). IRR is the internal rate of return. 
Table 16: Portfolios of Ventures that Had Their First Rounds in the Same Calendar Year

\begin{tabular}{|c|c|c|c|c|c|c|c|c|c|c|}
\hline $\begin{array}{l}\text { Year of } \\
\text { Round } 1\end{array}$ & $\mathrm{PME}_{\text {nodisc }}$ & \multicolumn{2}{|c|}{ PME GPME } & $\mathrm{ME}_{r f}$ & \multicolumn{2}{|c|}{ IRR \# Ventures } & $\begin{array}{c}\text { Amount } \\
\text { Raised }(\$ B)\end{array}$ & $\begin{array}{c}\text { Exit } \\
\text { Value }(\$ B)\end{array}$ & $\begin{array}{l}\text { \# With } \\
\text { 1st Val. }\end{array}$ & $\begin{array}{l}\% \text { With } \\
\text { 1st Val. }\end{array}$ \\
\hline 1980 & 1.85 & 1.16 & 1.02 & 1.46 & 0.31 & 55 & 0.5 & 1.2 & 0 & $0.0 \%$ \\
\hline 1981 & 2.29 & 1.62 & 1.51 & 1.86 & 0.61 & 194 & 2.0 & 5.7 & 0 & $0.0 \%$ \\
\hline 1982 & 1.75 & 0.80 & 0.69 & 1.22 & 0.11 & 253 & 2.3 & 5.0 & 0 & $0.0 \%$ \\
\hline 1983 & 3.48 & 0.52 & 0.42 & 1.47 & 0.07 & 428 & 3.3 & 15.3 & 1 & $0.2 \%$ \\
\hline 1984 & 0.87 & 0.39 & 0.34 & 0.61 & -0.02 & 418 & 3.3 & 3.5 & 2 & $0.5 \%$ \\
\hline 1985 & 1.67 & 0.45 & 0.37 & 0.97 & 0.05 & 332 & 2.1 & 4.4 & 2 & $0.6 \%$ \\
\hline 1986 & 1.86 & 0.60 & 0.52 & 1.10 & 0.06 & 370 & 3.2 & 7.9 & 6 & $1.6 \%$ \\
\hline 1987 & 1.86 & 0.89 & 0.82 & 1.31 & 0.10 & 423 & 3.1 & 7.3 & 6 & $1.4 \%$ \\
\hline 1988 & 2.63 & 1.63 & 1.48 & 2.15 & 0.30 & 418 & 3.6 & 12.7 & 15 & $3.6 \%$ \\
\hline 1989 & 2.29 & 0.98 & 0.86 & 1.65 & 0.14 & 364 & 3.2 & 10.4 & 15 & $4.1 \%$ \\
\hline 1990 & 2.74 & 1.35 & 1.21 & 2.11 & 0.22 & 273 & 2.6 & 9.7 & 12 & $4.4 \%$ \\
\hline 1991 & 5.07 & 2.52 & 2.22 & 4.03 & 0.51 & 198 & 2.3 & 17.2 & 28 & $14.1 \%$ \\
\hline 1992 & 6.96 & 3.38 & 2.89 & 5.74 & 0.63 & 230 & 4.6 & 38.5 & 58 & $25.2 \%$ \\
\hline 1993 & 2.81 & 2.01 & 1.87 & 2.56 & 0.60 & 229 & 4.9 & 17.0 & 66 & $28.8 \%$ \\
\hline 1994 & 6.12 & 3.25 & 2.78 & 5.15 & 0.70 & 238 & 6.7 & 51.2 & 76 & $31.9 \%$ \\
\hline 1995 & 2.91 & 1.78 & 1.57 & 2.56 & 0.55 & 529 & 13.7 & 50.6 & 226 & $42.7 \%$ \\
\hline 1996 & 2.87 & 2.07 & 1.92 & 2.63 & 0.77 & 778 & 24.1 & 82.9 & 311 & $40.0 \%$ \\
\hline 1997 & 2.67 & 2.11 & 2.05 & 2.46 & 0.78 & 878 & 30.5 & 96.7 & 302 & $34.4 \%$ \\
\hline 1998 & 2.53 & 2.23 & 2.25 & 2.38 & 1.09 & 1,131 & 43.7 & 131.9 & 385 & $34.0 \%$ \\
\hline 1999 & 1.38 & 1.18 & 1.29 & 1.22 & 0.08 & 1,857 & 68.5 & 110.2 & 662 & $35.6 \%$ \\
\hline 2000 & 0.98 & 0.87 & 1.00 & 0.85 & 0.00 & 2,446 & 64.7 & 86.9 & 923 & $37.7 \%$ \\
\hline 2001 & 1.31 & 1.00 & 1.06 & 1.19 & 0.05 & 944 & 25.6 & 38.1 & 343 & $36.3 \%$ \\
\hline 2002 & 1.75 & 1.24 & 1.24 & 1.62 & 0.14 & 698 & 21.1 & 39.1 & 181 & $25.9 \%$ \\
\hline 2003 & 1.99 & 1.49 & 1.50 & 1.86 & 0.21 & 669 & 22.3 & 45.4 & 126 & $18.8 \%$ \\
\hline 2004 & 1.91 & 1.43 & 1.48 & 1.77 & 0.15 & 854 & 26.2 & 53.0 & 80 & $9.4 \%$ \\
\hline 2005 & 2.27 & 1.72 & 1.77 & 2.14 & 0.20 & 930 & 29.6 & 74.4 & 67 & $7.2 \%$ \\
\hline 2006 & 2.05 & 1.54 & 1.56 & 1.98 & 0.19 & 1,105 & 35.1 & 81.2 & 57 & $5.2 \%$ \\
\hline
\end{tabular}

Notes: The table provides a historical time series of the return to investing in ventures. The full sample includes US-based ventures in SDC VentureXpert database that had the first funding round in 1980-2006, and we trace their funding rounds in 1980-2018. $\mathrm{PME}_{\text {nodisc }}$ is the venture PME without discounting the cash flows (i.e., $M_{t}=1$ ). PME uses in the SDF specification the PME's parameters (i.e., $a=0, b=1$ ). GPME uses the GPME's parameters (i.e., $a=0.033, b=1.444$ ). PME $_{r f}$ uses the risk free rate to discount the cash flows (i.e., $M_{t}=e^{-r_{f} t}$ ). IRR is the internal rate of return. 
Table 17: Model Selection for the Time-Series Analysis - Full Sample

\begin{tabular}{lcccccc}
\hline & \multicolumn{2}{c}{ BIC (1992Q1-2006Q4) } & \multicolumn{2}{c}{ BIC (1992Q1-1999Q1) } & \multicolumn{2}{c}{ BIC (1999Q2-2006Q4) } \\
\multicolumn{1}{c}{ Model } & PME & GPME & PME & GPME & PME & GPME \\
\hline AR(1) & 102.0 & 92.1 & $\mathbf{4 4 . 4}$ & $\mathbf{4 2 . 1}$ & 40.1 & 38.4 \\
MA(1) & 109.6 & 96.3 & 44.4 & 42.2 & 40.2 & 38.4 \\
ARMA(1,1) & 93.6 & 86.6 & 46.1 & 43.9 & 38.0 & 38.0 \\
AR(2) & $\mathbf{9 0 . 4}$ & $\mathbf{8 2 . 6}$ & 47.6 & 45.0 & $\mathbf{3 4 . 1}$ & $\mathbf{3 3 . 1}$ \\
MA(2) & 101.1 & 89.7 & 47.8 & 45.1 & 36.5 & 35.1 \\
ARMA(1,2) & 95.0 & 87.9 & 49.4 & 47.1 & 38.8 & 38.3 \\
ARMA(2,1) & 94.0 & 86.6 & 49.6 & 47.1 & 35.4 & 35.1 \\
ARMA(2,2) & 93.8 & 86.6 & 51.0 & 49.5 & 37.5 & 36.4 \\
\hline Chosen Model & $\mathrm{AR}(2)$ & $\mathrm{AR}(2)$ & $\mathrm{AR}(1)$ & $\mathrm{AR}(1)$ & $\mathrm{AR}(2)$ & $\mathrm{AR}(2)$ \\
Estimated Mean & 1.70 & 1.66 & 2.11 & 1.98 & 1.32 & 1.37 \\
Model Implied t & 9.85 & 10.47 & 13.70 & 12.60 & 3.98 & 4.72 \\
Newey-West t (lag=8) & 4.46 & 5.29 & 17.70 & 13.12 & 2.57 & 3.28 \\
Newey-West t (lag=4) & 5.51 & 6.37 & 15.64 & 12.42 & 3.15 & 4.00 \\
\hline
\end{tabular}

Notes: The table reports the best ARMA model that fits the time series of PME and GPME of ventures in different time periods. The sample includes US-based ventures in SDC VentureXpert database that had the first funding round in 1992-2006, and we trace their funding rounds in 1992-2018. The time Series of PME and GPME are winsorized at 5\% tails. We test whether the PME and GPME are statistically significantly greater than 1 . Model implied $t$ is based on the standard errors implied by the best ARMA model. Newey-West $t$ is based on Newey-West standard errors. 
Table 18: Model Selection for the Time-Series Analysis - No-bubble Subsample

\begin{tabular}{lcccc}
\hline & \multicolumn{2}{c}{ BIC (1992Q1-1999Q1) } & \multicolumn{2}{c}{ BIC (2001Q1-2006Q4) } \\
\multicolumn{1}{c}{ Model } & PME & GPME & PME & GPME \\
\hline AR(1) & $\mathbf{7 5 . 5}$ & $\mathbf{6 8 . 2}$ & 32.1 & 33.1 \\
MA(1) & $\mathbf{7 5 . 3}$ & $\mathbf{6 8 . 1}$ & 32.5 & 33.5 \\
ARMA(1,1) & 77.0 & 69.5 & 32.1 & 32.7 \\
AR(2) & 78.5 & 71.1 & $\mathbf{3 1 . 4}$ & $\mathbf{3 1 . 8}$ \\
MA(2) & 77.8 & 70.3 & $\mathbf{3 0 . 9}$ & $\mathbf{3 2 . 7}$ \\
ARMA(1,2) & 80.3 & 72.8 & 35.0 & 35.3 \\
ARMA(2,1) & 81.6 & 72.8 & 33.2 & 34.0 \\
ARMA(2,2) & 83.0 & 76.1 & 35.8 & 36.0 \\
\hline Chosen Model & AR(1) & AR(1) & AR $(2)$ & AR $(2)$ \\
Estimated Mean & 1.97 & 1.83 & 1.40 & 1.42 \\
Model Implied t & 6.40 & 6.30 & 4.39 & 4.55 \\
Newey West t (lag=8) & 4.85 & 4.96 & 3.68 & 3.77 \\
Newey West t (lag=4) & 5.56 & 5.63 & 4.25 & 4.40 \\
\hline
\end{tabular}

Notes: The table reports the best ARMA model that fits the time series of PME and GPME of ventures in different time periods. The sample includes US-based ventures in SDC VentureXpert database that had the first funding round had the first funding round in 1992-2006. We trace their funding rounds in 1992-2018, and exclude ventures that ever had any financing activities or exit events in 1999 and 2000. The time Series of PME and GPME are winsorized at 5\% tails. We test whether the PME and GPME are statistically significantly greater than 1 . Model implied $t$ is based on the standard errors implied by the best ARMA model. Newey-West t is based on Newey-West standard errors. 
Table 19: Structural Break Test

\begin{tabular}{|c|c|c|c|c|c|c|}
\hline \multirow[t]{2}{*}{ VARIABLES } & \multicolumn{2}{|c|}{ PME } & \multicolumn{2}{|c|}{ GPME } & \multicolumn{2}{|c|}{ IRR } \\
\hline & (1) & (2) & (3) & (4) & (5) & (6) \\
\hline PostBreak & & $\begin{array}{r}-0.840^{* * *} \\
(-7.600)\end{array}$ & & $\begin{array}{r}-0.658^{* * *} \\
(-6.190)\end{array}$ & & $\begin{array}{c}-0.599^{* * *} \\
(-12.786)\end{array}$ \\
\hline Constant & $\begin{array}{r}1.706^{* * *} \\
(22.055)\end{array}$ & $\begin{array}{r}2.140^{* * *} \\
(26.939)\end{array}$ & $\begin{array}{r}1.665^{* * *} \\
(24.536)\end{array}$ & $\begin{array}{r}2.005^{* * *} \\
(26.244)\end{array}$ & $\begin{array}{r}0.416^{* * *} \\
(9.166)\end{array}$ & $\begin{array}{r}0.725^{* * *} \\
(21.537)\end{array}$ \\
\hline Observations & 60 & 60 & 60 & 60 & 60 & 60 \\
\hline Break Date & $1999 q 1$ & - & $1999 \mathrm{q} 1$ & - & $1999 q 2$ & - \\
\hline Chi2 & 59.76 & - & 38.97 & - & 163.5 & - \\
\hline $\mathrm{P}$ Value & 0 & - & 0 & - & 0 & - \\
\hline White $t$ on PostBreak & - & $(-7.564)$ & - & $(-6.190)$ & - & $(-12.786)$ \\
\hline NW (lag $=8) t$ on PostBreak & - & $(-6.160)$ & - & $(-4.773)$ & - & $(-7.855)$ \\
\hline NW $(\mathrm{lag}=4) t$ on PostBreak & - & $(-6.835)$ & - & $(-5.368)$ & . & $(-9.156)$ \\
\hline
\end{tabular}

t-statistics in parentheses

${ }^{*} p<0.1,{ }^{* *} p<0.05,{ }^{* * *} p<0.01$

Notes: In columns 1, 3 and 5, The table shows the test statistics from the Supremum Wald tests of whether the constant parameter of time series of GPME, PME and IRR is different before and after an unknown break date, assuming the time series fluctuate around a constant. We also report in columns 2, 4 and 6 regression results from $\mathrm{GPME}_{t}=a+a_{1} \mathcal{I}_{t \geq 1999 Q 1}+\epsilon_{t}$, with t-statistics of $a_{1}$ using White standard errors and Newey-West standard errors. The sample includes all the US-based ventures in the SDC VentureXpert database and had the first funding round in 1992-2006, and we trace their funding rounds in 1992-2018. 
(This page intentionally left blank) 


\section{Internet Appendix}

(Not Intended for Publication)

\section{A. Data sources and data cleaning}

For 10,175 US-based ventures that had the first funding round in 1992-2006 and was not bankrupt according to VentureXpert data, we cross-checked their outcomes with various other data sources including PitchBook, Bloomberg, Nasdaq, Crunchbase and other Internet sources. Among the cross-checked ventures, 2,090 ventures remain private according to VentureXpert data. Among the 2,090 ventures, 628 exited through bankruptcy, 14 through IPO, and 460 through MA according to other data sources. Table IA.1 below lists the 14 ventures that exited through IPO according to other data sources.

Table IA.1: IPOs not Recorded by VentureXpert

\begin{tabular}{llrr}
\hline name & IPO exchange & \multicolumn{1}{c}{ IPO date } & PERMCO \\
\hline Ikano Communications Inc & NASDAQ & $9 / 22 / 2005$ & 47441 \\
EXDS Inc & NASDAQ & $3 / 19 / 1998$ & 16018 \\
Ivow Inc & NASDAQ & $7 / 3 / 1997$ & 15577 \\
Jmxi Inc & NASDAQ & $5 / 7 / 1999$ & 16518 \\
Rubio's Restaurants Inc & NASDAQ & $5 / 21 / 1999$ & 16543 \\
Greenway Health Inc & NYSE & $2 / 2 / 2012$ & 53986 \\
Ambicom Inc & OTC & $3 / 4 / 2011$ & \\
Modular Space Corp & OTC & $2 / 22 / 2017$ & \\
Infoteria Corp & TKS & $6 / 22 / 2007$ & \\
Morpho Technologies & TOKYO SE & $7 / 21 / 2011$ & \\
Crown Bioscience Inc & TPEX & $12 / 12 / 2016$ & \\
CoadNA Photonics Inc & TWSE & $9 / 9 / 2011$ & \\
Intelligent Epitaxy Technology Inc & TWSE & $7 / 24 / 2013$ & \\
Netex Inc & MADRID SE & $10 / 31 / 2017$ & \\
\hline
\end{tabular}


Table IA.2: Composition of Ventures by Years from the First Round - Cumulative Amount Raised and Exit Value

\begin{tabular}{|c|c|c|c|c|c|c|c|}
\hline $\begin{array}{r}\text { Years from } \\
\text { Round } 1\end{array}$ & $\begin{array}{c}\% \text { Private } \\
\text { (Active) }\end{array}$ & $\begin{array}{l}\% \text { Private } \\
\text { (Inactive) }\end{array}$ & $\%$ IPO & $\% \mathrm{MA}$ & $\%$ Bankrupt & $\begin{array}{l}\text { Cumul. IPO } \\
\text { Value }(\$ B)\end{array}$ & $\begin{array}{r}\text { Cumul. MA } \\
\text { Value (\$B) }\end{array}$ \\
\hline 1 & $98.2 \%$ & $0.0 \%$ & $1.2 \%$ & $0.6 \%$ & $0.1 \%$ & 104.1 & 81.8 \\
\hline 2 & $92.0 \%$ & $0.0 \%$ & $3.0 \%$ & $3.6 \%$ & $1.3 \%$ & 200.2 & 148.3 \\
\hline 3 & $84.8 \%$ & $0.0 \%$ & $5.9 \%$ & $7.2 \%$ & $2.2 \%$ & 267.4 & 196.6 \\
\hline 4 & $77.8 \%$ & $0.0 \%$ & $8.0 \%$ & $11.0 \%$ & $3.3 \%$ & 317.1 & 251.4 \\
\hline 5 & $66.2 \%$ & $3.3 \%$ & $9.9 \%$ & $15.4 \%$ & $5.2 \%$ & 354.0 & 323.3 \\
\hline 6 & $57.6 \%$ & $4.2 \%$ & $11.5 \%$ & $19.9 \%$ & $6.9 \%$ & 380.2 & 371.0 \\
\hline 7 & $48.6 \%$ & $5.3 \%$ & $12.8 \%$ & $24.3 \%$ & $9.0 \%$ & 431.0 & 424.6 \\
\hline 8 & $40.9 \%$ & $6.5 \%$ & $14.3 \%$ & $27.9 \%$ & $10.4 \%$ & 471.3 & 460.3 \\
\hline 9 & $34.4 \%$ & $7.5 \%$ & $15.2 \%$ & $31.4 \%$ & $11.5 \%$ & 487.4 & 505.9 \\
\hline 10 & $28.7 \%$ & $8.5 \%$ & $16.2 \%$ & $34.2 \%$ & $12.5 \%$ & 501.9 & 535.7 \\
\hline 11 & $23.6 \%$ & $9.4 \%$ & $16.9 \%$ & $37.0 \%$ & $13.1 \%$ & 513.7 & 568.5 \\
\hline 12 & $18.9 \%$ & $10.2 \%$ & $17.7 \%$ & $39.5 \%$ & $13.8 \%$ & 529.3 & 591.3 \\
\hline 13 & $15.1 \%$ & $10.8 \%$ & $18.3 \%$ & $41.6 \%$ & $14.2 \%$ & 539.9 & 610.9 \\
\hline 14 & $12.1 \%$ & $11.7 \%$ & $18.8 \%$ & $42.9 \%$ & $14.5 \%$ & 547.8 & 633.1 \\
\hline 15 & $9.6 \%$ & $12.6 \%$ & $19.0 \%$ & $44.1 \%$ & $14.6 \%$ & 551.9 & 643.5 \\
\hline 16 & $7.4 \%$ & $13.9 \%$ & $19.2 \%$ & $44.7 \%$ & $14.7 \%$ & 557.0 & 651.7 \\
\hline 17 & $5.6 \%$ & $14.8 \%$ & $19.5 \%$ & $45.3 \%$ & $14.9 \%$ & 558.4 & 659.9 \\
\hline 18 & $4.1 \%$ & $15.6 \%$ & $19.6 \%$ & $45.8 \%$ & $14.8 \%$ & 558.4 & 664.6 \\
\hline 19 & $3.0 \%$ & $16.4 \%$ & $19.6 \%$ & $46.0 \%$ & $14.9 \%$ & 558.5 & 667.0 \\
\hline 20 & $2.6 \%$ & $16.6 \%$ & $19.6 \%$ & $46.3 \%$ & $14.9 \%$ & 564.2 & 684.6 \\
\hline
\end{tabular}

Notes: The table reports the fraction of cumulative amount raised by ventures in each status, and the cumulative IPO value and MA value of ventures, by years from the first round. For example, \%IPO refers to the cumulative amount raised by ventures that have gone to IPO as of a number of years after the first round, as a percentage of the cumulative amount raised by all ventures as of that number of years after the first round. Within 2 years from the first round, ventures have raised $296.2 \$ \mathrm{~B}$ in total, and ventures that have gone to IPO have raised 9.0 \$B, hence the percentage is 3.6\% (9.0/296.2). \%Private (Active) refers to percent of cumulative amount raised by ventures that remain private as of a specific number of years after the first round, but remain active, that is, have had financing activities in the past 5 years. The sample includes 17,242 US-based ventures in SDC VentureXpert database that had the first funding round in 1980-2006, and we trace their funding rounds in 1980-2018. 
Figure IA.1: Nasdaq vs. S\&P500

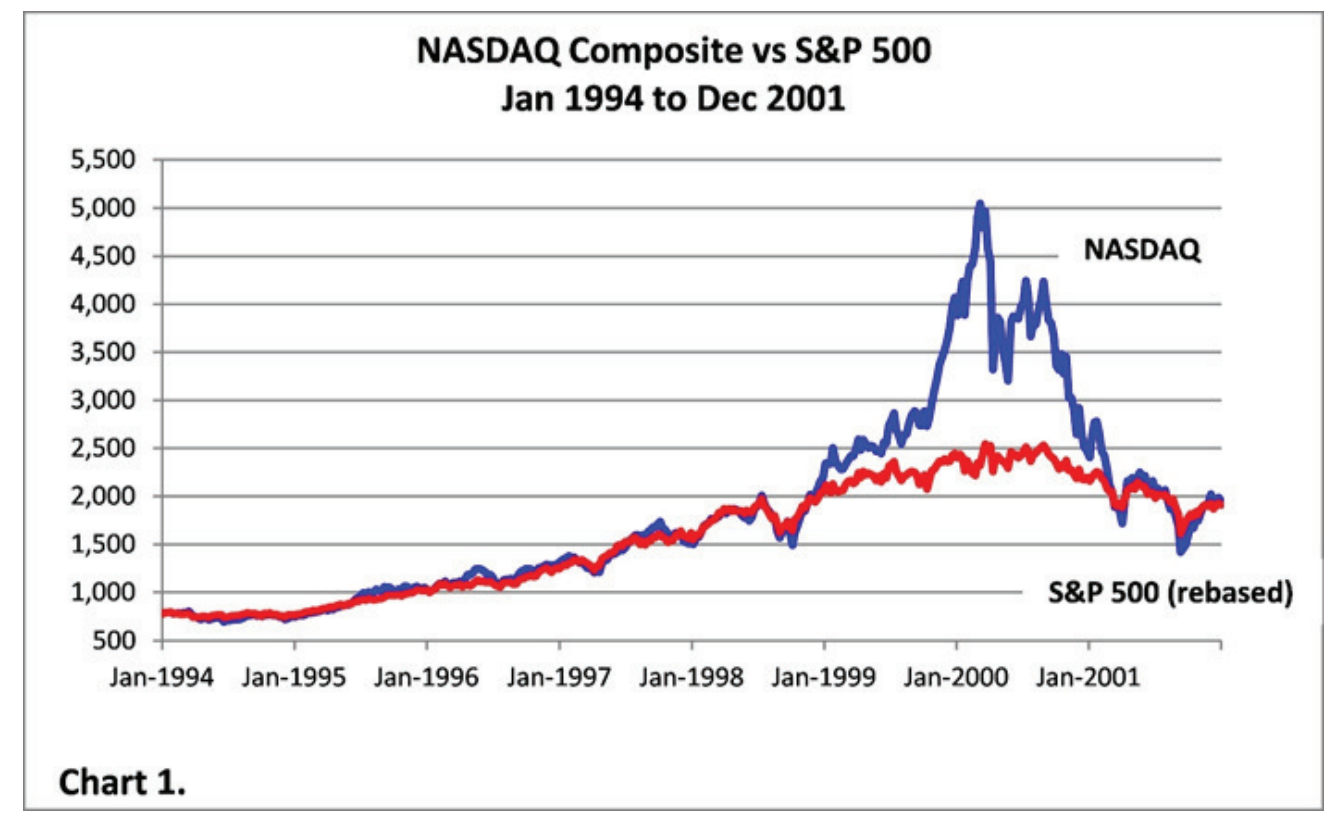

Notes: The figure plots the Nasdaq composite index and the S\&P500 from 1994 to 2001. We define the dotcom bubble period as from 1999 to 2000, when Nasdaq return significantly deviates from S\&P500. The S\&P500 index value is normalized to 771 in January 1994, which is the value as the Nasdaq composite index in January 1994.

\section{Figure IA.2: Histogram of Quarterly Venture NPV}

(a) PME Discounting

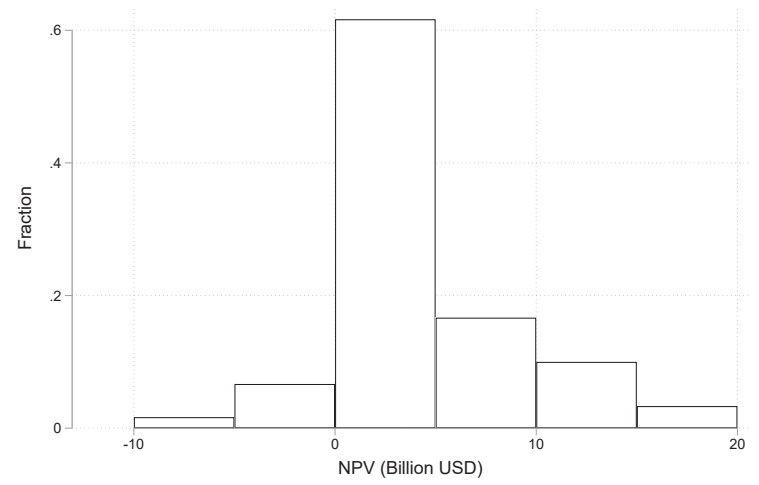

(b) GPME Discounting

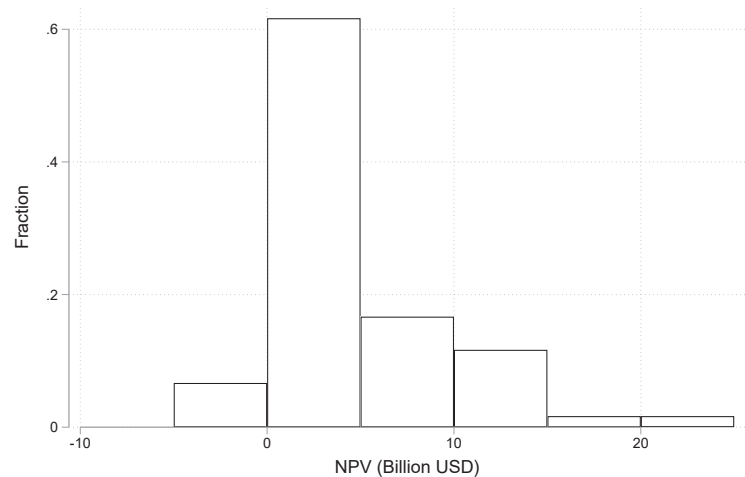

Notes: The figure plots the histogram of the NPV of the portfolio of ventures that received the first rounding round in each quarter. The sample includes 13,516 US-based ventures in SDC VentureXpert database that had the first funding round in 1992-2006, and we trace their funding rounds in 1992-2018. The cash flows are discounted with SDF specification in PME $(a=0, b=1)$ in Panel $(a)$, and discounted with SDF specification in GPME ( $a=0.033, b=1.444)$ in Panel $(b)$, to the venture's first funding round's date. 


\section{B. Robustness to alternative imputation models for first round own- ership given up}

In Table IA.3, IA.4 and Figure IA.3, the first round ownership given up is imputed using only data on the first rounds.

Table IA.3: Aggregate Portfolio of Ventures: Full Sample and Sub-Sample Results

\begin{tabular}{|c|c|c|c|c|c|c|c|}
\hline Sample & $\mathrm{PME}_{\text {nodisc }}$ & PME & PME & {$\left[\mathrm{E}_{r f} \mathrm{IRR} \#\right.$} & Ventures & $\begin{array}{c}\text { Amount } \\
\text { Raised }(\$ B)\end{array}$ & $\begin{array}{c}\text { Exit } \\
\text { Value }(\$ B)\end{array}$ \\
\hline Full Sample (Imputation) & 1.99 & 1.42 & 1.43 & .760 .22 & 17,242 & 452.8 & 1245.8 \\
\hline No-bubble Sample (Imputation) & 2.06 & 1.43 & 1.42 & 1.830 .20 & 10,542 & 210.2 & 600.5 \\
\hline Pre-2006 Sample (Imputation) & 2.05 & 1.51 & 1.48 & 1.820 .35 & 11,552 & 225.2 & 710.3 \\
\hline
\end{tabular}

Notes: This table is to be compared with Table 15, which provides the return to investing in ventures calculated in the full sample and sub-samples. First round ownership given up is imputed using only data on the first rounds, when constructing the return measures being tabulated in this table. 
Table IA.4: Portfolios of Ventures that Had Their First Rounds in the Same Calendar Year

\begin{tabular}{|c|c|c|c|c|c|c|c|c|c|c|}
\hline $\begin{array}{l}\text { Year of } \\
\text { Round } 1\end{array}$ & $\mathrm{PME}_{\text {nodisc }}$ & PME & \multicolumn{2}{|c|}{${ }_{P} \mathrm{PME} \mathrm{PME}_{r f}$} & IRR \# & Ventures & $\begin{array}{c}\text { Amount } \\
\text { Raised }(\$ B)\end{array}$ & $\begin{array}{c}\text { Exit } \\
\text { Value }(\$ B)\end{array}$ & \multicolumn{2}{|c|}{ \# With \% With } \\
\hline 1980 & 1.86 & 1.47 & 1.16 & 1.03 & 0.31 & 55 & 0.5 & 1.2 & 0 & $0.0 \%$ \\
\hline 1981 & 2.34 & 1.89 & 1.64 & 1.53 & 0.63 & 194 & 2.0 & 5.7 & 0 & $0.0 \%$ \\
\hline 1982 & 1.77 & 1.22 & 0.80 & 0.69 & 0.11 & 253 & 2.3 & 5.0 & 0 & $0.0 \%$ \\
\hline 1983 & 3.50 & 1.48 & 0.52 & 0.42 & 0.07 & 428 & 3.3 & 15.3 & 1 & $0.2 \%$ \\
\hline 1984 & 0.94 & 0.64 & 0.40 & 0.34 & -0.01 & 418 & 3.3 & 3.5 & 2 & $0.5 \%$ \\
\hline 1985 & 1.76 & 1.00 & 0.45 & 0.37 & 0.05 & 332 & 2.1 & 4.4 & 2 & $0.6 \%$ \\
\hline 1986 & 1.88 & 1.12 & 0.61 & 0.53 & 0.06 & 370 & 3.2 & 7.9 & 6 & $1.6 \%$ \\
\hline 1987 & 1.95 & 1.35 & 0.90 & 0.83 & 0.10 & 423 & 3.1 & 7.3 & 6 & $1.4 \%$ \\
\hline 1988 & 2.67 & 2.18 & 1.64 & 1.49 & 0.30 & 418 & 3.6 & 12.7 & 15 & $3.6 \%$ \\
\hline 1989 & 2.29 & 1.66 & 0.98 & 0.87 & 0.14 & 364 & 3.2 & 10.4 & 15 & $4.1 \%$ \\
\hline 1990 & 2.88 & 2.24 & 1.44 & 1.29 & 0.25 & 273 & 2.6 & 9.7 & 12 & $4.4 \%$ \\
\hline 1991 & 4.88 & 3.87 & 2.41 & 2.11 & 0.48 & 198 & 2.3 & 17.2 & 28 & $14.1 \%$ \\
\hline 1992 & 7.16 & 5.93 & 3.51 & 3.01 & 0.66 & 230 & 4.6 & 38.5 & 58 & $25.2 \%$ \\
\hline 1993 & 2.80 & 2.54 & 2.00 & 1.85 & 0.59 & 229 & 4.9 & 17.0 & 66 & $28.8 \%$ \\
\hline 1994 & 6.17 & 5.20 & 3.28 & 2.81 & 0.70 & 238 & 6.7 & 51.2 & 76 & $31.9 \%$ \\
\hline 1995 & 2.92 & 2.58 & 1.79 & 1.58 & 0.55 & 529 & 13.7 & 50.6 & 226 & $42.7 \%$ \\
\hline 1996 & 2.90 & 2.67 & 2.11 & 1.96 & 0.80 & 778 & 24.1 & 82.9 & 311 & $40.0 \%$ \\
\hline 1997 & 2.70 & 2.50 & 2.15 & 2.09 & 0.81 & 878 & 30.5 & 96.7 & 302 & $34.4 \%$ \\
\hline 1998 & 2.55 & 2.39 & 2.25 & 2.27 & 1.12 & 1,131 & 43.7 & 131.9 & 385 & $34.0 \%$ \\
\hline 1999 & 1.37 & 1.22 & 1.18 & 1.29 & 0.08 & 1,857 & 68.5 & 110.2 & 662 & $35.6 \%$ \\
\hline 2000 & 0.98 & 0.85 & 0.87 & 1.00 & 0.00 & 2,446 & 64.7 & 86.9 & 923 & $37.7 \%$ \\
\hline 2001 & 1.28 & 1.16 & 0.98 & 1.03 & 0.05 & 944 & 25.6 & 38.1 & 343 & $36.3 \%$ \\
\hline 2002 & 1.70 & 1.57 & 1.20 & 1.21 & 0.13 & 698 & 21.1 & 39.1 & 181 & $25.9 \%$ \\
\hline 2003 & 1.93 & 1.80 & 1.43 & 1.44 & 0.19 & 669 & 22.3 & 45.4 & 126 & $18.8 \%$ \\
\hline 2004 & 1.87 & 1.73 & 1.39 & 1.44 & 0.15 & 854 & 26.2 & 53.0 & 80 & $9.4 \%$ \\
\hline 2005 & 2.23 & 2.09 & 1.69 & 1.74 & 0.20 & 930 & 29.6 & 74.4 & 67 & $7.2 \%$ \\
\hline 2006 & 2.09 & 2.02 & 1.58 & 1.60 & 0.20 & 1,105 & 35.1 & 81.2 & 57 & $5.2 \%$ \\
\hline
\end{tabular}

Notes: The table is to be compared with Table 16, which provides a historical time series of the return to investing in ventures. First round ownership given up is imputed using only data on the first rounds, when constructing the return measures being tabulated in this table. 
Figure IA.3: Portfolios of Ventures that Had Their First Rounds in the Same Calendar Quarter

(a) PME

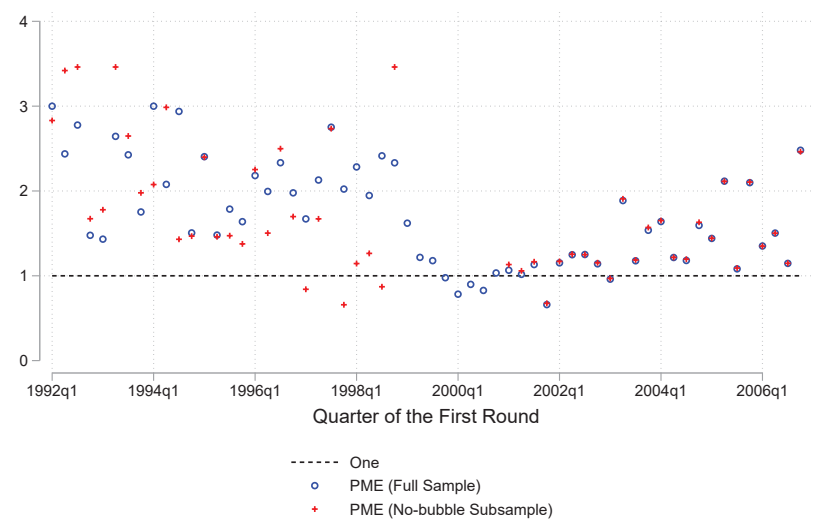

(b) GPME

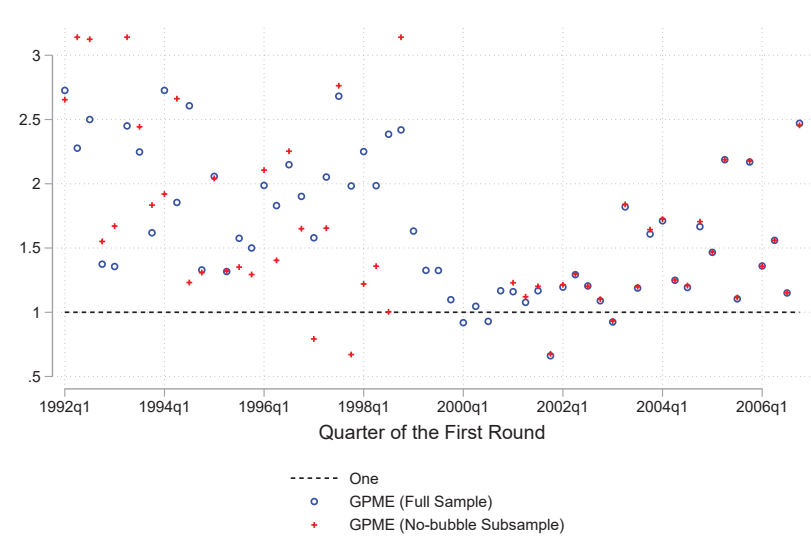

(c) IRR

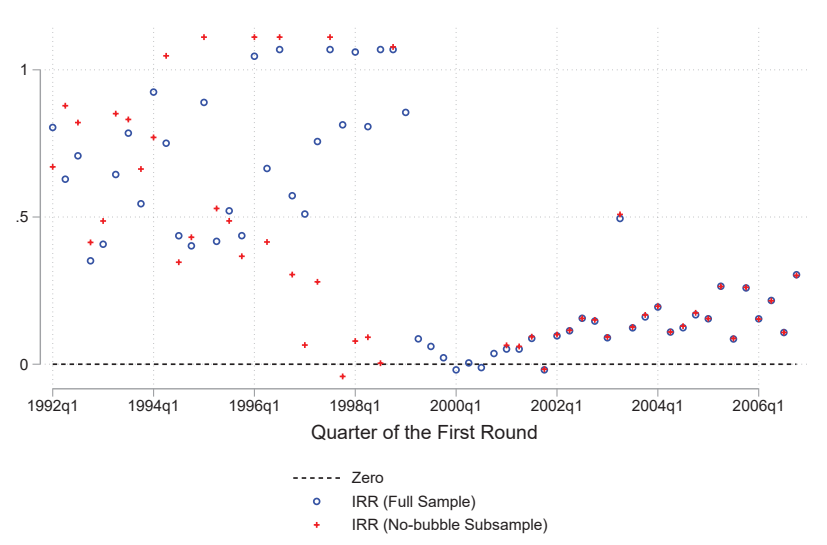

Notes: The figure is to be compared with Figure 5, which plots the PME, GPME and IRR of the portfolio of ventures that received the first funding round in each quarter. First round ownership given up is imputed using only data on the first rounds, when constructing the return measures being plotted in this figure. 


\section{Sensitivity to changes in errors in imputed values, and boot- strapped standard errors}

Table IA.5: Portfolios of Ventures that Had Their First Rounds in the Same Calendar Year

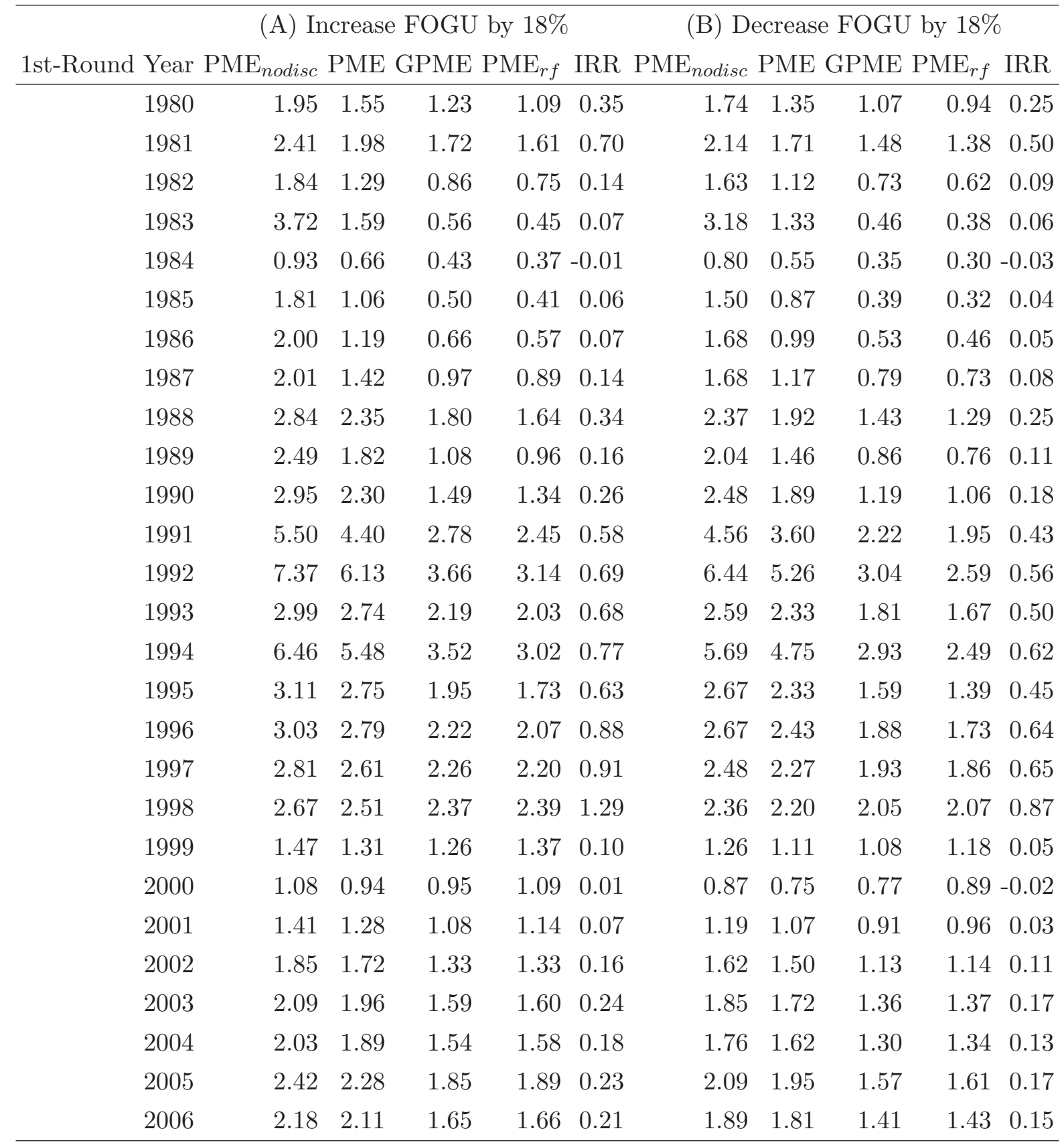

Notes: In the table, FOGU refers to first round ownership given up. The table is to be compared with Table 16, which provides a historical time series of the return to investing in ventures. In Panel (A) we increase first round ownership given up of all ventures by one standard deviation, i.e., 18\%. In Panel (B) we decrease first round ownership given up of all ventures by $18 \%$. 
Table IA.6: Portfolios of Ventures that Had Their First Rounds in the Same Calendar Year

\begin{tabular}{|c|c|c|c|c|c|c|c|c|c|c|}
\hline & & (A) Incre & ease $\mathrm{E}$ & it Valu & by $25 \%$ & (B) Decr & ease $\mathrm{E}$ & xit Val & es by 2 & $5 \%$ \\
\hline 1st-Round & Year & $\mathrm{ME}_{\text {nodisc }}$ & $\mathrm{PMl}$ & PME & $\mathrm{ME}_{r f} \mathrm{IRR}$ & $\mathrm{PME}_{\text {nodisc }}$ & PME & GPME & $\mathrm{ME}_{r f}$ & IRR \\
\hline & 1980 & 2.32 & 1.83 & 1.45 & 1.280 .44 & 1.39 & 1.10 & 0.87 & 0.77 & 0.15 \\
\hline & 1981 & 2.86 & 2.32 & 2.02 & 1.880 .83 & 1.72 & 1.39 & 1.21 & 1.13 & 0.35 \\
\hline & 1982 & 2.19 & 1.52 & 1.00 & $\begin{array}{lll}0.87 & 0.21\end{array}$ & 1.31 & 0.91 & 0.60 & 0.52 & 0.04 \\
\hline & 1983 & 4.35 & 1.84 & 0.65 & 0.520 .09 & 2.61 & 1.11 & 0.39 & 0.31 & 0.05 \\
\hline & 1984 & 1.09 & 0.76 & 0.49 & 0.420 .01 & 0.66 & 0.46 & 0.29 & 0.25 & -0.05 \\
\hline & 1985 & 2.08 & 1.22 & 0.56 & 0.460 .07 & 1.25 & 0.73 & 0.34 & 0.27 & 0.02 \\
\hline & 1986 & 2.32 & 1.37 & 0.75 & 0.650 .08 & 1.39 & 0.82 & 0.45 & 0.39 & 0.03 \\
\hline & 1987 & 2.33 & 1.63 & 1.11 & 1.020 .15 & 1.40 & 0.98 & 0.67 & 0.61 & 0.05 \\
\hline & 1988 & 3.29 & 2.69 & 2.04 & 1.840 .38 & 1.97 & 1.61 & 1.22 & 1.11 & 0.21 \\
\hline & 1989 & 2.86 & 2.07 & 1.22 & 1.080 .19 & 1.71 & 1.24 & 0.73 & 0.65 & 0.08 \\
\hline & 1990 & 3.42 & 2.64 & 1.69 & 1.510 .30 & 2.05 & 1.59 & 1.01 & 0.91 & 0.14 \\
\hline & 1991 & 6.34 & 5.04 & 3.15 & 2.770 .65 & 3.80 & 3.02 & 1.89 & 1.66 & 0.37 \\
\hline & 1992 & 8.69 & 7.18 & 4.22 & 3.610 .75 & 5.22 & 4.31 & 2.53 & 2.17 & 0.49 \\
\hline & 1993 & 3.52 & 3.20 & 2.52 & 2.330 .77 & 2.11 & 1.92 & 1.51 & 1.40 & 0.40 \\
\hline & 1994 & 7.65 & 6.44 & 4.06 & 3.470 .84 & 4.59 & 3.87 & 2.44 & 2.08 & 0.54 \\
\hline & 1995 & 3.64 & 3.20 & 2.23 & 1.960 .72 & 2.18 & 1.92 & 1.34 & 1.18 & 0.36 \\
\hline & 1996 & 3.59 & 3.29 & 2.58 & 2.401 .01 & 2.15 & 1.97 & 1.55 & 1.44 & 0.50 \\
\hline & 1997 & 3.33 & 3.08 & 2.64 & 2.561 .04 & 2.00 & 1.85 & 1.58 & 1.54 & 0.49 \\
\hline & 1998 & 3.16 & 2.97 & 2.79 & 2.811 .53 & 1.90 & 1.78 & 1.67 & 1.69 & 0.62 \\
\hline & 1999 & 1.72 & 1.53 & 1.48 & 1.610 .15 & 1.03 & 0.92 & 0.89 & 0.97 & 0.01 \\
\hline & 2000 & 1.23 & 1.06 & 1.09 & 1.250 .03 & 0.74 & 0.64 & 0.65 & 0.75 & -0.04 \\
\hline & 2001 & 1.64 & 1.49 & 1.25 & 1.320 .10 & 0.98 & 0.89 & 0.75 & 0.79 & 0.00 \\
\hline & 2002 & 2.18 & 2.02 & 1.55 & 1.560 .21 & 1.31 & 1.21 & 0.93 & 0.93 & 0.06 \\
\hline & 2003 & 2.48 & 2.32 & 1.86 & 1.870 .30 & 1.49 & 1.39 & 1.12 & 1.12 & 0.11 \\
\hline & 2004 & 2.39 & 2.21 & 1.79 & 1.840 .22 & 1.43 & 1.33 & 1.07 & 1.11 & 0.08 \\
\hline & 2005 & 2.84 & 2.67 & 2.15 & $2.21 \quad 0.27$ & 1.70 & 1.60 & 1.29 & 1.33 & 0.13 \\
\hline & 2006 & 2.56 & 2.47 & 1.93 & 1.950 .26 & 1.54 & 1.48 & 1.16 & 1.17 & 0.11 \\
\hline
\end{tabular}

Notes: The table is to be compared with Table 16, which provides a historical time series of the return to investing in ventures. In Panel (A) we increase the exit values of all ventures by $25 \%$. In Panel (B) we decrease the exit values of all ventures by $25 \%$. 
Table IA.7: Portfolios of Ventures that Had Their First Rounds in the Same Calendar Year: Bootstrapped 95\% Confidence Intervals

\begin{tabular}{|c|c|c|c|c|c|c|c|c|c|c|c|}
\hline 1st-Round & Year & $\mathrm{PME}_{\text {nodisc }}^{l}$ & $\mathrm{PME}_{\text {nodisc }}^{u}$ & $\mathrm{PME}^{l}$ & $\mathrm{PME}^{u}$ & $\mathrm{GPME}^{l}$ & $\mathrm{GPME}^{u}$ & $\mathrm{PME}_{r f}^{l}$ & $\mathrm{PME}_{r f}^{u}$ & $\mathrm{IRR}^{l}$ & $\mathrm{IRR}^{u}$ \\
\hline & 1980 & 0.93 & 2.90 & 0.53 & 1.83 & 0.50 & 1.62 & 0.63 & 2.29 & -0.01 & 0.68 \\
\hline & 1981 & 0.21 & 3.61 & -0.10 & 2.76 & -0.13 & 2.59 & 0.02 & 3.08 & -0.24 & 1.22 \\
\hline & 1982 & 1.20 & 2.25 & 0.57 & 1.07 & 0.48 & 0.93 & 0.88 & 1.58 & -0.04 & 0.19 \\
\hline & 1983 & -0.64 & 6.02 & 0.30 & 0.72 & 0.26 & 0.58 & 0.12 & 2.38 & 0.04 & 0.14 \\
\hline & 1984 & 0.67 & 1.06 & 0.29 & 0.48 & 0.24 & 0.42 & 0.48 & 0.75 & -0.05 & 0.01 \\
\hline & 1985 & -0.25 & 2.68 & 0.16 & 0.64 & 0.17 & 0.50 & -0.01 & 1.50 & -0.02 & 0.13 \\
\hline & 1986 & 0.62 & 2.70 & 0.36 & 0.77 & 0.33 & 0.66 & 0.49 & 1.50 & 0.02 & 0.11 \\
\hline & 1987 & 0.99 & 2.32 & 0.69 & 1.05 & 0.62 & 0.97 & 0.86 & 1.59 & 0.05 & 0.14 \\
\hline & 1988 & 0.61 & 3.87 & 0.27 & 2.43 & 0.24 & 2.20 & 0.47 & 3.19 & 0.07 & 0.52 \\
\hline & 1989 & 1.12 & 3.29 & 0.63 & 1.27 & 0.57 & 1.10 & 0.89 & 2.29 & 0.07 & 0.23 \\
\hline & 1990 & 1.68 & 3.59 & 0.85 & 1.72 & 0.76 & 1.54 & 1.31 & 2.65 & 0.12 & 0.31 \\
\hline & 1991 & 2.14 & 7.48 & 1.53 & 3.36 & 1.43 & 2.92 & 2.01 & 5.78 & 0.20 & 0.63 \\
\hline & 1992 & 0.36 & 11.12 & 1.24 & 4.85 & 1.38 & 4.03 & 0.60 & 8.93 & 0.45 & 0.84 \\
\hline & 1993 & 2.24 & 3.30 & 1.61 & 2.41 & 1.48 & 2.23 & 2.08 & 3.04 & 0.41 & 0.72 \\
\hline & 1994 & 2.17 & 9.64 & 1.31 & 4.97 & 1.24 & 4.18 & 1.78 & 8.08 & 0.46 & 1.01 \\
\hline & 1995 & 2.48 & 3.32 & 1.53 & 2.03 & 1.36 & 1.77 & 2.17 & 2.94 & 0.39 & 0.69 \\
\hline & 1996 & 2.54 & 3.24 & 1.83 & 2.34 & 1.70 & 2.16 & 2.34 & 2.99 & 0.58 & 0.94 \\
\hline & 1997 & 2.07 & 3.12 & 1.60 & 2.51 & 1.56 & 2.43 & 1.89 & 2.91 & 0.48 & 1.02 \\
\hline & 1998 & 2.06 & 2.88 & 1.78 & 2.55 & 1.81 & 2.56 & 1.90 & 2.72 & 0.63 & 1.46 \\
\hline & 1999 & 1.16 & 1.52 & 1.02 & 1.29 & 1.13 & 1.40 & 1.02 & 1.34 & 0.02 & 0.10 \\
\hline & 2000 & 0.90 & 1.08 & 0.78 & 0.95 & 0.90 & 1.09 & 0.77 & 0.94 & -0.02 & 0.01 \\
\hline & 2001 & 1.07 & 1.47 & 0.83 & 1.12 & 0.88 & 1.19 & 0.97 & 1.32 & 0.02 & 0.08 \\
\hline & 2002 & 1.47 & 1.99 & 1.03 & 1.39 & 1.04 & 1.40 & 1.36 & 1.84 & 0.08 & 0.17 \\
\hline & 2003 & 1.68 & 2.32 & 1.21 & 1.77 & 1.21 & 1.77 & 1.57 & 2.16 & 0.10 & 0.28 \\
\hline & 2004 & 1.61 & 2.15 & 1.26 & 1.61 & 1.29 & 1.68 & 1.51 & 2.00 & 0.12 & 0.19 \\
\hline & 2005 & 1.76 & 2.73 & 1.30 & 2.09 & 1.33 & 2.17 & 1.66 & 2.56 & 0.15 & 0.27 \\
\hline & 2006 & 1.24 & 2.49 & 1.00 & 1.83 & 1.05 & 1.85 & 1.18 & 2.40 & 0.10 & 0.24 \\
\hline
\end{tabular}

Notes: The table provides the bootstrapped $95 \%$ confidence intervals of the historical time series of the return to investing in ventures. The full sample includes US-based ventures in SDC VentureXpert database that had the first funding round in 1980-2006, and we trace their funding rounds in 1980-2018. We construct 100 bootstrap samples each of the same size as the full sample, and from a equal-probability random draw of ventures with replacement. In each bootstrap sample, we re-estimate the imputation models and use the reestimated models to impute the missing data, and construct the return estimates. The bootstrap distribution of return estimates is used to construct confidence intervals of venture returns in the population. The table is to be compared with Table 16, where $\mathrm{PME}_{\text {nodisc }}$ is venture PME without discounting the cash flows (i.e., $M_{t}=1$ ). PME uses in the SDF specification the PME's parameters (i.e., $a=0, b=1$ ), GPME uses the GPME's parameters (i.e., $a=0.033, b=1.444$ ), $\mathrm{PME}_{r f}$ uses the risk free rate to discount the cash flows (i.e., $M_{t}=e^{-r_{f} t}$ ), IRR is the internal rate of return. The variables superscripted with $l$ and $u$, for example, $\mathrm{PME}_{\text {nodisc }}^{l}$ and $\mathrm{PME}_{\text {nodisc }}^{u}$, are the lower and upper boundaries of $95 \%$ confidence intervals of the corresponding venture return measure. 